\title{
Adoption and implementation of AIDS education in Dutch secondary schools
}

Citation for published version (APA):

Paulussen, T. G. W. (1994). Adoption and implementation of AIDS education in Dutch secondary schools. [Doctoral Thesis, Maastricht University]. Landelijk Centrum GVO. https://doi.org/10.26481/dis.19941013tp

Document status and date:

Published: 01/01/1994

DOI:

10.26481/dis.19941013tp

Document Version:

Publisher's PDF, also known as Version of record

\section{Please check the document version of this publication:}

- A submitted manuscript is the version of the article upon submission and before peer-review. There can be important differences between the submitted version and the official published version of record.

People interested in the research are advised to contact the author for the final version of the publication, or visit the DOI to the publisher's website.

- The final author version and the galley proof are versions of the publication after peer review.

- The final published version features the final layout of the paper including the volume, issue and page numbers.

Link to publication

\footnotetext{
General rights rights.

- You may freely distribute the URL identifying the publication in the public portal. please follow below link for the End User Agreement:

www.umlib.nl/taverne-license

Take down policy

If you believe that this document breaches copyright please contact us at:

repository@maastrichtuniversity.nl

providing details and we will investigate your claim.
}

Copyright and moral rights for the publications made accessible in the public portal are retained by the authors and/or other copyright owners and it is a condition of accessing publications that users recognise and abide by the legal requirements associated with these

- Users may download and print one copy of any publication from the public portal for the purpose of private study or research.

- You may not further distribute the material or use it for any profit-making activity or commercial gain

If the publication is distributed under the terms of Article $25 \mathrm{fa}$ of the Dutch Copyright Act, indicated by the "Taverne" license above, 


\section{Colophon}

Adoption and implementation of AIDS education in Dutch secondary schools, Theo G.W. Paulussen, Dutch Centre for Health Promotion and Health Education, Utrecht, October 1994. Price DFL 35,00. Order number INT-6494. If you wish to order this publication, please transfer the required amount to: Dutch Centre for Health Promotion and Health Education (DCH), P.O. Box 5104, 3502 JC Utrecht, The Netherlands, Bank account no.: 68.75.24.105 ING Bank N.V. Please state: order number, your name, address and country.

Dutch Centre for Health Promotion and Health Education, telephone +31 309711 55, fax +3130971166 . 


\section{Adoption and implementation of AIDS education in Dutch secondary schools}




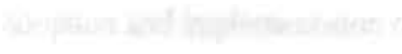

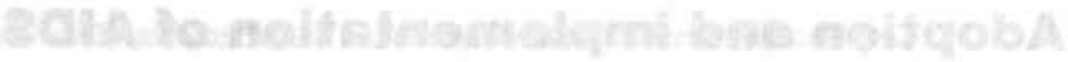

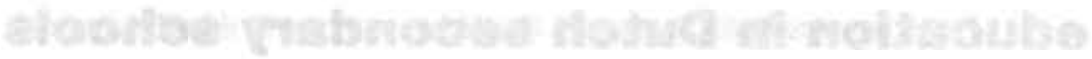




\title{
Adoption and implementation of AIDS education in Dutch secondary schools
}

\author{
PROEFSCHRIFT
}

\author{
ter verkrijging van de graad van doctor \\ aan de Rijksuniversiteit Limburg te Maastricht, \\ op gezag van de Rector Magnificus, Prof. dr H. Philipsen, \\ volgens het besluit van het College van Dekanen, \\ in het openbaar te verdedigen op \\ donderdag 13 oktober 1994 om 14.00 uur \\ door \\ Theodorus Gerardus Wilhelmus Paulussen \\ geboren te Alphen en Riel op 29 oktober 1956
}




\section{Promotores:}

Prof. dr G.J. Kok

Prof. dr G.S. Parcel (Cniversity of Texas, Houston, USA)

\section{Beoordelingscommissie:}

Prof. dr H.G. Schmidt (Voorzitter)

Dr R.A. Knibbe

Prof. dr N.A.J. Lagerweij (Universiteit Utrecht)

Prof. dr F.J.N. Nijhuis

Prof. dr A.B. Steckler (University of North Carolina, Chapel Hill, USA)

\section{CIP-data Koninklijke Bibliotheek Den Haag}

Paulussen, Theodorus Gerardus Wilhelmus

Adoption and implementation of AlDS education in Dutch secondary schools / Theo G.W. Paulussen. - Utrecht : Landelijk Centrum GVO. Ill.

Proefschrift Maastricht. Mel lit. opg. - Mel samenvatting in het Nederlands ISBN 90-6928-163-5 geb.

NUGI $735 / 724$

Trefw.: ADDS / gezondheidsvoorlichting en -opvoeding ; voortgezet onderwijs

Een gedeelte van het in dit proefschrift beschreven onderzoek is gefinancierd door het ministerie van Welzijn, Volksgezondheid en Cultuur. 


\section{Acknowledgements}

This dissertation mainly originates from my participation in the school AIDS education project at the Dutch Centre for Health Promotion and Health Education (DCH). Since the described research was initially not carried out to serve that purpose, I would like to express my gratitude to those who later convinced me about and actually helped me with writing this dissertation.

My advisors, Gerjo Kok and Guy Parcel, and Herman Schaalma contributed mostly to preserve my confidence in completing this work within a restricted time span. Gerjo, to whom I feel deep respect both personally and professionally, already educated me about health education research when I was with him as a university student. I not only owe thanks to 'my professor' for his ongoing intellectual inspiration, but also for his generous gesture that removed the practical barriers for writing this dissertation. Guy provided thoughtful and specific comments on the various drafts of this dissertation and should prevent the reader for facing hurdles that are logically or linguistically impossible to take. Herman, my 'un-official' advisor and a great friend and colleague, was always ready and willing to provide detailed feedback on all kinds of mature and immature theoretical or practical ideas to proceed with. With Herman, writing this thesis was at least fun.

I am also grateful to Hester Kuipers and her supervisor Arend-Jan Waarlo who invested a lot of their time and skills in the qualitative part of this research. My colleagues with whom I am at DCH's School Health Unit were and still are very supportive in every stage of my work; thanks. Especially I would like to mention Piet Wijnsma, Jo Reinders and Peter Dankmeijer, with whom I initially started to work on DCH's AIDS-project. They, each in their own way, showed to be inspiring referents when it comes to bridging the gab between educational theory and practice.

Last but certainly not least, I would like to thank my beloved expert in social support, Maria. 



\section{Contents}

\section{PART ONE}

Chapter 1 Overview 11

- Introduction $\quad 12$

- AIDS education in Dutch secondary schools 13

General guidelines $\quad 13$

$\begin{array}{ll}\text { Teacher training } & 14\end{array}$

Schools' entry state of affairs $\quad 15$

$\begin{array}{lr}\text { Dutch AIDS curricula } & 15\end{array}$

$\begin{array}{ll}\text { Research questions } & 17\end{array}$

- Process of curriculum innovation $\quad 18$

- Research framework $\quad 20$

Approach to dependent variables $\quad 21$

Approach to curriculum-related beliefs $\quad 22$

\begin{tabular}{ll} 
Attitudes & 22 \\
\hline
\end{tabular}

Subjective norms $\quad 22$

Self-efficacy 23

Approach to exogenous model variables 23

Interactive context $\quad 23$

Information source $\quad 24$

General dispositions $\quad 24$

- Methods $\quad 25$

$\begin{array}{ll}\text { Preliminary research } & 25\end{array}$

Validation by curriculum developers $\quad 25$

$\begin{array}{ll}\text { Teacher interviews } & 25\end{array}$

$\begin{array}{ll}\text { Subjects } & 26\end{array}$

- Results $\quad 26$

$\begin{array}{ll}\text { Diffusion prevalence } & 27\end{array}$

Antecedents to AIDS education and curriculum utilization 28

Adoption of classroom AIDS education $\quad 30$

Awareness-knowledge about AIDS curricula 31

Adoption of AIDS curricula and teachers' choice intentions 31

Implementation of AIDS curricula 31

- Limitations 32

- General discussion and conclusions 33

- Implications 36

Development of validated materials $\quad 36$

$\begin{array}{ll}\text { Promoting access to available practices } & 37\end{array}$

In-person assistance during implementation 38

Development of school level support 40

Empowerment of the local linkage subsystem $\quad 41$

\section{PART TWO}

Chapter 2 Review of the literature 43

- Introduction $\quad 44$

- Curriculum and curriculum evaluation $\quad 44$

- Diffusion of innovation theory 47

- Process of curriculum innovation 49

Dissemination $\quad 50$ 
Adoption

Implementation $\quad 52$

Continuation 53

- Determinants of curriculum innovation 54

Characteristics of the sociopolitical context 54

Education support structure $\quad 54$

Health support structure $\quad 55$

Policy press on the development system $\quad 55$

Characteristics of the innovation 56

Characteristics of the adopting unit $\quad 59$

Organizational climate conditions $\quad 59$

Teachers' planning behavior and thought processes 61

$\begin{array}{ll}\text { Characteristics of the innovation strategy } & 63\end{array}$

- Research on school health education innovation $\quad 66$

Effectiveness of school health education $\quad 66$

$\begin{array}{ll}\text { Antecedents to school health education innovation } & 67\end{array}$

$\begin{array}{ll}\text { School-based sex education } & 68\end{array}$

School-based AIDS education $\quad 70$

- Toward a conceptual framework 72

$\begin{array}{ll}\text { Theory of Planned Behavior } & 73\end{array}$

$\begin{array}{ll}\text { Research framework } & 74\end{array}$

Endogenous model variables $\quad 74$

Exogenous model variables $\quad 76$

Chapter 3 Antecedents to adoption of classroom-based AIDS

$\begin{array}{ll}\text { education in secondary schools } & 79\end{array}$

- Introduction

- Theoretical background 80

- Methods 83

$\begin{array}{ll}\text { The questionnaire } & 83\end{array}$

Sample procedure $\quad 84$

Data analysis $\quad 84$

- Results $\quad 85$

Sample description $\quad 85$

Past implementation of AIDS education $\quad 85$

Determinants of teachers' intentions to provide AIDS education 85

The impact of experience with classroom AIDS education $\quad 87$

- Discussion

- Implications

Chapter 4 Diffusion of AIDS curricula among Dutch secondary school teachers

Introduction

- Curriculum characteristics

- Theoretical background

- Methods

Subjects

$\begin{array}{ll}\text { The questionnaire } & 100\end{array}$

Data analysis 101

- Results

Awareness-knowledge about AIDS curricula 102

Adoption of AIDS curricula 
$\begin{array}{lr}\text { Teachers' choice intentions } & 104\end{array}$

- Discussion 107

- Implications 110

Chapter 5 Implementation of AIDS curricula by Dutch secondary school teachers

- Introduction

114

- Theoretical framework

115

Dependent variables

116

Curriculum-related beliefs

117

$\begin{array}{ll}\text { Exogenous model variables } & 117\end{array}$

- Methods

118

Subjects

118

The questionnaire

118

- Results

120

Sample description

120

Implementation

120

Antecedents to implementation

120

- Discussion

123

- Implications

References

Summary

Samenvatting

Curriculum Vitae 


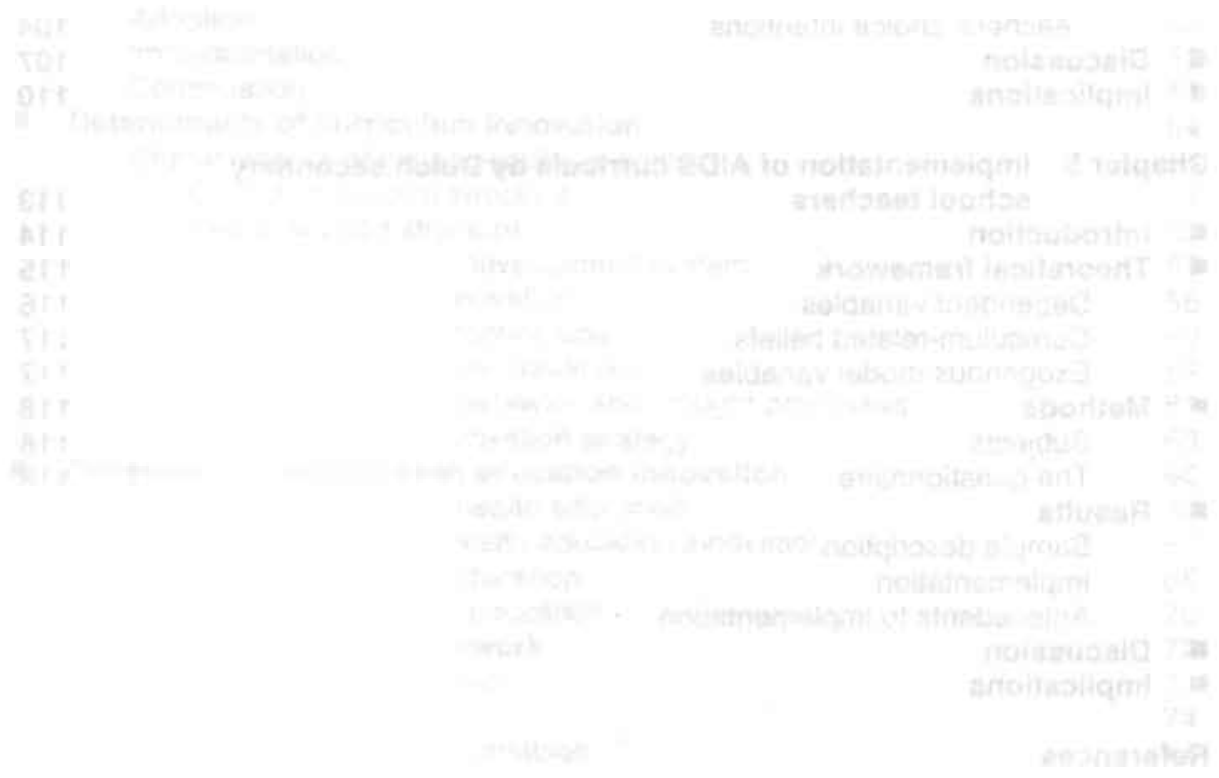




\section{PART ONE}

Chapter 1

\section{Overview}




\section{Introduction}

Since in the early eighties when the first cases of acquired immune deficiency syndrome (ADS) were diagnosed in the Netherlands, prevention of the spread of the human immune deficiency virus (HIV) has become an important focus for Dutch public health policies. In the absence of a cure for HIV infection, primary prevention is the only logical response to the current epidemic. It is recognized that adolescents, besides high-risk groups (homosexual men and intravenous drug users), are an important segment of the general population for receiving AIDS education (DiClemente, 1989). Their need for support in coping with this life-threatening issue is not clearly legitimated by the prevalence of AIDS among Dutch adolescents. Up to October 1993, only seven AIDS cases within the ages of 10-19 had been notified (Chief Inspectorate of Public Health, 1993). The HIV prevalence among teenagers is unknown since anonymous HIV antibody testing is deliberately excluded from the Dutch AIDS prevention policy. There remain, however, at least three reasons why an AIDS prevention policy is due to fail when the adolescent population is ignored: (1) health education programs appear to be most effective when reaching audiences that have not yet formed high-risk behavior patterns (Basch, 1989); (2) with a growing epidemic more adolescents will be confronted with people with AIDS or infected with HIV; and (3) a considerable proportion of Dutch adolescents still refrain from HIV preventive behaviors (Vogels \& Van der Vliet, 1990). Moreover, because of the long time interval from infection to the appearance of symptoms, approximately 10 years, young adults notified as having AIDS may have contracted HIV as teenagers (Curran at al., 1985, in DiClemente, 1989). By October 1993, 462 young Dutch adults within the ages of 20-29 have been diagnosed having AIDS.

AIDS/HIV incidence or prevalence may provide a valuable basis for estimating the urgency and the setting of priority objectives for a national policy on AUDS prevention. On the other hand, epidemiologic data hardly give direction to the various decisions one has to take regarding content, methods, media, and procedures for implementation of a particular educational intervention. Effective health education programs, however, are characteristically rooted in a planning process that accounts for the empirical and theory-based linkage between the health behavior in question, the psychosocial behavioral determinants, the options for intervention, and the antecedents to program implementation (cf. Mullan et al., 1985; Green \& Kreuter, 1991)

A survey conducted by vogels \& Van der Vliet (1990) among nearly 11,500 pupils from Dutch secondary schools (age 11-18) provides a detailed diagnosis of the AIDS-related behaviors of Dutch teenagers. About $22 \%$ of the respondents reported coitus experience with at least one partner; $60 \%$ reported having intercourse without using condoms. Based on behavioral parameters, 'sexual experience', 'own condom use', 'condom use of partners', it was estimated that one third of all pupils older than the age of 17 had risked infection with some sexual transmitted disease. Although some misconceptions were still prevalent, most pupils appeared to be well informed about HIV transmissions and risk-reducing behaviors. When compared to their counterparts, pupis in 
vocational education appeared to be least knowledgable about HIV prevention and expressed more negative attitudes toward people with AIDS.

Richard et al. (1991), and Schaalma et al. (1993) extensively explored the social and psychological determinants of Dutch adolescents' HIV-related risk behaviors. When taken together, their empirical findings indicate:

- knowledge about AIDS/HIV is hardly related to adolescents' risk-reducing behavior;

- perceived risk of contracting AIDS is generally low, and only appears to have a modest effect on future behavior;

- with growing age and sexual experience, perseverance in consistent condom use declines, attitudes become more negative (awkward to use, reducing pleasure), while contraception appears to be the main reason for condom use;

- with growing sexual experience, adolescents are most likely to perceive negative social norms, especially from peers and partners;

- self-efficacy expectations toward assertive communication is a strong predictor of sexual risk behavior; also difficulties are expected with purchasing condoms and taking them along.

\section{AIDS education in Dutch secondary schools}

During the mid-eighties it was recognized that the introduction of school-based AIDS education in Dutch secondary schools needed to be part of the national program on AIIS prevention. Schools, with the potential of reaching nearly all teenagers, represent an optimal setting for conducting HIV prevention programs (cf. Kerr et al., 1989). Health professionals at the local level first initiated support activities for Dutch secondary school teachers. When more schools started to articulate their need for assistance, organizations within the education support structure also became slightly involved. In 1988, the government established a project at the Dutch Centre for Health Promotion and Health Education $(\overline{\mathrm{DCH}})$ in order to coordinate some of the major initiatives at the local and national level. The most visible activities initiated by DCH's AIDS project focused on: (a) the development and dissemination of a brochure providing background information and general guidelines for developing a school-based AIDS prevention policy, (b) the development of a network of local teacher-trainers, (c) research on the state of affairs in general sex education and AIDS education in secondary schools, and (d) the development and dissemination of exemplary curricular materials for classroom-based AmS education.

\section{General guidelines}

For strategic reasons it was felt necessary to build coalitions among relevant actors, both within the health care and the education support structure. Consensus about some starting-points for dealing with a ideologically sensitive issue like AIIDS education needed to be accomplished without 
frustrating all the good work that was already going on. In 1989, a brochure was send to all Dutch secondary schools and provided a global outline of the essentials of a school-based AIDS education policy (Wijnsma, 1989). The reluctance to become more specific at that time is at least partly explained by the absence of systematic information about adolescents' HIV preventive behaviors and related determinants, and about the educational means with proven impact. The major points of departure one became agreed upon were:

- school-based AIDS education should be based on a process of shared vision-building within schools;

- classroom AIDS education should structurally be embedded in general sex education and health education;

- AIDS education should be part of schools' formal policy,

- AIDS education should go beyond the provision of mere bio-medical knowledge; it should also be focused on attitudes and social skills, so that students learn to talk frankly about sexuality with their peers and to insist on either having no sex or safe sex;

- AIDS education should take students' development, experience and preferred sexual lifestyle as a starting point, and should prevent stigmatization of any (sexual) lifestyle and/or people with AIDS/HIV;

- AIDS education should be provided by teachers, not by external experts.

None of the support activities initiated at the national level were targeted at specific teacher segments, mainly because of the absence of an administrative mandate for any particular subject area to either provide AIDS/sex education or health education. As a consequence, classroom implementation of health content in Dutch secondary schools heavily relies on teachers' motivation or commitment in this respect. Nevertheless, most secondary schools in the Netherlands $(88 \%)$ do actually provide general sex education, usually addressed by teachers in biology, social studies, health education', and/or religious education (Mellink, 1989).

\section{Teacher training}

Additional efforts were devoted at the development of a network of local teacher-training teams. These teams generally consisted of sex educators of the Family Planning Association and health educators of municipal health authorities. Funding and coordination of the network was a joint responsibility of the DCH's AIDS project and the national bureau of the Family Planning Association. From 1989 to 1991, about 24 local in-service courses were provided, reaching 239 secondary teachers. The local training tearns were responsible for content and organization of the in-service workshops. These courses generally consisted of four to eight 4-hour sessions, and varied considerably in method and scope. For the greater part the programs focused on the delivery of

Healtb education is only part of the core curriculum in a fen junior nocational schools. 
background information about AIDS and HIV prevention, on relevant teaching formats for classroom instruction, and on teachers' personal assessment of values and attitudes towards sexuality in general, sexuality of young people, and homosexuality.

\section{Schools' entry state of affairs}

A nationwide survey from late 1988 indicated that $64 \%$ of all responding secondary school teachers were already engaged in AIDS education activities (Mellink, 1989). Teachers in health education (96\%) were most involved, followed by teachers in biology (87\%), social studies (66\%), and student-counsellors (30\%). School level aggregates indicated that in $85 \%$ of all schools at least one teacher was involved in some kind of AIDS education.

The survey showed that teachers in biology generally addressed physiological content: puberty, the human immune system and the disease agent. Teachers in social studies mainly addressed attitudes towards people infected with HIV, drug-users and homosexuals. Topics covered by health education, which is only part of the core curriculum in some junior vocational schools, were both biologically and attitudinally/socially oriented. Teachers' direct response to alternative needs for support focused on acquiring more background information, documentation, and curricular materials for classroom instruction. Those already delivering AIDS information indicated the absence of a formal school-policy and lack of collegial support as the major impediments for their educational efforts.

\section{Dutch AIDS curricula}

Table 1.1 briefly characterizes four curricular packages that were developed and disseminated within the framework of the national ALDS project during the period 1988-1989. Curriculum A, "Aids, het komt je niet aanwaaien", became available first (end of 1988), and was co-produced by the Dutch Educational Television Network (NOT) and sex education specialists. Immediately after the accompanying video was broadcast, representatives of Protestant schools started to question its central message. According to their ideological concem, the curriculum was too narrowly focused on AIDS and condom use, while underestimating sexual abstinence as an adequate coping response. Their opposition even led to a public debate in the Dutch parliament. Atthough unintended, this resulted in much free publicity for Curriculum A, as well as in additional governmental funding of an AIDS curriculum for Protestant schools, "Een Wereld van Verschil" (Curriculum B), designed by the Protestant Educational Advisory Centre (CPS).

Later on, it was assumed that these two curricula did not properly match the differential interests and cognitive abilities of students in different educational levels. Therefore, Curriculum C, "Ziek van de Liefde", was designed for senior secondary education (senior general and preuniversity education), and Curriculum D, "Net dat ene moment", for junior secondary levels (junior vocational and junior general education). These curricula were produced by the Dutch STD Foundation and the Municipal Health Authority of the city of Rotterdam respectively. 
Table 1.1. Characteristics of four nationally disseminated AIDS education curricula.

\begin{tabular}{|c|c|c|c|c|}
\hline & Curriculum A & Curriculum B & Curriculum C & Curriculum D \\
\hline Products & $\begin{array}{l}\text { - student magazine } \\
\text { - teacher manual } \\
\text { - video }\end{array}$ & $\begin{array}{l}\text { - student magazine } \\
\text { - teacher manual } \\
\text { - video }\end{array}$ & $\begin{array}{l}\text { - student magazine } \\
\text { - teacher manual } \\
\text { (no video) }\end{array}$ & $\begin{array}{l}\text { - student magazine } \\
\text { - teacher manual } \\
\text { - video }\end{array}$ \\
\hline $\begin{array}{l}\text { Target } \\
\text { group }\end{array}$ & all secondary schools & $\begin{array}{l}\text { all Protestant } \\
\text { secondary schools }\end{array}$ & $\begin{array}{l}\text { senior general and } \\
\text { pre-university schools }\end{array}$ & $\begin{array}{l}\text { junior vocational and } \\
\text { junior general schools }\end{array}$ \\
\hline \# lessons & 4 lessons & 6 lessons & $\begin{array}{l}8 \text { lessons ( } 4 \text { basic and } 4 \\
\text { optional) }\end{array}$ & $\begin{array}{l}\text { not specified; provides } \\
21 \text { leaming accivities }\end{array}$ \\
\hline Content & $\begin{array}{l}\text { ADS: testing, safe sex, } \\
\text { purchase/use condoms, } \\
\text { anti-discrimination }\end{array}$ & $\begin{array}{l}\text { intimate relationships: } \\
\text { attractiveness, love, } \\
\text { sexuality }\end{array}$ & $\begin{array}{l}\text { STD/AIDS: response to } \\
\text { SID-infection, } \\
\text { purchase/use condoms, } \\
\text { anti-discrimination }\end{array}$ & $\begin{array}{l}\text { AIDS/sexuality: inter- } \\
\text { ethnic differences, } \\
\text { physical/emotional } \\
\text { attractiveness }\end{array}$ \\
\hline $\begin{array}{l}\text { Learning } \\
\text { objectives }\end{array}$ & $\begin{array}{l}\text { knowledge, values, com- } \\
\text { munication skills }\end{array}$ & norms and values & $\begin{array}{l}\text { knowledge, values, com- } \\
\text { munication skills }\end{array}$ & knowledge and values \\
\hline $\begin{array}{l}\text { Learning } \\
\text { activities }\end{array}$ & $\begin{array}{l}\text { group discussions, role- } \\
\text { play, questionnaire, } \\
\text { demonstration, } \\
\text { buying condoms }\end{array}$ & $\begin{array}{l}\text { group discussions, read- } \\
\text { ing articles, optional } \\
\text { creative assignments }\end{array}$ & $\begin{array}{l}\text { group discussions, role- } \\
\text { play, demonstration, } \\
\text { buying condoms, } \\
\text { writing assignments }\end{array}$ & $\begin{array}{l}\text { group discussions, } \\
\text { interviews, role-play, } \\
\text { drawing cartoons, } \\
\text { writing assignments }\end{array}$ \\
\hline Costs & $\begin{array}{l}\text { video: Dfl. } 72,50 \\
\text { manural: Dfl. 4,- } \\
5 \text { magarines: Dfl. 4,- }\end{array}$ & $\begin{array}{l}\text { video: Dfl. } 30,- \\
\text { manual: Dfl. } 15,- \\
\text { magazines: Dfl. } 9.50\end{array}$ & free of charge & $\begin{array}{l}\text { Complete package } \\
\text { (video included): } \\
\text { Dfl. } 19,50\end{array}$ \\
\hline Sold exp. & $\begin{array}{l}\text { end '88-summer ' } 91 \text { : } \\
86,655\end{array}$ & $\begin{array}{l}\text { end '89-summer '91: } \\
6,874\end{array}$ & $\begin{array}{l}\text { end '89-summer '91: } \\
130,184\end{array}$ & $\begin{array}{l}\text { end '89-summer '91: } \\
306\end{array}$ \\
\hline
\end{tabular}

All curricula focused on students' personal and social development. They kept the transfer of knowledge to a minimum and mainly emphasized active forms of learning (e.g. inquiry learning). The accompanying teacher manuals provided guidelines for flexible use and for creating a safe classroom atmosphere conducive to peer-directed exchange of personal opinions, values and experiences. Only Curriculum $\mathrm{C}$ was not accompanied by a dramatized video and could be purchased without any charge.

The curricula mainly differed in content and design. Curriculum B placed HIV prevention in a broader context of norms and values constituting intimate relationships. AIDS and sexual transmitted diseases (STDs) received minor attention in this curriculum. Curriculun A primarily addressed HIV transmission and preventive behaviors. Curriculum $C$ also broadened the scope to other STDs. Curriculum $\mathrm{D}$ additionally emphasized cultural determination of sexual lifestyles. When compared to the other curricula, Curriculum $\mathrm{D}$ was much more visually designed, keeping the use of text-formats to a minimum. 
None of these curricula was designed for any particular teaching subject. A clearly articulated theoretical basis for the development of content and learning activities was absent in all curricular packages. Only Curriculum B was built around an explicit didactic model. Every lesson started with a general introduction by the teacher, then the topic was visualized by video fragments, followed by guided class discussions and text formats providing additional background information. Optional teaching formats provided for a more thorough exchange of personal values and opinions (small group work, creative assignments).

Beside mass media support, all ADS curricula were disseminated without any deliberate guidance, e.g. school visits or curriculum-related in-service training. Dissemination heavily relied on advertisements in newspapers and specialist journals, and on direct mail of material overviews and of complimentary copies of student magazines.

\section{Research questions}

In 1991, two years after their initial release, a survey was conducted aimed at exploring the antecedents to teachers' adoption and implementation of the four nationally disseminated AIDS curricula. This was first because none of these so-called "first generation" AIDS curricula had been subject to any rigorous evaluation before, neither on the student level nor on the teacher level, and second, because a new project was planned for developing a theory-based AIDS curriculum which, unlike the "first generation" curricula, would be focused on empirically validated determinants of adolescents' HIV preventive behaviors. The research on antecedents of teachers' utilization of the "first generation" AIDS curricula was expected to provide grounded cues for anticipating possible implementation barriers during the stage of development of the new theory-based AIDS curriculum. The research questions that guided the survey are the subject of this thesis:

- To what extent do Dutch secondary teachers provide classroom-based AInS education?

- To what extent do they have awareness-knowledge about the four nationally disseminated AIDS curricula?

- To what extent are these exemplary curricula adopted by teachers?

- To what extent are the curricular materials implemented by teachers?

- What teacher characteristics or factors in their immediate task environment can be identified as imporiant antecedents to teachers' (a) adoption of classroom-based AIDS education in general, (b) awareness-knowledge about the nationally disseminated ALS curricula, (c) adoption of these exemplary curricula, (d) intention to use one curriculum rather than another, and (e) implementation of these curricula? 
In the remaining of part of this chapter, the research framework used for answering these research questions will be introduced. The overview will be completed with a general discussion of the major results, as well as their implications for improving school support policies.

Part Two of this thesis discusses the theoretical foundation and empirical findings of the present study in more detail. Chapter 2, the first chapter of Part Two, provides a review of the literature that constituted the research framework. It addresses theory and empirical research on curriculum innovation, teachers' planning behavior and related thought processes, as well as school health education innovation, including sex/AIDS education. The next chapter, Chapter 3, presents the results of the present study concerning the prevalence and antecedents of classroom-based AIDS education among Dutch secondary teachers, irrespective of the use of any particular curriculum program. Chapter 4 addresses the determinants and prevalence of teachers' awareness-knowledge about and adoption of the nationally disseminated AIDS curricula, as well as teachers' tendency to adopt one curriculum rather than another (choice intentions). Results regarding the determinants and prevalence of teachers' implementation of these exemplary AIDS curricula are presented in Chapter 5.

\section{Process of curriculum innovation}

The introduction of curricular materials may be an important vehicle to put a pedagogical innovation into practice, but is usually not an end in itself. Curricular materials are meant to provide teachers with operational procedures exemplary for the usually more broadly defined innovation's concepts and ideals. The desired outcomes of a curriculum innovation may even be out of reach if teachers use the exemplary materials without coming to grips with the underlying theories or beliefs (Fullan, $1991^{2}$ ). Therefore, a curriculum innovation is generally not conceived of as just a single discrete event in time, rather than as a developmental process involving four subsequent stages: dissenination, adoption, implementation, and continuation (cf. Kolbe \& Iverson, 1981; Rogers, 1983; Fullan, 1991'). Dissemination concerns the transfer of innovation information to potential users, e.g. teachers. After the information is obtained and processed, the recipient will develop to a greater or lesser extent an intention to use the innovation: adoption. Implementation refers to the process of actual use, or what the innovation consists of in practice (Fullan \& Pomfret, 1977). Continuation succeeds initial implementation; the innovation has become a legitimate normal practice and the allocation of resources (time, money) are routinely made (Miles \& Louis, 1987).

Contemporary research on curriculum innovations and knowledge utilization appear to challenge some of the normative assumptions associated with the classical diffusion of innovation theory (Rogers, 1983). The classical model is characterized as essentially input-driven, while potential users are conceived of as "rational actors" preoccupied with evaluating consequences of alternative courses of action relative to the goals they want to maximize (Rich, 1991). Moreover, 
research within this paradigm primarily focuses on adoption, and related innovation attributes and characteristics of adopter calegories (e.g. innovators, laggards). Rogers (1983) identified five attributes determining innovation adoption: relative advantage, compatibility, complexity, trialability, and observability. Rogers' generalizations are, however, largely based on agricultural innovations, and appeared to be unstable within educational contexts; partly because curriculum innovations are characteristically complex in nature, and often unpredictable regarding their 'relative advantage' for potential users (Leithwood, 1991). In contrast with many technological innovations, like hybrid corn, educational innovations often involve the transfer of information that may not have any hardware aspects. Educational innovations can therefore more easily be modified by the user, or they can be assimilated superficially without any real change in practice (cf. Larsen, 1981; Fullan, $1991^{2}$ ). This has been clearly demonstrated by the large-scale curriculum innovation studies carried out by the Rand Corporation (cf. Berman \& Mclaughlin, 1978). These studies showed that innovation adoption could readily be accomplished by externally defined guidelines and additional funding. Successful implementation was, however, exceptional and appeared to be primarily dependent on local contingencies (McLaughlin, 1990). Comparable implementation failures are reported by Dutch educational researchers (Appelhof, 1989). These and other empirical findings underscore the limited value of a one-sided focus on innovation attributes when investigating curriculum innovations. The characteristics of a curriculum innovation appear to be subject to change after dissemination into the user system, which may not be entirely controllable on the part of the innovation initiator.

Doyle \& Ponder (1977-78) provided a promising frame of reference for investigating the rather critical linkages between curriculum development, dissemination, and utilization. According to Doyle \& Ponder, any curriculum innovation needs to pass the "practicality ethic" of teachers, especially under normal circumstances in which teachers are the final arbiters of classroom practices. Three criteria are assumed to constitute teachers' anticipated practicality: instrumentality, congruence, and costs. An innovation will be perceived as instrumental when it provides clearly specified procedural referents for the proposed classroom practices (how-to-do information). Statements of principle, theory, or prespecified learning outcomes are not perceived as practical. Congruence refers to the innovation's compatibility with the prevailing classroom conditions; both in terms of student reactions (interest, learning) and teachers preferred mode of relating to students. Perceived costs are referred to as the ratio between amount of return to investment; both financial and personal (e.g. time, ease, recognition by peer-teachers, student enthusiasm).

In conclusion, the focus of contemporary research on curriculum innovations gradually departs from the innovation itself to the process by which the curriculum is shaped in practice. In accordance with Doyle \& Ponder (1977-78), other innovation scholars have also emphasized teachers' construction of meaning about new classroom practices as most critical for real change to occur (cf. Ashton \& Webb, 1986; Eveland, 1987; Crandall, 1989; Rich, 1990; Fullan, 1991"; Cousins \& Leithwood, 1993). 


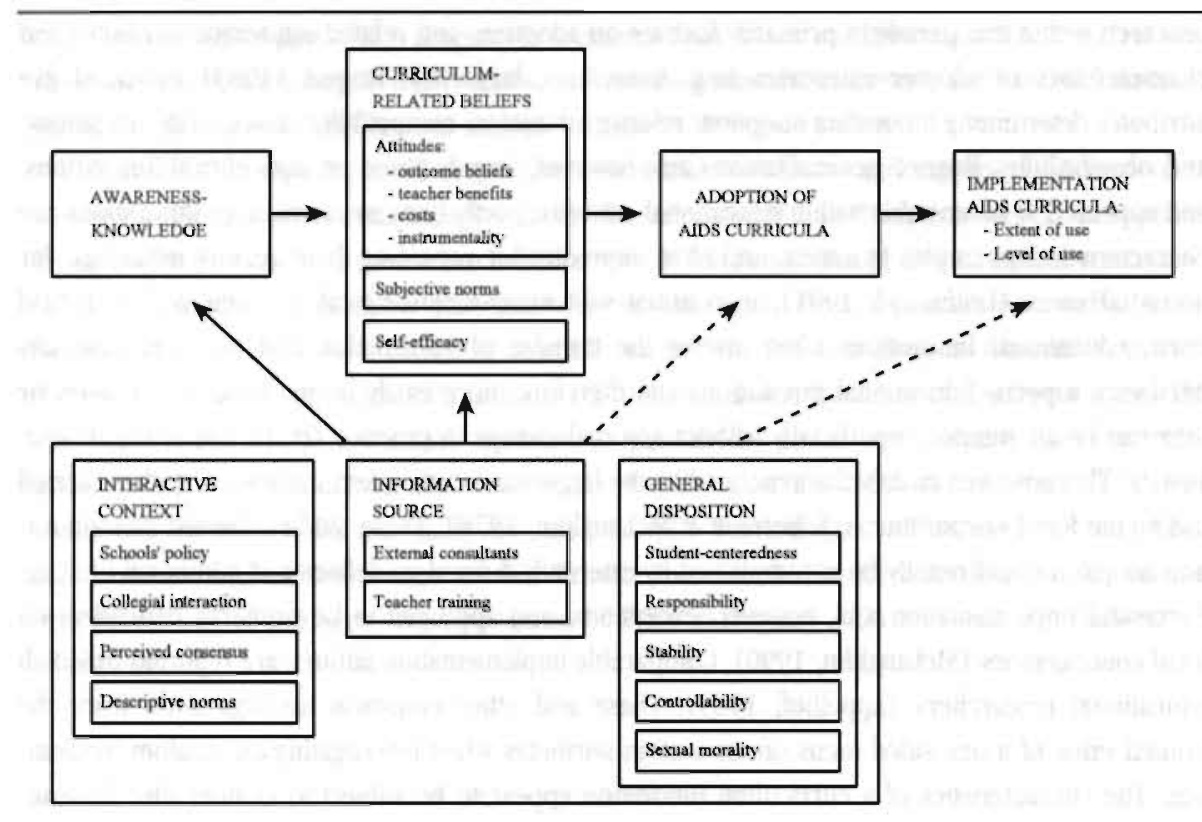

Figure 1.1. Framework for investigating the process of teachers' innovation-decision making about the nationally disseminated AIDS curricula.

\section{Research framework}

The present study focuses on the first three stages of the innovation-decision process, leading from teachers' awareness-knowledge, via adoption, to initial implementation of four nationally disseminated AIDS curricula. The stage of continuation is beyond the confines of this study since data were gathered two years after initial release of the AIDS curricula. Continuation is generally expected to occur over an extended period of time, varying from two to five years; especially when curriculum activities are not repeated very often, as with AIDS education (cf. Hall \& Hord, 1987; Joyce \& Showers, 1988; Crandall, 1989).

The Theory of Planned Behavior (Ajzen, 1987; 1991) was used as a frame of reference for structuring teachers' social and psychological dispositions toward their innovation-decision making about the AIDS curricula. The theory postulates that behavior is best predicted by individual's intentions. In turn, behavioral intentions are best predicted by corresponding measures of attitudes, subjective norms, and control beliefs (self-efficacy; Bandura, 1986). Although the Theory of Planned 
Behavior is not commonly applied to curriculum innovations, there are some good reasons to expect that it suits our interests.First, the innovation is pedagogical in nature; therefore it mainly calls for new teaching strategies and role relationships with students rather than new organizational arrangements at the school level (cf. Doyle \& Ponder, 1977; Brown \& McIntyre, 1982). Second, teaching is conceived of as an intentional act, and teachers' planning decisions are guided by their thoughts and values (cf. Shavelson \& Stern, 1981; Clark \& Peterson, 1986, Borko et al., 1990). Third, the innovation-process takes place within a sociopolitical context where the autonomy of schools and teachers is the prevailing norm; as with other teaching contents, AIDS education in Dutch secondary schools is not mandated by any external authority. Data were gathered within naturalistic teaching settings, in the absence of any external control condition like the ones that usually accompany field experiments (e.g. additional funding, specific training courses, classroom observation). Therefore, we did not focus directly on students or on the organizational context of classrooms and schools, but we only explored these factors as they affected teachers' innovationdecision making.

Empirical research on curriculum innovations, on teachers' planning behavior and thoughts, and on school health education innovation was reviewed in order to specify belief structures or general dispositions that might be incompatible with teachers' acceptance of AIDS education or the exemplary curricular materials. The resulting research framework is graphically presented in Figure 1.1. The review of the literature is more extensively discussed in Chapter 2 (Part Two).

\section{Approach to dependent variables}

Intention and behavior according to the Theory of Planned Behavior parallel two stages in the innovation-decision process: adoption and implementation respectively. Teachers' adoption was conceptualized as their intention to use the AIDS curricula during classroom-based HIV instruction. It was conceived of as more than just a bivariate entity. Intentions were expected to gradually vary in strength; absolute rejection or adoption only mark two opposite poles of this dimension.

In regard to teachers' actual use of the AIDS curricula, two implementation indices were applied. The quantitative aspects of use were represented by "extent of use", defined as the proportion of learning activities applied by the teacher, relative to all proposed curriculum activities. "Level of use" accounted for the qualitative aspects of use. According to validation studies, beside nonuse, only three levels of use appear to exist: (1) partial use, the user selects portions which are appropriate and disregards others, (2) full use, exactly in the form as presented to the user, and (3) adaptive use, the user modifies the information to fit with own needs (cf. Tillema \& Koster, 1990). The level of use scale was adapted from previous educational research conducted by Tillema et al. $\left(1989^{\mathrm{a}} ; 1989^{h}\right)$. Teachers were asked to select one out of five hierarchically ordered descriptors that best represented their curriculum utilization:

- I am using some of the ideas provided by the curriculum, but I disregard others;

- I am using many ideas provided by the curriculum for my own lesson plan; 
- I am using it as an outline for my own lesson plan, and apply some of the proposed activities in the form as prescribed by the curriculum;

- I am making full use of the curriculum, mostly in a form as prescribed;

- I am making full use of the curriculum, and, because of my increased mastery, I am able to modify it in a form to better fit my own and my pupils' needs.

The first two descriptors correspond mostly to partial use, the next two are close to full use. The last descriptor corresponds to adaptive use, use that is meaningful to the individual teacher.

\section{Approach to curriculum-related beliefs}

Exemplary curricular materials are essentially carriers of information. Awareness-knowledge about this information will not automatically lead to adoption or implementation. The information will first be processed; the teacher will estimate its congruence with his/her own social and psychological predisposition. Teachers may anticipate the innovation's consequences (attitudes), approval or disapproval of important agents in teachers' immediate task-environment (subjective norms), and their own capacity to use the information (self-efficacy). Teachers' judgements are not only expected to vary across and within these information units, but also across different curricula since every curriculum carries its own, unique information. Therefore, the curriculum-related beliefs were specified for all four AIDS curricula separately.

Attitudes. The attitude construct was divided into four substructures: (a) student learning outcomes (outcome beliefs), (b) perceived personal benefits of use (teacher benefits), (c) financial costs incurred in purchasing the curriculum (costs), and (d) instrumentality, the extent to which the curriculum was perceived as instrumental to meet the prevailing concerns in teachers' instructional planning. The first two belief structures referred to the ends of the educational process favoring students and the teacher respectively. The last two factors accounted for the acceptability of expected financial and personal investments in or risks of utilizing the curriculum.

Outcome beliefs were indexed as a weighted result of teachers' perceived feasibility and importance of the student learning outcomes as proposed by the curriculum in question. Teacher benefits comprised both expectations about improvement in teacher-student relations, and about what utilization researchers might tern 'conceptual use', namely, increased insight into ways to improve one's own AIDS education efforts. Costs corresponded to teachers' expectations whether financial costs impeded curriculum utilization. Perceived instrumentality referred to whether the curriculum met teachers' primary planning concerns, including expectations about time/ease of pre-active planning, about students' involvement during classroom interaction, and about the extent to which the curriculum provided clearly defined procedural referents.

Subjectve norms. Perceived subjective norms addressed the influence of important social agents on teachers' innovation-decision making. The normative beliefs of students, the school principal, 
school board, colleagues in their own and other subject departments, external consultants and parents were weighted by their motivation to comply with each of these referents in their task-environment.

Self-efficacy. Self-efficacy is conceived of as a context-specific behavioral determinant, not a personality trait (Bandura, 1986). Therefore, self-efticacy estimates should account for teachers' skill-related concerns within the structural units of their instructional planning (cf. Shavelson \& Stern, 1981). It was assumed that teachers, vis-à-vis a given curriculum proposal, would at least estimate their own ability to (a) guide required leaming activities, (b) adapt content and objectives to students' entry behavior, and (c) organize and manage the classroom as an efficient and safe learning environment. Research on classroom sex education suggested the incorporation of an additional skill-related domain, namely, (d) the ability to communicate effectively/frankly about sexuality with students (cf. Herz et al, 1986; Levenson-Gingiss \& Hamilton, 1989²).

\section{Approach to exogenous model variables}

The Theory of Planned Behavior originally suggests that intentions and behavior are ultimately directed by attitudinal, normative and control beliefs salient to the behavior of interest (cf. Ajzen, 1987; 1991). Other factors are expected to be mediated by these endogenous model variables. Recently, however, Ajzen (1991) has discussed some empirical examples demonstrating that, at least in certain contexts, more general dispositions can additionally account for significant proportions of variance in behavioral intentions, like feelings of moral obligation and responsibility to perform.

For the present purposes, teachers' general dispositions, interactive climate conditions and dissemination sources were treated as exogenous to the primary innovation-decision process. They were expected to affect indirectly adoption and implementation by influencing the more specific curriculum-related beliefs. The exogenous model variables may, however, have a direct impact on teachers' awareness-knowledge about the curricula. Awareness-knowledge can actively be obtained on the part of the user, directed by one or more of the exogenous factors. The dotted arrows in Figure 1.1 to adoption and implementation expresses Ajzen's tentative proposition that in certain situations an additional direct impact of exogenous variables may be present.

Interactive context. Schools' formal ADS education policy may result from or reinforce internal improvement efforts, and was expected to direct teachers' decision making in this regard. When content and organization of AIDS education is formally outlined by the school work plan and/or teachers' curriculum work plan, it may also strengthen the idea that AIDS education is more than the concern of the individual teacher.

The frequency of collegial interaction about HIV instruction and the degree to which teachers attained consensus with their colleagues may be indicative for a participative task-environment, 
which is frequently associated with acceptance of new classroom practices (Fullan \& Pomfret, 1977; Huberman \& Miles, 1984; (randall, 1989; Rosenholtz, 1989; Fullan, 1991").

Since frequent collegial interaction may be rather uncommon to particular schools, perceived behavior of peer-teachers may operate as a descriptive norm to teacher's own curriculum-decision making instead (cf. Grube et al., 1986).

Information source. As demonstrated by much educational and non-educational research, innovation utilization may also be determined by the directness with which innovation information is obtained (cf. Rogers, 1983; Grandall, 1989; Fullan, 1991²). In the present research, a general distinction was made between the mere provision of information by mass media channels and faceto-face dissemination channels (external consultants; in this case usually local health and/or sex educators).

Attendance on teacher training courses about AIDS/sex education may have indirectly affected curriculum awareness, adoption or implementation, not only because the exemplary curricula were often brought to the attention of participants, but also because the courses' primary aim was to enhance teachers' mastery expectation with regard to classroom AIDS education.

General dispositions. The specific curriculum-related beliefs will, in turn, be affected by more generic dispositions or personality traits. Teacher attributions for the causes of students' performance have shown to affect teachers' educational decision making. e.g. about the type of goals and activities they select for their students (Brophy \& Rohrkemper, 1981; Ames, 1983; Clark \& Peterson, 1986). It was hypothesized that teachers who believed the causes of students' AIDS-related behaviors were unstable and controllable, would be more willing to provide AIIS education than those believing these causes were stable and beyond the control of classroom instruction. In the present research, teachers rated their perceived stability and controllability of factors they assumed to cause students' lack of knowledge, negative attitudes and lack of social skills toward AIDS-preventive behaviors.

As illustrated by Ames (1983), teachers' attributions may be linked to their responsibility to teach. Levenson-Gingiss and Hamilton $\left(1989^{2}\right)$ positively associated teachers' sense of responsibility with their intention to continue to teach a sex education course. They also found that teachers who intended to continue had a more permissive moral orientation toward sexuality than those who no longer intended to teach the course. The responsibility scale used in the present research was based on the results of the preliminary research, described in the next section. The sexual morality scale was adapted from previous research carried out by Luijkx et al. (1987).

Student-centeredness is assumed to express the teachers' general ideological orientation toward education (Rich, 1990). It represents teachers' tendency to consider students' perspective and to accept students' social and personal development as a legitimate goal for education. The applied student-centeredness scale appeared to be valid and reliable in previous Dutch educational research (Den Hertog, 1990). 
Finally, several demographic characteristics were measured: teachers' age, religious affiliation, gender, years of teaching experience, subject area, school's denomination (Catholic, Protestant, and public), and schooleducational level. Educational level was classified into two clusters: junior level (junior vocational and junior general secondary education) and senior level (senior general secondary education and pre-university education).

\section{Methods}

A questionnaire was developed for estimating the variables in the research framework. The literature provided rather broad domains or clusters of factors that still needed further specification for the writing of scale-items. Only level of use, student-centeredness, and sexual morality were indexed by scales that, at least in their original format, proved to be valid and reliable in other research projects; see Tillema et al., 1989 ${ }^{\text {b }}$, Den Hertog, 1990, and Luijkx et al., 1987, respectively.

\section{Preliminary research}

To ascertain internal validity of some of the remaining model variables, a preliminary qualitative investigation was conducted among the designers of the four AIDS curricula and a sample of 21 secondary school teachers. Both the curriculum designers and the teachers were interviewed individuallỵ.

Validation by curriculum developers. The interviews with curriculum developers focused on the construction of the outcome beliefs and self-efficacy scales. At first, the student learning outcomes and teaching behaviors or classroom conditions as prescribed by the curricular materials were further specified by four members of the AIDS project of the DCH. After they had attained an acceptable degree of agreement about a set of specifications representing a given curriculum, the corresponding curriculum designers judged and further adapted these specifications. The resulting sets, confirmed by the respective designers as adequately representing their curriculum, were used for the writing of the outcome beliefs and self-efficacy items.

Teacher interviews. Twenty-one secondary school teachers were individually interviewed to assess their salient beliefs toward classroom HIV instruction. In order to gain enough variety; teachers were deliberately selected to ensure the presence of teachers who had not yet provided AIDS education, teachers who already had but without using the AIDS curricula, and teachers who had already initially implemented one of the curricula. Construction of the teacher benefits, instrumentality, subjective norms, and responsibility scales was based in the results of the teacher interviews. 


\section{Subjects}

A stratified multistage sample of 988 secondary schools was used to select teachers for a crosssectional survey conducted mid-1991. Equally representation of Catholic, Protestant and public schools was used as an entry criterion. The school principal was contacted by telephone, and requested to distribute one questionnaire in each of the following subject departments: biology, social studies, religious education, and health education (if present). From the 3564 copies sent to them, 1133 teachers $(32 \%)$ from 620 schools $(63 \%)$ returned a questionnaire.

The number of sample subjects used for the final analyses further decreased to 956 teachers (27\%) from 532 schools (54\%) because of the procedure chosen to deal with the rather considerable amount of missing data. All respondents were deleted who had at least one missing response to the variables used for analyzing the antecedents to teachers' adoption of AIDS education, irrespective of the adoption or use of any particular curriculum (Chapter 3 ). This rather conservative procedure was justified by both univariate and multivariate tests. Absence of valid data to single variables, as well as the tendency of having missing values, were insignificantly related to teachers intention to implement and past implementation of classroom-based AIDS education. Moreover, the randomness of teachers' failure to respond in relation to their intention to provide AIDS education was confirmed by multivariate "missing-data plus plugged-blanks" tests (Cohen \& Cohen (1983).

The resulting data of 956 teachers were the basis for all the analyses. About $64 \%$ of these respondents were working in junior secondary education, and $36 \%$ in senior secondary education. Regarding schools' denomination, 29\% taught in public schools, 36\% in Catholic schools, and 35\% in Protestant schools. Teachers were divided into four subject areas: biology (39\%), social studies $(30 \%)$, religious education (16\%), and a mixed-category (16\%) mainly consisting of teachers in health education and student counselors.

\section{Results}

The remaining part of the overview provides an integral discussion of the major research findings and their implications for improving school support policies. Part Two of this thesis addresses the empirical results in more detail. Prevalence and antecedents of classroom-based AIDS education, irrespective of the use of any particular curricular material, are presented in Chapter 3. For this purpose, the research framework presented in Figure 1.1 was slightly adapted. The following factors were deleted because they were assessed in direct association with the AIDS curricula: awareness-knowledge, teacher benefits, costs, instrumentality, and information obtained from external consultants. Also attendance on teacher training courses was ignored since in-service training was assumed to be logically irrelevant to teachers who are unwilling to engage in HIV instruction. Outcome beliefs and self-efficacy scales were applicable since the scale items were not stated in clirect relation to the curriculum from which they were initially derived. Subjective norms 


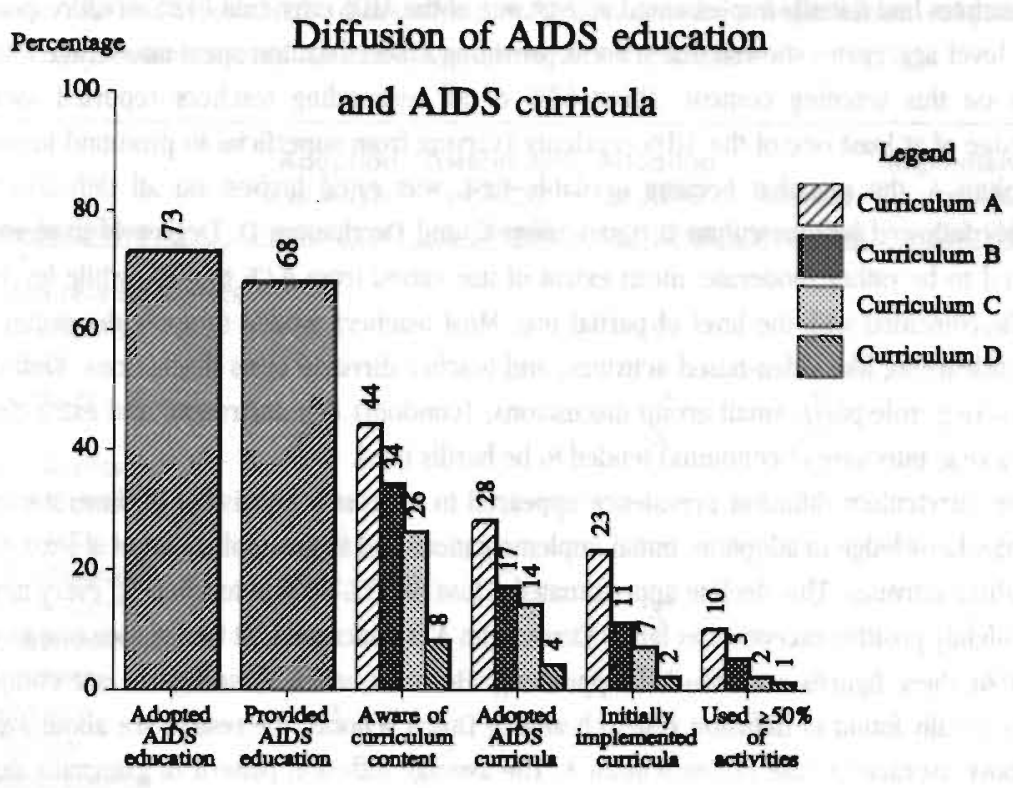

Figure 1.2. AlDS education prevalence and the diffusion of AIDS curricula $(N=956)$.

and descriptive norms also remained in the model since they were both indexed in relation to separate AIDS curricula and to AIDS education in general.

Chapter 4 presents results regarding the determinants and prevalence of teachers' awarenessknowledge about and adoption of the AIDS curricula, as well as their tendency to adopt one curriculum rather than another (choice intentions). The model applied to answer these research questions was identical to the one presented in Figure 1.1, only with exclusion of the teacher benefits construct which was only assessed by teachers who had implemented the curricula.

Determinants and prevalence of teachers' implementation of the ADS curricula are discussed in Chapter 5. Although teachers might have used more than one curriculum, they were requested to only respond to the implementation indices of the curriculum that provided them with the most important directive for their instructional planning. The factor costs was ignored since financial costs are no longer relevant after the materials had been purchased.

\section{Diffusion prevalence}

Diffusion prevalence of classroom AIDS education and the exemplary curricula is summarized in Figure 1.2. About $73 \%$ of the respondents positively intended to engage in classroom-based AIDS 
education during the next school year; $68 \%$ were already involved in HIV instruction, while $62 \%$ of these teachers had initially implemented at least one of the AIDS curricula ( $42 \%$ of all respondents). School level aggregates showed that schools providing ADS education spent an average total of 5.2 lessons on this teaching content. About $63 \%$ of all responding teachers reported awarenessknowledge of at least one of the AlDs curricula (varying from superficial to profound knowledge). Curriculum $A$, the one that became available first, was rated highest on all diffusion indices; invariably followed by Curriculum B, Curriculum C, and Curriculum D. Degree of implementation appeared to be rather moderate: mean extent of use varied from $42 \%$ to $47 \%$, while levels of use generally coincided with the level of partial use. Most teachers tended to apply the rather passive forms of learning like video-based activities, and teacher directed class discussions. Skill-oriented activities (e.g. role-play), small group discussions, (condom) demonstration, and extra-classroom activities (e.g. purchase of condoms) tended to be hardly used.

The curriculum diffusion prevalence appeared to express a consistent decline, starting from awareness-knowledge to adoption, initial implementation, and to the application of at least half of all curriculum activities. This decline approximated a loss of $40 \%-60 \%$ of teachers in every next stage, with a slightly positive exception as far as Curriculum A is concerned. At first glance one might conclude that these figures are rather disappointing. However, when these figures are compared to patterns usually found in diffusion research among Dutch schools, the results are about average or even above average in case of Curriculum A. The average diffusion pattern of externally developed written information indicates that generally about $50 \%$ of teachers do receive that information, while only $25 \%$ actively take notice of its content, and only 5-10\% tinally use the information in one way or another (Stokking \& Leenders, 1990; 1992).

Involvement in AIDS education appeared to be unrelated to teacher's age, years of teaching experience, or school's denomination. Differences were found regarding teacher's gender, religious affiliation, educational level, and subject area. Compared to male teachers, more female teachers were involved in classroom AIDS education (77\% versus $66 \%$ ). More teachers admitting Catholicism (34\%) or Protestantism (36\%) appeared to provide AIDS education than teachers who reported any other religious affiliation (28\%) or no religion (22\%). When compared to teachers in social studies $(65 \%)$ and religious education $(38 \%)$, AIDS education was more prevalent among teachers in biology $(78 \%)$ and teachers in health education or student counselors (85\%). Finally, significantly more teachers from senior educational levels initially implemented AIDS education than teachers in junior secondary education.

\section{Antecedents to AIDS education and curriculum utilization}

The research framework was applied to teachers' (a) intention to provide AIDS education, (b) awareness-knowledge about the AIDS curricula, (c) curriculum adoption, (d) intention to use one curriculum rather than another (choice intentions), and (e) curriculum implementation. Table 1.2 provides a global overview of variables that accounted for significant proportions of unique variance in these criterion variables, when adjusting for the influence of other factors. The results were 
Table 1.2. Predictor variables that entered the regression models on teachers' adoption of classroom-based AIDS education, and awareness-knowledge about, adoption and implementation of the exemplary curricular materials.

\begin{tabular}{|c|c|c|c|c|c|}
\hline Predictor variables & $\begin{array}{c}\text { Adoption } \\
\text { of AIDS } \\
\text { education }\end{array}$ & $\begin{array}{c}\text { Awareness } \\
\text { of AIDS } \\
\text { curricula } \\
\end{array}$ & $\begin{array}{c}\text { Adoption } \\
\text { of AIDS } \\
\text { curricula } \\
\end{array}$ & $\begin{array}{l}\text { Choice } \\
\text { intention }\end{array}$ & $\begin{array}{c}\text { Implementation } \\
\text { of AIDS } \\
\text { curricula }\end{array}$ \\
\hline \multicolumn{6}{|c|}{ Curriculum-related beliefs } \\
\hline Subjective norms & $\mathrm{X}$ & & $X^{*}$ & $X$ & $X^{*}$ \\
\hline Self-efficacy & $x$ & & $\ldots$ & $X$ & $X^{*}$ \\
\hline Instrumentality & & & $X^{*}$ & $\mathrm{X}^{*}$ & $X^{*}$ \\
\hline Costs & & & $-X$ & $\mathrm{X}^{*}$ & \\
\hline Teacher benefits & & & & & $X^{*}$ \\
\hline \multicolumn{6}{|l|}{ Interactive Context } \\
\hline Schools' policy & $x$ & - & - & - & $X^{*}$ \\
\hline Collegial interaction & $x$ & $\mathrm{X}^{*}$ & - & - & $\mathrm{X}$ \\
\hline Descriptive norms & - & $X^{*}$ & $\mathrm{X}^{*}$ & $\mathrm{X}^{*}$ & - \\
\hline \multicolumn{6}{|l|}{ General dispositions } \\
\hline Sexual morality & $\mathrm{X}$ & - & $X^{*}$ & $X^{*}$ & $X$ \\
\hline Responsibility & $x$ & $\mathrm{X}$ & -. & - & - \\
\hline Controllability & - & - & - & - & $X$ \\
\hline \multicolumn{6}{|l|}{ Information source } \\
\hline External consultants & & & - & $X$ & $X$ \\
\hline \multicolumn{6}{|l|}{ Demographics } \\
\hline Public & - & $-X$ & - & - & - \\
\hline Catholic & - & - & - & - & $X^{*}$ \\
\hline Protestant & - & $\mathrm{X}$ & - & - & - \\
\hline \multicolumn{6}{|l|}{ Teaching subject } \\
\hline Biology & - & $-X$ & -. & - & $-X$ \\
\hline Religious education & - & $\mathrm{X}$ & $\ldots$ & -. & .. \\
\hline
\end{tabular}

\footnotetext{
a blank field indicates that the variable was ignored for building the regression model;

- variables that were considered for building the regression model but failed to enter the equation;

$\mathrm{X}$ entered the regression model, and correlated positively with the criterion;

- $X$ entered the regression model, and correlated negatively with the criterion;

$X^{*}$ entered the regression model of more than one curriculum (not in effect in the first column).
}

obtained by using stepwise multiple regression analysis, and multivariate logistic regression in case of awareness-knowledge (bivariate criterion). In all analyses, predictors were entered according to their theoretically expected order: endogenous variables in the first step and exogenous model variables in the second step. The additional predictive property of demographics was explored in a third step, if zero-order correlations with the criterion appeared to be statistically significant (Pearson's r). 
Although awareness-knowledge, adoption and implementation was modeled for each curriculum separately (see Chapters 4 and 5), the differential impact of predictor variables in regard to different AIDS curricula is ignored in the overview given in Table 1.2. The distinction between extent and level of use is also omitted. A predictor is marked as significant, when it entered the regression equation of at least one curriculum. Variables in the research framework that did not enter any single regression model are not presented in Table 1.2: outcome beliefs, perceived consensus, student-centeredness, perceived stability of determinants of students' HIV-risk behavior, and attendance of in-service training. The same applies to most demographics: age, religious affiliation, gender, years of teaching experience, and educational level. This does necessary imply that they were unrelated to successive criterion variables, but rather that their predictive properties are restricted when adjusting for the impact of other factors.

Adoption of classroom ADS education. Teachers' intention to engage in classroom AIDS education, irrespective of the use of any specific curriculum, was best predicted by perceived subjective norms and self-efficacy. In accordance with research on teacher planning behavior, students appeared to have most potential in affecting teachers' adoption decision, followed by colleagues in their own teaching department and the school principal. Above all, teachers' selfefficacy was constituted by their perceived ability to talk frankly about sexuality with students. Although their estimated ability to apply skill-oriented teaching formats was generally low, it appeared to be less determinative when compared to the other three efficacy domains: talking about sex, adapting objectives and content to student needs, and applying classroom management strategies for attaining an efficient and safe learning environment.

The additional impact of exogenous model variables seems to confirm that teachers' adoption of AIDS education is affected by both situational and personal factors: school policy, frequency of collegial interaction, personal sexual morality, and sense of responsibility. Only $34 \%$ of all respondents reported the presence of a formal school policy on AIDS education, while $91 \%$ of teachers not providing AIDS education worked in schools where these regulations were absent. Comparably, frequency of collegial interaction about HIV instruction appeared to be generally low: $19 \%$ never discussed the topic in an official meeting with colleagues, while $53 \%$ reported having such a meeting less than once a year. Moreover, high intentions to engage in classroom AIDS education activities seemed to come along with a relatively permissive sexual morality and high sense of responsibility toward HIV instruction. Teachers who were least willing to provide AIDS education tended to absolve their responsibility by referring to other subject matter priorities, and to the incompatibility of education within the domain of students' social and personal development with their interpretation of the nature of their teaching subject. These perceptions seem to be highly personal since significant differences were only detected within, rather than between teaching subjects. 
Awareness-knowledge about AIDS curricula. Analyses of awareness-knowledge indicated that colleagues had played a prominent role in diffusing these curricula. Descriptive norms (used by colleagues) and frequency of collegial interaction best predicted teachers' curriculum awareness. Awareness-knowledge about Curriculum $C$ was also positively associated with sense of responsibility. Awareness of Curriculum B, the one that was specifically developed for Protestant schools, was most prominent among those teaching in Protestant schools and teachers in religious education, while teachers of biology and those in public schools appeared to be least knowledgeable about Curricu$\operatorname{lum} B$.

Adoption of ADS curricula and teachers' chotce intentions. Antecedents to teachers' adoption of the AIDS curricula paralleled those related to AIDS education in general as far as subjective norms and sexual morality is concerned. Only adoption of Curriculum B appeared not to be hindered by teachers' sexual morality. Regarding perceived subjective norms, students and colleagues in the teachers' own department appeared to be most decisive for teachers' curriculum adoption. Colleagues as an important source of reference for teachers' adoption decision was confirmed by the entrance of descriptive norms in nearly all regression models. The entrance of perceived instrumentality in all regressions on curriculum adoption confirmed not only teachers' tendency to anticipate students' involvement in curriculum activities, but also that perceived degree of procedural clarity of these curricular materials was utmost critical to teachers' intentions to use them. Although not expected, correlations between self-efficacy and the adoption indices were low; in two instances even non-significant. When teachers decide upon using a single curriculum, financial costs hardly appeared to be a leading principle.

Teachers' choice intentions were only statistically significant when comparing Curriculum B with $\mathrm{C}$, indicating a preference for adoption of curriculum $\mathrm{B}$ rather than $\mathrm{C}$. Choice intentions including Curriculum $\mathrm{D}$ were, however, not computed since too few teachers indicated having combined knowledge of Curriculum D and one of the other curricula. Differential preferences toward using Curriculum A, B, or C were predicted by almost the same factors as those that were related to adoption of single curricula. Only teachers' preference of using Curriculum A rather than $C$ was additionally related to differential self-efficacy; indicating that teachers' self-efficacy was generally more congruent with the teaching behaviors and classroom conditions prescribed by Curriculum A than those prescribed by Curriculum C. Teachers who preferred using Curriculum C rather than A were significantly more often personally supported by external consultants than those preferred using Curriculum A. Finally, in comparison with teachers' adoption of single curricula, financial costs seem to become a more important criterion when they are choosing between alternative curricula.

Implementation of ADS curricula. Antecedents to implementation of Curriculum D were also disregarded since the curriculum was only used by 16 respondents. Implementation of the other AIDS curricula appeared to be most strongly associated with the curriculum-related beliefs. 
Perceived instrumentaity was even more decisive to implementation than to adoption. In contrast to adoption, teachers' self-efficacy again became an important determinant, especially concerning the use of Curricula $\mathrm{A}$ and $\mathrm{C}$. Subjective norms significantly affected implementation of Curricula $\mathrm{A}$ and B. Perceived teacher benefits, a construct only applied to the stage of curriculum implementation, accounted for significant proportions of variability in implementation of Curricula $A$ and $B$. The presence of a formal school policy additionally affected implementation of Curricula $\mathrm{A}$ and $\mathrm{C}$, while frequency of collegial interaction also affected implementation of Curriculum A. Sexual morality and perceived controllability additionally predicted implementation of Curriculum A. Teachers using Curriculum B who were supported by external consultants tended to implement their curriculum to a higher extent than their counterparts lacking external support. Finally, teachers from Catholic schools generally implemented Curricula $B$ and $C$ to a significantly higher degree than their counterparts in Protestant or public schools. This is remarkable since Curriculum B was specifically designed for Protestant schools. Although more teachers in biology tended to engage in classroom AIDS education, their degree of curriculum implementation generally appeared to be lower when compared to their colleagues in other subject areas. This demographic variables, however, only entered the regression on implementation of Curriculum $\mathrm{C}$.

\section{Limitations}

The prevalence scores found in the present study need to be interpreted with caution, since they might be biased by the relatively low response $(27 \%)$. The actual response rate cannot be computed since the delivery of questionnaires merely relied on the school principal acting as a gobetween. Assessments in regard to possible selective attrition indicated that response was, however, not affected by school's denomination, educational level and teaching subject. Response also appeared to be independent of use/nonuse of the AIDS curricula. Schools not providing AIDS education appeared to be stightly over-represented among non-responding schools. The latter two assessments were based on information provided by the principal during initial telephone contact, which, however, proved to be at variance with the teacher data. According to principals' information, AIDS education was prevalent among $95 \%$ of all schools $97 \%$ among responding, $93 \%$ among non-responding schools). In contrast, school level aggregates of the teacher data showed that this percentage among responding schools was about $82 \%$. This discrepancy calls into question the value of relying on principals' knowledge of teacher implementation, as has also been challenged by other innovation researchers (cf. Fullan \& Pomfret, 1977). In conclusion, although response analyses provided some indications favoring the representativeness of the present data, reservations still need to be made about the accuracy of the reported prevalence and absolute meanscores (è.g. adoption rate). 
Generalization in regard to the innovation determinants may be less restricted since they are based on correlational analyses which are expected to be less vulnerable to possible selective attrition. On the other hand, because of the cross-sectional nature of the research data, conclusions about the importance and sequence of the social and psychological antecedents to teachers' innovation-decision making are still tentative. Future longitudinal and/or intervention studies are needed to determine which variables are most predictive for teachers' transition to subsequent stages in the curriculum innovation process.

\section{General discussion and conclusions}

Given these limitations, the prevalence of AIDS education among Dutch secondary schools and teachers in 1991 appeared to be at least as high as in 1988. When the present data are compared to those reported by Mellink (1989), school level prevalence had slightly decreased from $85 \%$ to $82 \%$, while the number of teachers involved in AIDS education had slightly increased from $65 \%$ to $68 \%$. The most striking change between 1988 and 1991, however, appeared to be the increase in the number of Protestant schools providing AIDS education. It seems fair to conclude that the development of a specific curriculum for Protestant schools has had its intended effect. When compared to Catholic and public schools, significantly fewer Protestant schools provided AIDS education in 1988. This backlog among Protestant schools appeared to have vanished in 1991.

The Theory of Planned Behavior (Ajzen, 1987; 1991) has proven to be a useful frame of reference for investigating teachers' processing of information vis-à-vis a given pedagogical innovation. When findings from research on curriculum innovations and teacher planning behavior are integrated, it effectively highlights possible mismatches between curriculum characteristics and the prevailing psychosocial predisposition of teachers in naturalistic teaching settings. Adoption and implementation appeared to be more strongly related to the prespecified curriculum-related beliefs than to personality traits, school or demographic factors. The proportions of variance in the adoption and implementation indices accounted for by the curriculum-related beliefs varied from $20 \%$ to $46 \%$, while the total proportions of explained variances, including exogenous model variables; varied between $25 \%$ and $49 \%$.

The "explained" variances in adoption and implementation may have been limited by high intercorrelations among some predictor variables. Most illustrative in this respect were teachers' responses to statements regarding the importance and feasibility of prespecified student learning outcomes. Outcome beliefs did not enter any regression model when adjusting for the impact of other factors, although zero-order correlations were statistically significant with nearly all criterion variables. The limited impact of outcome beliefs was mainly caused by its common variance with teachers' self-efficacy estimates. It suggests that teachers' assessments of student learning outcomes were partly directed by their mastery expectations about related instructional means (cf. Guskey, 
1988; Smylie, 1988). Atternatively, the limited impact of outcome beliefs is supported by an accumulation of research on teachers' planning behavior. Teachers appear to be more concerned with procedural content and approval or disapproval of referents within their task environment, including students (cf. Shavelson \& Stern, 1981; Clark \& Peterson, 1986; Borko et al., 1990). This general tendency was underscored by the fact that teachers' knowledge of and intentions to use the curricula were not significantly related to differential educational levels, although two curricula were specifically designed for senior and junior levels, Curricula $\mathrm{C}$ and $\mathrm{D}$ respectively.

Perceived subjective norms appeared to be an important determinant in every stage in teachers' innovation-decision making. Students, colleagues in the teachers own department, and the school principal were most important social referents. In contrast with what has been found in other research on educational innovations, the impact of external consultants was not confirmed by the present data, whether measured in the subjective norm format or in the format assessing whether teachers actually received information from external consultants. Only $16 \%$ of the teachers who intended to provide AIDS education and who were knowledgeable about the AIDS curricula had received information by personal communication with an external support agent.

Adoption of AIDS education was more prevalent among those who frequently interacted with colleagues about HIV instruction. Moreover, peer-teachers appeared to be the most important source of information about the available ADS curricula, and curriculum adoption was more likely when colleagues already used the curriculum (descriptive norms). The impact of perceived colleague behavior was, however, restricted to the stage of adoption. Taken together, it appeared that colleagues provided important standards for teachers' decision making regarding adoption of AIDS education and of exemplary curricular materials. Actual implementation of the AIDS curricula appeared to be more influenced by other teacher concerns, like anticipated student reactions.

Students seemed to affect teachers' willingness to engage in AIDS education activities, as well as their adoption and implementation of exemplary curricular materials. In contrast to their counterparts, teachers who positively intended to provide AIDS education not only expected that their students would highly approve of HIV instruction, they also appeared to be more willing to consider these expectations as an important directive for their instructional planning. As is confirmed by the impact of perceived teacher benefits and instrumentality of the AIDS curricula, anticipated students enthusiasm and involvement in the proposed curriculum activities seemed to be a powerful incentive for teachers' utilization of curriculum activities.

Besides anticipated students' reactions, perceived instrumentality was also constituted by judgements about time/ease of pre-active planning and the extent to which the curriculum provides clear procedural knowledge (how-to-do specifications). Perceived instrumentality was related to nearly all curriculum adoption and implementation indices. It underscores the importance of meeting teachers' need for practicality when attempting to introduce new classroom practices.

Teachers' self-efficacy estimates clearly affected adoption of HIV instruction and curriculum implementation, but not teachers' adoption of the AIDS curricula. One might speculate that teachers who are facing the decision to provide AIDS education, anticipate possible barriers in relation to 
their ability to overcome them. If teachers end up with rather low mastery expectations, they are likely to reject AIDS education and balance this decision by attributing low controllability to the determinants of students' HIV-related behaviors, and/or by referring to other content priorities or to the incompatibility of AIDS education with the basics of their teaching profession/subject (responsibility). The relatively high correlations of self-efficacy with perceived controllability $(r=45)$ and with sense of responsibility $(r=.46)$ is indicative of this general tendency. Next, after acceptance of HIV instruction, awareness and adoption of the exemplary curricula appeared to be largely directed by teachers' tendency to rely on and to conform to colleague information and behavior respectively. In contrast to adoption, implementation of the AIDS curricula might be conceived of as behavior that is less overt to colleagues since it takes place in relative isolation of the classroom. This may also explain teachers' gradual shift from colleagues to students as important sources of reference for gaining socially directed approval or disapproval in the stage of implementation. Again, self-efficacy becomes an important factor since the teacher will anticipate being successful, only when he/she feels confident in talking frankly about sexuality with students, adapting content and activities to students' interests, and applying requisite strategies for classroom management. In this stage, implementation may be even further constrained when low-efficacy teachers lack the support of AIDS curricula providing enough procedural clarity about how to operate effectively within these skillrelated domains of classroom instruction.

The interaction of self-efficacy with teachers' ideological orientations and environmental conditions needs further attention, since it may endanger long-term acceptability of school-based AIDS education. Teachers' sexual morality appeared to be related not only to adoption and implementation, but also to efficacy expectations $(r=30)$. This suggests that teachers with a restrictive sexual morality will, among others, feel less comfortable in talking about sexuality with their students. While lacking sufficient confidence, teachers may at the same time feel compelled to engage in HIV instruction by social pressure, for example, induced by school policy or colleague interactions. Neither teachers nor students will take advantage of teachers who persistently anticipate being unsuccessful. In that case teachers might fail to attribute the problem to inappropriate knowledge of successful approaches, but rather to their own inability to teach or to students' inability to learn, regardless of the method applied (Smylie, 1988). In order to be sensitive to this issue, external change agents and AIDS curriculum designers will need to go beyond emphasizing the ideal ends of school-based AIDS education. They had better provide leads for gradual improvement of teachers' efforts that induce some tangible short-term success, which in turn may induce perceptions of greater ideological congruence with what is valued by either external or internal change agents (Rich, 1990). 


\section{Implications}

The practical implications of the study results need some qualification since none of the AIDS curricula has been subject to systematic evaluation on the student level. Given the sincere practical problems teachers are facing with putting the curricula into operation, while the external advocate of change cannot legitimize teachers' investment in some thorough modifications of classroom practices, it seems rational throughout that many teachers appeared to have implemented rather superficial changes. Teachers' reluctance to invest more into improving their mastery over some of the proposed skill-oriented teaching formats appears to parallel the resource system's rather onesided focus on obtaining short-term adoption. As yet, the innovation strategy mainly relied on oneway mass media communication and one-shot teacher workshops, while disregarding the allocation of requisite resources for actual implementation. The present situation may be exemplary for the "two community" metaphor of knowledge utilization, referring to the prevailing gap between the reward systems of external policy-makers and the practice-based community (cf. Rich, 1991).

Besides these reservations, the present results provided additional leads for improvement of school support activities. In order to facilitate AIDS education implementation, these improvement efforts should combine:

- development of clear and validated materials (development);

- promotion of access to available practices, both by mass media and face-to-face communication (adoption);

- in-person assistance during later implementation (implementation);

- development of collegiality and school level support for ongoing improvement (continuation);

- empowerment of the local linkage subsystem.

\section{Development of validated materials}

Quality curricular materials are those that are both theoretically and practically valid. In order to have an impact on students' HTV preventive behaviors, one should first examine and specify related social and psychological determinants. Research on the determinants of Dutch adolescents' risk-reducing behaviors already provided a validated basis for selecting priority learning objectives for classroom-based AIDS education (cf. Richard et al., 1991; Schaalma et al., 1993). Subsequently, in order to design theoretically sound materials, the development process encompasses (a) matching student learning objectives with a focused theory-based framework of pedagogical and educational methods ${ }^{2}$, and (b) selecting and writing exemplary teaching formats according this prespecified theoretical framework. In order to ensure practical validity, the next steps comprise of (c) development of a practice-based framework matching teachers' educational planning behavior, 
and (d) pre-testing the draft teaching guide and student materials, and redesigning these drafts accordingly. The latter is critical for determining prior acceptance by at least teachers and students before the curriculum is widely disseminated.

The necessity to develop a practice-based framework is clearly illustrated by the work of Van den Akker $\left(1988^{2} ; 1988^{\mathrm{b}}\right)$. In order to induce teacher learning about a given curriculum change, research on educational innovations, teacher planning and adult learning were translated into a framework that shaped the general outline of curricular materials. Field experiments showed that the onset of teacher learning about the curriculum innovation was associated with materials that (1) stimulated teachers to an elaborate 'internal dialogue' about the essentials of their teaching role (e.g. by asking questions about their own situation, by suggesting prior trials with unfamiliar elements, by structuring expectations about possible student reactions), and that (2) provided clear procedural advice about the implications for classroom practices (e.g. by estimation of time, by suggestions for grouping, distribution of tasks and materials, by providing possible variations of responses to student feedback information).

Practical validity will be further enhanced by linking key-representatives of the practice-based community to the development process, whether teachers or policymakers. The writing of concrete operational lesson units might be a collaborative effort of professional curriculum developers and experienced teachers who are committed to the innovation. In order to gain political back-up, policymakers may be represented in a temporary advisory board. This is of specific interest when, like AIDS education, the content is expected to be controversial. After all, this approach appeared to have led to promising results in case of the development of the AIDS curriculum for Protestant schools.

\section{Promoting access to available practices}

Promotion of the AIDS curricula should take a combined format of mass media and face-to-face communication. The present results indicated that teachers' access to information about the curricula was limited, even among those intending to provide classroom AIDS education. Their awareness-knowledge about the AIDS curricula varied between $10 \%$ and $49 \%$. However, when informed, relatively large proportions of these teachers decided positively about using the curricula (50\% to $78 \%$ ). Therefore, a most cost-effective approach would be maximizing access to information about the AIDS curricula.

Little impact can be expected of a promotion strategy that mainly emphasizes the desirability of achieving particular student learning outcomes. As indicated by the present results, perceived practicality relative to self-efficacy expectations and perceived subjective norms appear to be priority teacher concerns. In promoting the AIDS curricula one might anticipate these concerns by incorporating 'symbolic modeling' into mass media messages (Bandura, 1986). According to Bandura, vicarious learning about an innovation will be induced by observing (symbolic) models demonstrating effective use of the innovation and related, valued outcomes. Modeling is expected to have great potential in the present context since teachers' adoption of AIDS education and the AIDS 
curricula was strongly affected by colleague information and perceived social pressure of colleagues and students. Parcel et al. $\left(1989^{\text {b }}\right)$ illustrated how video-based modeling can effectively be integrated into a mass media strategy to promote school-based tobacco prevention programs. When applied to ADS education, video-fragments should provide opportunities to observe congruent rolemodels demonstrating short term benefits, effective use of maragement and teaching strategies and positive student outcomes. Short tern benefits can be made salient by demonstrating students' success in discussing sexuality issues, as with communicating students' approval of learning activities by showing their active involvement and enjoyment. Anticipated practicality will be further enhanced by demonstrating requisite teacher skills for talking about sexuality with students, as well as for applying student-centered and classroom management strategies that win students' attitude and skill-related outcomes. Besides audio-visual communication, similar information units can be integrated into written mass media messages (leaflets, advertisements, program descriptions or reviews in specialist teacher journals). The reach of postal information (e.g. leaflets, overviews, complimentary copies) will be increased when it is directly mailed to individual teachers, or at least to teachers' subject department (Stokking \& Leenders, 1992).

Although a significant impact was not confirmed by the present data, a cumulation of research have demonstrated the surplus value of teachers' face-to-face contacts with external consultants (Crandall, 1989; Mclaughlin, 1990; Tillema \& Koster, 1990; Fullan, 1991 ${ }^{\pi}$ ). External consultants can facilitate active initiation of the change process by promoting informed, local choices about alternative practices. Teachers' commitment will be further enhanced by providing assistance for the development of implementation schedules, program adjustment to local characteristics without diminishing the core of the innovation, and arrangement of training facilities (Crandall, 1989). At the initiation stage the external consultant needs to ensure the principal's support of teachers' improvement efforts. At least a minimum level of support will be needed in order to legitimize teachers' requests for requisite resources (e.q. materials or training). The principal's active involvement will, however, yield more impressive results since he/she is in the position to shape participative climate conditions conducive for long-term success. Moreover, there appears to be little research evidence for the involvement of many people in the early stages of the change process. As Fullan $\left(1991^{2}\right)$ asserts: "It is more likely the case that small groups of people begin and, if successful, build momentum. Active initiation, starting small and thinking big, bias for action, and learning by doing are all aspects of making change more manageable, by getting the process underway in a desirable direction."

\section{In-person assistance during implementation}

As with face-to-face contacts with external consultants, it is not the availability of teacher training per se, but the quality with which it is provided that appears to be decisive for successful implementation. The mere provision of information about curricular materials, one-shot workshops, or occasional visits by external change agents, have been shown to fall short in meeting the affective, cognitive, and skill-related support needs of those involved in the change process (Crandall, 1989). 
Teachers' experiences during initial implementation of the AIDS curricula will, however, be an important directive for their motivation and commitment toward future endeavors. In order to yield some early success or progress during initial implementation, experienced consultants should help define successive goals for improvement over time that are feasible within the restrictions of teachers' initial ability and/or given context characteristics (e.g. classroom composition).

objectives for in-service training need to be selected accordingly. As confirmed by research within the framework of the Concerns Based Adoption Model, in the early stages of implementation teachers' needs and concerns are throughout personal and focused on short-term procedural content (cf. Hall \& Loucks, 1978; Hall \& Hord, 1987). Concerns about meeting students' needs and learning outcomes, or cooperation with other teachers, will only become prevalent after a minimum level of routine in classroom utilization is obtained. This can take a period of time varying from two to five years (cf. Hall \& Hord, 1987; Joyce \& Showers, 1988; Crandall, 1989). Therefore, initial inservice preparation should emphasize teachers' understanding of the core principles of the innovation and increase their self-efficacy about requisite teaching skills to ascertain short-term success (e.g. active student involvement in discussing sexuality), while refraining from premature pressures for outcome evaluation.

Research on staff development have indicated that improvement in innovation-related teacher skills can hardly be expected when it does not comprise the following training components: (a) presentation of theory and research explaining the rationale behind skills and strategies to be changed, (b) demonstration of good practices (direct modeling), (c) opportunities for the practice of skill under simulated conditions (guided enactment), (d) performance feedback (nonevaluative), and (e) coaching during self-directed application of acquired skills (cf. Bandura, 1986; Joyce \& Showers, 1988; Crandall, 1989). Especially, the transfer of newly acquired skills to actual classroom instruction largely depends on the application of in-class coaching (Joyce \& Showers, 1988). Although follow-up assistance during classroom implementation can be provided by external consultants, collegial work on the mastery of innovation practices may even be a more powerful incentive for teachers' commitment to the innovation. As demonstrated by the present and other data on curriculum innovations, peer-teachers do provide an important and credible frame of reference to act upon (cf. Crandall, 1989; Rosenholz, 1989; Fullan, 1991 ${ }^{2}$ ). Therefore, external consultants best promote opportunities for colleague consultation about HIV instruction. This is not to say that one needs to seek school-wide involvement, which even may be counterproductive, but to stimulate collaboration among multiple small groups of teachers, inside or outside the school. For example, as a follow-up assignment to initial training, trainees can be divided into groups of two or three teachers who visit each others' classrooms. Peer-observation of teacher behavior and student reactions by means of pre-structured protocols can be used for feedback during follow-up training sessions (cf. Levenson-Gingiss, 1992). 


\section{Development of school level support}

Aithough the present study does not particularly address the stage of continuation, others have shown that attention to teacher concerns about their impact on students' achievement and empowerment of school level support become critical to ongoing implementation (Berman et al., 1977; Huberman \& Miles, 1984; Hall \& Hord, 1987). In order to encourage and reinforce commitment of teachers who become experienced users, staff. development efforts need to depart gradually from mainly providing technical assistance to teachers' procedural mastery. In addition, two incentives should be provided to prevent their distraction of the innovation and to produce higher levels of use: (a) feedback on outcome performance, and (b) reinforcement through recognition (cf. Parcel et al., 1990). Lp to this stage, application of these incentives would be rather meaningless since in the later states of implementation teachers become first concerned about student learning outcomes and they become interested in collaborative efforts to improve their impact (cf. Hall \& Hord, 1987).

Staff development should incorporate 'booster' sessions for professional dialogue about modifications to improve student outcomes. Planning for improvement might be based in goalsetting theory (Locke \& Latham, 1991), while using systematically gathered implementation and outcome data for providing performance feedback. Teachers' present performance in relation to student outcomes can be used as a point of departure for goal-setting. According to goal-setting theory, teachers' will expend more effort on future attempts and will be more likely to achieve improvement when setting challenging goals, than when setting easy goals or no goals at all; at least on condition of teachers' mastery over requisite skills and goal-acceptance. Again, performance feedback in relation students' outcomes may direct goal-setting and program planning for renewed implementation.

Reinforcement through recognition may be accomplished by promoting experienced teachers to take leadership roles in training or serve as consultants for teachers who are still inexperienced in providing HIV instruction (cf. Levenson-Gingiss, 1992). It may not only reinforce their motivation for ongoing involvement, but it also provides the necessary pressure and support for new staff members to get involved in the innovation. The latter is essential since turnover of experienced staff members is generally found to be an important threat to innovation continuity (Fullan, 19912).

Discontinuation can further be prevented when classroom-based AIDS education gets embedded into schools' formal policy. It may provide regulations on timetable scheduling and procedures for the allocation of resources, including continuing assistance of new teachers by experienced colleagues ( $\mathrm{f}$. Huberman \& Miles, 1984). Moreover, as with the onset of the innovation process, the principal's active support in providing access to necessary resources and opportunities for collaboration anong colleagues, have proved to be important factors for program continuity (Berman et al., 1977, Crandall, 1989). 


\section{Empowerment of the local linkage subsystem}

The present study stresses the process curriculum innovations. The introduction of classroombased AIDS education encompasses a learning process for both students and teachers. Temporary "hit and run" projects without responsive follow-up assistance will inevitably fail since they ignore the genuine barriers to teachers' implementation of classroom practices that are critical to affect students' HIV-risk behaviors; peer-led small group work, role-playing, (condom) demonstration, extra-classroom activities (e.g. purchase of condoms).

Fmpowerment of the local linkage subsystem is a prerequisite to guarantee sustained in-person assistance of teachers dedicated to providing classroom-based AIDS education. However, most teachers already involved in AIDS education still did not appear to have had personal contact with external consultants (local health/sex educators). And when they had, or had attended locally provided in-service workshops, only a limited impact on curriculum adoption or implementation could be detected. Nevertheless, the previously described improvement policy will only succeed if local consultants get more involved since the actual provision of follow-up assistance to individual schools or teachers is beyond the capacity of the national support agencies involved in AIDS education. Others have demonstrated that local linkers can significantly contribute to the implementation of new classroom practices: e.g. by providing in-depth information about the innovation, demonstration of alternative practices, assistance to adjust programs and to implementation planning, arranging training facilities, and by follow-up visits to assist, provide feedback, and reassure adopters (cf. Crandall, 1989).

It is realistic to expect that many local health/sex educators who are called upon to take these change agent roles also have affective, cognitive, and skill-related support needs. Although they will have expert knowledge about AIDS content, or even may have educated students themselves, many of them will still be rather inexperienced at providing in-person assistance to secondary teachers involved in curriculum changes. In order to prevent frustration on the part of both the assisters and assisted, it is advisable throughout not to waste energy with attempts to involve as many schools or teachers as possible. Local consultants better build on working with teachers who are ready and willing to consider alternative practices. It will not only benefit the teacher but also increases the likelihood of obtaining rewarding success for the assister, which will foster his/her confidence as a linking agent. It is the national resource system's responsibility to stimulate and facilitate the actors in the local linkage system. As Crandall (1989) asserted: "During change efforts, apparently, individuals in every category benefit from receiving support and assistance; what they give is enhanced by what they get." 


\section{PART TWO}

Chapter 2

Review of the literature 


\section{Introduction}

This chapter addresses theory and empirical research on curriculum innovation, teachers' planning behavior and related thought processes, as well as on school health education innovation, including sex/AIDS education. It provides a more profound insight into the line of reasoning, choices and assumptions underlying the present study on AIDS education innovation in Dutch secondary schools.

The introduction of classroom-based AIIS education, as with other curriculum innovations, is aimed al changing the transactional process between teachers and students. Therefore, curriculum innovations are distinguishable from other educational innovations, like administrative or organizational innovations. They mainly call for new teaching strategies and role relationships with students, rather than new organizational arrangements at the school level (cf. Fullan \& Pomfret, 1977; Doyle \& Ponder, 1977; Leithwood \& Montgomery, 1980; Brown \& McIntyre, 1982). However, a diversity of meanings and definitions of curriculum, curriculum innovation, and curriculum evaluation still remain (cf. Goodlad et al., 1979; Glathorn, 1987; Fullan, 1991²).

This chapter starts with exploring the concepts of curriculum and curriculum evaluation. Then we will discuss diffusion of innovation theory, before addressing theory and research on curriculum innovation and related determinants. Next, empirical research on school health education innovation will be summarized, including general sex and AIDS education. Finally, we will discuss the conceptual underpinning of the research framework that was applied to teachers' innovationdecision making about four nationally disseminated AIIDS curricula.

\section{Curriculum and curriculum evaluation}

The goals of schooling are basically twofold: (1) the development of students' academic and cognitive skills and knowledge, and (2) the development of students' individual and social skills and knowledge necessary to function occupationally and sociopolitically (Fullan, 1991 ${ }^{2}$ ). Since the goals and means of education are rooted in society, at least in pluralistic democracies, school performan$c e$ is not only subject to change by internal forces (e.g. schools/teachers), but also by actors more or less exiernal to the education system (e.g. employer/labour unions, parents). The educational debate may, however, stress various aspects of the curriculum; usually depending on one's position or responsibility relative to the education system. This appears to be rather critical for any attempt to change the details of the curriculum in schools, especially when initiated from outside. For example, an external advocate of change may be highly involved in pushing a particular curriculum innovation forward by emphasizing its ideologically appropriateness. Teachers, however, may be most con- 


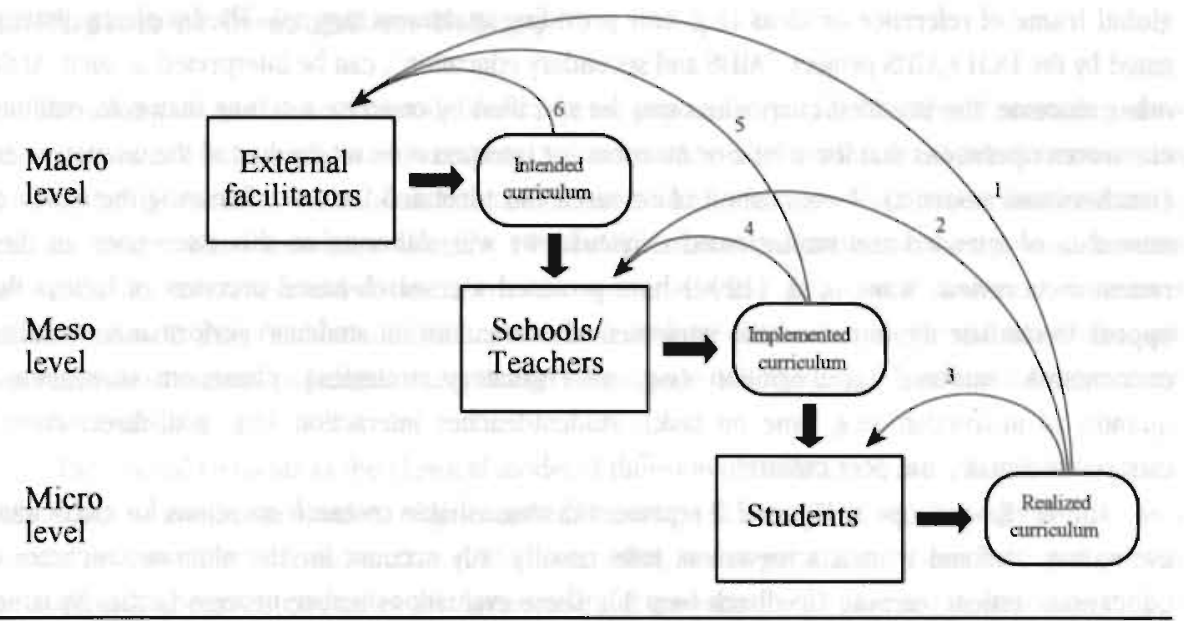

Figure 2.1. Multi-level curriculum definition (adapted from Pelgrum, 1989).

cerned about its implications for their daily classroom practices (cf. Doyle \& Ponder, 1977-78). This tendency of external advocates to confuse the change with the process of change, even led Fullan (1991") form the proposition that: "... the more an advocate is committed to a particular innovation, the less likely he or she is to be effective in getting it implemented".

Leithwood (1991) provided a definition of the term curriculum that addresses its process character: "A curriculum is a set of decisions about what outcomes are desired for students as a result of their educational experiences, and the instructional activities likely to facilitate the achievement of these outcomes." It clarifies that desired student outcomes (value-based) and related instructional features (practice-based) are subject to a process of decision making, reflecting the social construction of meaning about schooling by the actors involved, even interacting from within various subsystems.

Given the restriction to externally initiated curriculum changes, this curriculum definition can be expanded according to the multi-level linkages between those most directly involved: (1) the intended or ideal curriculum (macro-level), as codified in curriculum documents disseminated by the external advocate of change, (2) the implemented curriculum (meso-level), as put into practice by schools and teachers, and (3) the realized curriculum (micro-level), as experienced by students (cf. Pelgrum, 1989). Figure 2.1 graphically represents these curriculum images, together with research questions relevant for evaluating the process of curriculum-decision making (feedback loops). For the present purposes, the model is not further refined, although on the macro level regional intermediaries can be discerned from national support agents or policy makers, and the curriculum applied by teachers can be discerned from the one prescribed at the school level (cf. Goodlad et al., 1979; Glatthom, 1987). 
The inlended curriculum, as defined by the external change facilitator, may be shaped by a global frame of reference or ideas (e.g. only providing attainment targets). The brochure disseminated by the DCH's AIDS project, "ADS and secondary education", can be interpreted as such. At the other extreme, the intended curriculum may be specified by concrete teaching materials outlining classroom operations that leave little or no room for interpretation on the part of the ultimate users (teachers and students). A cumulation of research has identified factors influencing the match or mismatch of intended and implemented curricula; we will elaborate on this issue later. In their recent meta-review, Wang et al. (1990) have provided a research-based overview of factors that appear to mediate the impact of the implemented curriculum on students' performance (realized curriculum): students' metacognition (e.g. self-regulatory strategies), classroom management, quantity of instruction (e.g. time on task), student/eacher interaction (e.g. goal-directedness), classroom climate, and peer culture.

The feedback loops in Figure 2.1 represent distinguishable research questions for curriculum evaluation. National written achievement tests usually only account for the ultimate outcomes of education: student learning (feedback loop 1). These evaluations ignore process factors by which student test-scores may be mediated. This type of curriculum evaluation is most vulnerable to the frequently cited "Type III error", referring to those situations in which negative outcomes are falsely attributed to an ineffective program when, in fact, the program was not or was improperly implemented (cf. Basch et al., 1985). Schools or teachers usually perform this type of curriculum evaluation on a regular basis (feedback loop 2). Besides variations in classroom implementation, also factors determining students' mental processing of classroom instruction may explain possible mismatches 'between the implemented and realized curriculum; e.g. aptitude variables, students' motivation, classroom climate (feedback loop 3). Fullan \& Pomfret (1977) have underscored this issue by stating: "The important point is that it is students' interpretations of teacher behavior, and not teacher behavior per se, that determines whether the innovation is implemented". When accounting for the match between the intended and implemented curriculum, monitoring teachers' interpretation of the intended curriculum and variability in curriculum implementation may also provide important feedback information (loops 4 and 5 respectively). Finally, the intended curriculum may also be subject to evaluation ("alpha testing") by colleagues or curriculum designers not in the development group (feedback loop 6; cf. Scriven, 1991).

In sum, evaluation of the process of curriculum-decision making focuses on acquiring information about factors mediating possible discrepancies between the intended, implemented and realized curriculum. These three types of curriculum and the actors involved in curriculum enactment are linked hierarchically, each level having its own "input", "throughput" and "output" characteristics. The research that is subject in this thesis focuses on feedback loops 4 and 5 . It investigates teachers" construction of meaning about the nationally disseminated AIDS curricula (intended curriculum) in relation to variability in actual classroom HIV instruction (implemented curriculum). 


\section{Diffusion of innovation theory}

Thinking about the innovation-decision process appears to parallel the line of reasoning about the process of curriculum-decision making. An innovation is generally conceived of as essentially knowledge-based; it can be an idea, practice or any kind of information that is perceived as new by the one aware of that knowledge (Rogers, 1983). Diffusion is the communication process between those having awareness-knowledge about the innovation and those who have not. Sometimes dissemination is discerned from diffusion, when referring to whether or not the spread of information throughout a given population was planned on purpose. We will use diffusion and dissemination synonymously.

The critical elements in the classical model of diffusion of innovations are: (1) the innovation, (2) which is communicated through certain channels, (3) over time, (4) among members of a social system (Rogers \& Shoemaker, 1971). According to this paradigm, research need to provide scientifically grounded guides for the development of innovations, and for its transfer from the test setting to the user population. The early studies primarily focused on associating adoption rates with innovation attributes and characteristics of adopter categories (cf. Larsen, 1981; Rogers, 1983; Schinke et al., 1991). Innovation scholars generated several lists of program attributes affecting adoption, more or less similar to the ones identified by Rogers (1983):

- relative advantage, the unique benefits of the innovation over other practices;

- compatibility, the match between the innovation and the sociocultural, economic, and ideological value system of the adopter;

- complexity, the degree of difficulty in understanding and using an innovation;

- trialability, the degree to which the innovation can be split up for small-scale experiments;

- observability, the visibility of the innovation's results.

Zaltman \& Duncan (1977), for example, have expanded this list with the innovation's impact on social relations, reversibility, communicability, time, risk and uncertainty, commitment, and capacity for the innovation to be updated.

According to the classical approach to the diffusion of innovations, members of the user system are conceived of as rational actors who are preoccupied with analyzing consequences of atternative courses of action relative to the goals they want to maximize (Rich, 1991). It is assumed that after initial development and field testing, adoption will almost obviously follow awareness-knowledge about the innovation in case the program meets the prescribed quality standards. In order to optimize communication efforts, researchers additionally identified patterns of adoption over time by different segments in the user population. For many innovations the cumulative adoption percentages appear to follow an S-shaped diffusion curve. Based on the lag period between acquiring awareness-knowledge and adoption, Rogers (1983) identified five adopter categories: innovators, early adopters, early majority, late majority, and laggards. Innovators are labelled as 
being eager to try new ideas while taking the risks for failure and loss (e.g. economically). When compared to innovators, early adopiers are characterized as being more respecied by their network peers. Since they are perceived as making deliberately wise decisions, they are assumed to operate as role models for the early majority who generally take more lime for their innovation-decision making. Early majority adopters have the gateway capacity to reach the average members of a social system. Late maịority adopters and laggards are characterized as gradually more closed to new ideas, while their innovation adoption is most determined by social or economic pressures.

Communication channels have additionally been categorized according their differential contribution to the rate or speed of acceptance of innovations. Mass media channels (radio, television, newspapers) appear to be more important for initiating awareness-knowledge, while interpersonal channels (face-to-face contacts) generally have more effect on adoption decisions. Mass media channels appear to be more important for earlier adopters, while face-to-face exchange is more critical to later adopters (Rogers, 1983).

The traditional model has been criticized from different perspectives. In the area of curriculum innovation, this criticism became most apparent after the publications of the widely cited Rand Change Agent study (cf. Berman \& McLaughlin, 1978). The results indicated that the net return to federal seed money programs was "the adoption of many innovations, the successful implementation of few, and the long-run continuation of still fewer" (McLaughlin, 1990). Because of these and other disappointing results, like the ones reported by Dutch educational researchers (cf. Appelhof, 1989), the normative assumptions associated with the classical diffusion model became challenged:

1. The classical model is essentially input-driven. In the early studies it was assumed that innovation meant the adoption of an entire set of recommendations as outlined by the resource system. It was believed that incomplete adoption could be prevented by optimizing the innovation's attributes. The studies merely counted the number of complete adoption, often producing rather meaningless data (Larsen, 1981). One explanation for not incorporating process variables (e.g. contextual factors) was that the early studies mainly addressed agricultural innovations like hybrid corn seed. Research on social innovations, like educational programs, showed, however, that complete adoption was generally the exception rather than the rule (cf. Mclaughlin, 1990). These innovations, unlike hỵbrid corn, can be modified, partially used, or assimilated superficially without any real change in practice (cf. Larsen, 1981; Fullan, 1991 $1^{1}$ ). As a consequence, the characteristics of a social innovation may change over time after it is disseminated into the user system.

2. It is a priori valuable to use new information. New practices were assumed to be inherenty superior to established ones; rejection can only be attributed to "laggardness", or "irrationality" on the part of the adopting units (Feller, 1981). Rejection of a valued but practically rather illdeveloped change may, however, reflect more rationality than its adoption (cf. Doyle \& Ponder, 1977-78). Or as Eveland (1987) has put it: "If all the costs are to be paid by the lower hierarchical levels. of the system and all the benefits appropriated by the upper levels, "resistance to change" is not merely understandable but positively rational". 
3. The adopter is conceived of as a "utility maximizer". The rational actor will acquire, and more or less automatically use all information relevant to reaching valued goals. It is, however, frequently demonstrated that teachers, like most other people, do not conform to this means-end model (cf. Clark \& Peterson, 1986). The acquisition of new information may be restricted by the amount of attention one is able to allocate to the problem of interest, by time resources needed for a comprehensive search of alternative approaches, or by the tendency to rely solely on internal information resources that the decision maker has already invested in (cf. Rich, 1991; Fullan, 1991 ${ }^{2}$ ). Teachers' innovation-decision making will be based on a variety of normative and pragmatic criteria as well (Doyle \& Ponder, 1977-78).

4. Promising results of an innovation produced during efficacy testing do not necessarily survive in naturalistic settings. The control mechanisms that usually accompany those field trials, like the allocation of additional funding, or specific training courses, are typically absent in the normal teaching environment (cf. Doyle \& Ponder, 1977-78; Schinke et al., 1991; Fullan, 1991³).

In sum, these criticisms basically emphasize the model's failure to recognize that the diffusion of innovations is a dynamic process rather than a single discrete event. Adoption has shown to be only one step in a multiple step process which is not entirely controllable on the part of the resource system. Reorientation is required to depart from the rather one-sided focus on innovation attributes or the innovativeness of particular user segments, to studying the process of innovation-decision making. It is concluded that the success of any significant innovation will largely depend on the critical linkages between the construction of meaning about the innovation by those responsible for knowledge creation, diffusion, and utilization (cf. Rich, 1991).

\section{Process of curriculum innovation}

The introduction of new curricular materials is not an end in itself. Teaching materials are meant to be instrumental to the introduction of the innovation's central concepts and ideas. It offers operational classroom procedures exemplary for the usually more broadly defined innovative ideals. It is meant to facilitate teachers' comprehension of the nature and essence of the change proposal, and therefore may enhance the innovation's communicability.

Whether or not imposed from outside, curriculum innovation at the classroom level ultimately involves: (1) the use of new teacbing materials, (2) the application of new teacbing approaches (teaching strategies or activities), and (3) the alteration of teacher beliefs congruent with the pedagogical assumptions and theories underlying the innovation (Fullan, 1991"). The first two dimensions of change are behavioral and can therefore readily be observed. Others have pointed at the primacy of teacher beliefs by emphasizing that what teachers do depends on what they believe, think or feel (cf. Shavelson \& Stern, 1981; Clark \& Peterson, 1986; Eveland, 1987; Cousins \& 


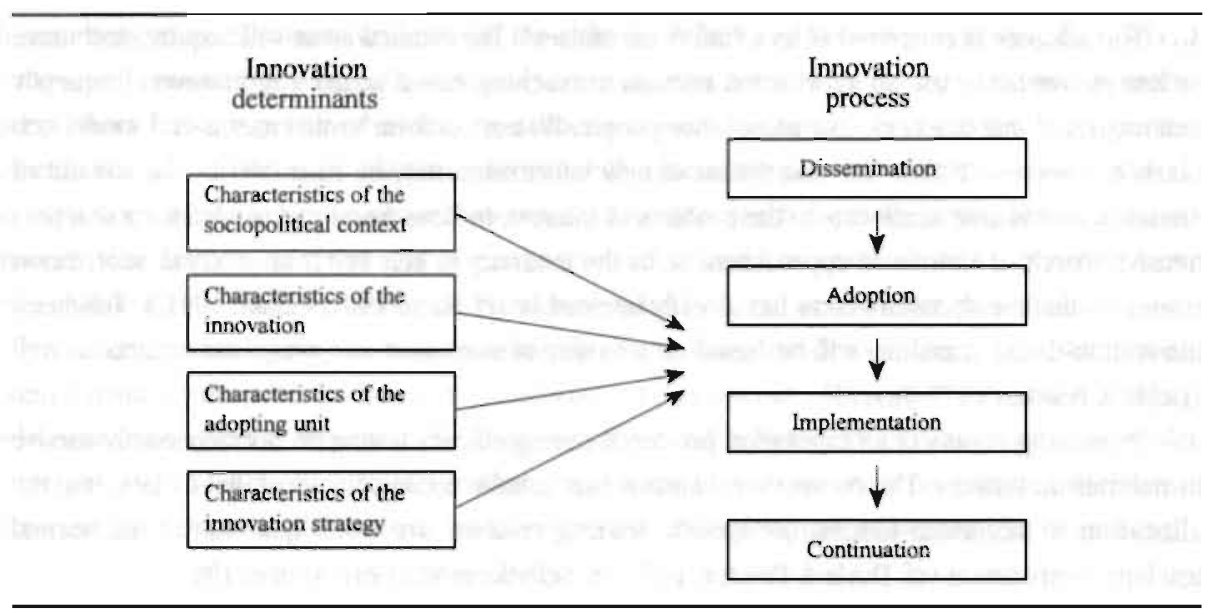

Figure 2.2. Determinants of the process of curriculum innovation.

Leithwood, 1993). After all, the desired outcomes of a given curriculum innovation are likely to be out of reach if a teacher uses the materials or alters some behaviors without coming to grips with the underlying theories or beliefs.

The interrelated steps in the innovation process following the stage of development, are presented in Figure 2.2. Athough some steps have been more refined, we have distinguished four stages: dissemination, adoption, implementation, and continuation. These subsequent stages can be conceived of as potential failure points for lasting change to occur (Orlandi et al., 1990), and may involve numerous factors at each stage. In line with Fullan \& Pomfret (1977), we have organized the innovation determinants into four broad categories: (1) the sociopolitical context, (2) the innovation, (3) the adopting unit, and (4) the innovation strategy. The variables in these categories, on which we will elaborate later, are well grounded in empirical research on adoption and implementation. According to the overview provided by Miles \& Louis (1987), most factors are also strongly associated with the stage of continuation, though a clear picture of which variables or clusters of variables are most critical to a particular stage is still lacking.

\section{Dissemination}

Curriculum dissemination is concerned with bringing ideas about student outcomes and instructional activities to the attention of potential users who are unaware of these ideas (Leithwood, 1991). The ultimate users of teaching materials are teachers and students, but there may be intermediate users as well (e.g. regional school administrators, department heads). Intermediate users may be more or less important for the transfer of externally developed curricula to the classroom, depending on the structure of the education system, both inside and outside school (cf. Marsh \& Huberman, 1984). 
Dissemination of externally developed curricular materials encompasses at least three distinct substages: (1) sending out of information about the materials, (2) receiving or retrieving information by the potential user, and (3) processing by the user of that information (Leithwood, 1991; Rich, 1991). Curriculum information can be sent out in various forms, by mass media channels (advertisements in journals, brochures, leaflets, complimentary copies, news letters), or by face-toface contacts (advisory teacher visits, in-service days).

Recent research among Dutch secondary schools demonstrated that about $50 \%$ of teachers are usually beyond the reach of externally developed written communication (Stokking \& Leenders, 1990; 1992). Although the reception rate increases slightly when information is personally addressed, these figures appear to be indicative for the poor transport of external information in school organizations. Teachers themselves may also be selective in obtaining information relevant to a felt need. Although the primacy of face-to-face contacts with external consultants is confirmed by most diffusion research, teachers generally act in a context of isolation, having almost no personal contact with even a small part of the education network outside school (Fullan, 1991"). Organization sociologists have explained the individual decision makers' preference to invest in and rely on "inhouse" information as an attempt to minimize levels of risk and uncertainty in solving the problem at hand (Rich, 1991). Research on social control and innovation additionally indicated that under circumstances of increased task difficulty and ambiguity, individuals tend to gain approval via conformity to information generated within their own task-environment, even when this information is objectively erroneous (Nemeth \& Staw, 1989).

Perceived credibility and value congruence of the data source may not only determine whether or not information exchange will be accomplished, but also the processing of that information once received. It may direct the attention the teacher is willing to allocate for understanding the information, for testing its validity, or for accommodating it to a form that matches his/her own situation. According to the "two community" metaphor of knowledge utilization, the processing of externally developed knowledge may be negatively affected by competing value systems of developers and researchers on the one hand, and the practice-based community on the other hand (disseminators/teachers). The two cultures are identified as having differential conceptions of time and reward systems (Rich, 1991). Teachers are working under what Huberman (1983) has called the "classroom press", the press for adapting to unpredictable everchanging classroom conditions that call for concrete and immediate solutions. Rewards may be the effective management of discipline or interpersonal conflict, covering the curriculum, or having an impact on the achievement of one or two students (Fullan, 1991 ${ }^{\mathrm{a}}$ ). Program managers responsible for dissemination are usually pressed and rewarded by policy makers and sponsors for delivering the program as soon as possible. On the other hand, researchers and program developers are willing to go beyond the original delivery date for the sake of a "better product" that is rewarded by the academic or scientific community. Lazarsfeld \& Merton's concepts of homophily and hetrophily is an other way of describing the cultural gap between different actors in the innovation process (cf. Kolbe \& Iverson, 1981, Basch, 1984). Especially in case of AIDS education, the advocates of this pedagogical 
innovation, most often health educators, cannot generally refer to a long tradition of working with Dutch secondary school teachers. The degree to which teachers perceive them as having similar interests or status (homo- versus heterophilous) may direct their receptiveness to information provided by these external advocates of change.

\section{Adoption}

Once the information is obtained and processed, the recipients finally decide whether the change proposal will be applied completely or partially in the form as recommended by the disseminator, or in a version adjusted according the teachers' own preferences. Adoption is defined as the intention or decision to use the innovation. Some authors view the adoption or rejection of a given innovation as the endpoint of the dissemination stage. Since it may also involve steps to prepare for actual change, the first stage is sometimes labelled initiation or mobilization. Although diffusion research has associated curriculum attributes with adoption, the process of curriculum adoption is still not clearly understood; partially due to the lack of valid measures of adoption (Loucks, 1991).

\section{Implementation}

Definition and measurement may become even more complicated when dealing with curriculum implementation. Irrespective of either externally or locally developed curricula, implementation refers to the process of actual use of the innovation or what it consists of in practice (Fullan \& Pomfret, 1977). There are generally two distinct schools of thought about curriculum implementation: the fidelity approach and the mutual adaption approach. The fidelity perspective is based on the assumption that the desired outcomes of a curriculum innovation can be reached when it is applied according to certain requirements prespecified by the developers. Within this perspective, curriculum implementation is measured as the degree to which actual use corresponds to intended or planned use. According to the mutual adaptation perspective, it is inappropriate to copy prespecified curricula to differential settings; both the innovation and the user need mutual adjustment in order to reach the valued outcomes of a given innovation. Since adaptation is based on relatively unstructured premises, studies within this perspective usually take the form of action research.

Problems associated with conceptualizing and measuring implementation are extensively discussed by educational researchers (cf. Fullan \& Pomfret, 1977; Leithwood \& Montgomery, 1980; Scheirer \& Rezmovic, 1983; Cousins \& Leithwood, 1986), as well as by researchers working within the broader context of knowledge utilization (cf. Conner, 1981, Larsen, 1981; Rich, 1991). In order to come to grips with some of the pervasive issues, one might distinguish the quantitative and qualitative aspects of implementation. The quantitative aspects are accounted for by estimates such as extent of use (e.g. the proportion of applied activities required by the curriculum), frequency of use, intensity of use (e.g. number of teachers using the curriculum), duration of use, etc. (cf. Tillema et al., $1989^{\mathrm{b}}$ ). The qualitative aspects of implementation are usually accounted for by estimating differential levels of use. The widely applied "Level of Use" framework, introduced by Hall 
\& Loucks (1978), has been recognized as the most sophisticated and explicit conceptualization of the fidelity orientation (Fullan \& Pomfret, 1977). Hall \& Loucks have postulated that with increased mastery over time, individual users may go through seven levels of use, ranging from nonuse, wia mechanical use, to the level of renewal. Despite these and other attempts at refinement, the concept of level of use still has not reached acceptable measurement procedures (Larsen, 1981; Rich, 1991). Moreover, validation studies appear to find only a few levels: (1) nonuse, the new information may have been considered but nothing is being done with it yet, (2) partial use, the user selects portions which are appropriate and ignores others, (3) full use, exacly in the form as presented to the user, and (4) adaptive use, users adapt the information to fit their own needs (cf. Tillema et al., $1989^{\star} ; 1989^{\text {; }}$; Tillema \& Koster, 1990).

Utilization scholars have further differentiated "instrumental" and "conceptual" use. Instrumental use refers to cases in which the user can cite and document the specific way in which the acquired knowledge is being used ( $\mathrm{cf}$. Larsen, 1981). The previously described quantitative and qualitative aspects of use can be labelled as such, since both are directy observable. Conceptual use emphasizes the user's mental processes vis-à-vis an innovation; it refers to changes in a decision maker's thinking about the issue without putting information to any specific, documental use. New information may have a delayed and diffused impact and is therefore less readily observable (Rich, 1991). Athough the construct of conceptual use is still poorly developed, it seems to approximate most what is valued by the mutual adaptation approach.

The complexities involved in conceptualizing use led larsen (1981) to conclude that: "Utilization is to great extent a function of the operational definition used. Studies limited to a single indicator of utilization, and one which is action-based, measure one narrow dimension and may be expected to miss whole classes of outcome". Also others have advocated to include more than one measure of utilization (cf. Fullan \& Ponfret, 1977; Scheirer \& Rezmovic, 1983).

\section{Continuation}

Since the previous stage is most often referred to as the stage in which teachers initially implement the new curriculum, continuation is added to the model because initial implementation not necessarily implies attainment of longevity. Sometines this final stage is termed institutionalization or incorporation when one wants to distinguish the process of continuation on the organizational or individual level respectively. Continuation mearis that the curriculum has become a legitimate normal practice; the change is "self-evident", no longer seen as a change, taken for granted, while allocations of time and money are routinely made (Miles \& Louis, 1987). One of the eminent factors endangering continuation is staff and/or administrative turnover (Fullan, 199! ${ }^{2}$ ). Although there is a variety of conceptual argument involved in this final stage (cf. Miles \& Louis, 1987), we will not further elaborate on it, since the present thesis is primarily concerned with the preceding stages of the innovation process. 


\section{Determinants of curriculum innovation}

This section provides an empirically based overview of factors mediating the transition from dissemination, to adoption and implementation of curriculum innovations. We do not claim to cite all background literature addressing determinants of a variety of curriculum innovations. Our main purpose is to elucidate the meaning of classroom-based AIDS education innovation by outining some prominent characteristics of the context in which it need to be shaped in practice. Therefore, we predominantly relied on secondary sources, which are also recommended for those seeking more detailed background and references to primary sources.

\section{Characteristics of the sociopolitical context}

Schools are embedded in a social network of, or even collaborate with agencies at the local or provincial level (e.g. local government, municipal health authority, local advisory centers), or at the state or national level (e.g. teacher training centers, development and support centers, teacher unions). The term sociopolitical context is used to refer to an amalgam of policy, legislations, or any other pressure of agencies or interest groups outside the school organization. New policy or programs may arise when, according to these institutions' perception, schools appear to fall short in meeting young people's educational needs or socially valued goals.

Health care professionals, epidemiologists, health/sex educators, first picked up the message to respond to the AIDS threat, and, among other things, initiated external support activities for secondary schools. In order to estimate the impact of the nationally developed AIDS curricula, it is necessary to keep in mind some of the particular background charac-teristics of the Dutch education and health system.

Education support structure. The Dutch education system operates rather decentralized, and is emphatically directed by the concept of "educational freedom". This is not only reflected by the citizen's freedom of choice berween schools, but also by a constitutional amendment that prohibits governmental interference in the details of the curriculum in schools. Schools report to individual independent governing boards, and not to a local government authority as in some other countries. As a consequence, schools cannot be mandated to choose any particular textbook, educational material, or curricular program, whatsoever. There do exist rather globally defined atainment targets which are also used as a point of reference for the national written exams at the end of secondary education. Although a great deal of operational freedom is guaranteed, schools and teachers generally tend to use the content covered by these attainment targets as a directive for their own curriculum planning: especially during the last two to three years of secondary education.

Because of this governmental restraint toward curriculum matters, the outcomes of any curriculum innovation rely heavily on schools'teachers' commitment to change, as on the persuasive skill of the external advocate of change. The education support system, funded by the 
Ministry of Education and Science, actually consists of five institutional sectors, four of them formally having the responsibility to respond to the needs and requests of secondary schools throughout the country:

- National Educational Advisory Centres (LPCs; one for Catholic, one for Protestant, and one for Public schools): their work encompasses counseling and development activities (not individual student counseling), evaluation and providing advice and information;

- Foundation for Educational Research (SVO): draws up research programs and provides grants for educational research;

- National Institute for Curriculum Development (SLO): develops master teaching plans, models for (sections of) school workplans, and exemplary teaching materials;

- National Institute for Educational Measurement (CITO): develops achievement tests, like the national written exams. ${ }^{1}$

Despite their potential capacity, these educational support agencies, with the exception of the Protestant Educational Advisory Centre, have hardly contributed to the introduction of AIDS education in secondary schools so far. One of the most pervasive arguments to stay on the side was the absence of health education in the core curriculum of most secondary education. With regard to general sex education, there also appeared to be little curriculum planning at the school level (Mellink, 1989). Therefore, on the part of the education support structure, including the ministry, it could be argued that AIDS is primarily a health problem, and not an educational problem.

Health support structure. External endeavors to facilitate the introduction of school-based AIDS education were mainly accounted for by agencies within the health care system, funded by the Ministry of Welfare, Health, and Cultural Affairs, or by private funds. As far as school-based AIDS education is concerned, the health care institutions operated within the broader framework of the national program on HIV prevention. On the national level, the support agencies most directly involved were, and still are, the Dutch Centre for Health Promotion and Health Education (DCH), the SID Foundation, and the Family Planning Association. The ones contributing most on the local community level are health educators and school physicians of the municipal health authorities, and local family planning associations. Although a relatively close link exists in practice, none of the local agencies formally operate under the governing umbrella of their counterparts on the national level.

Policy press on the development system. Besides the rather complicated relationships between schools, the health care system and the education support system, agencies responsible for included). 
development and dissemination of new curricular programs may, in turn, be forced upon by governmental bureaucracies or program funders. Although there is little empirical research on this particular field of curriculum innovation, in their review Fullan \& Pomfret (1977) have addressed policy issues affecting variability in curriculum implementation at the school level. They will be briefly highiighted in so far as they appear to be related to the development of the Dutch AIDS curricula.

It was found that large-scale curriculum programs directed by governmental bureaucracies usually emphasized obtaining adoption while disregarding the allocation of capacity necessary for actual implementation. As with the development of the Dutch AIDS curricula, policy pressures

mainly emphasized the visibility of efforts, aimed at delivering curricular materials and obtaining high adoption rates in as short a time as possible. It appears that the availability of visible products and verbal adoption are politically most rewarding. This may have had some important negative side effects on implementation. First, development and dissemination of these curricular materials was not preceded by any attempt to obtain or determine acceptance on the part of the ultimate users (teachers and students). Second, no efforts were undertaken to fine grade implementation procedures; for example by means of adequate pre-testing. Moreover, with the exception of the Protestant Educational Advisory Centre, none of the other development teams or agencies conducted any sort of evaluation after dissemination of the AIDS curricula. Under these circumstances, there is a high risk involved for teachers' utilization. If implementation succeeds at the expense of teacher's investment to make it work in practice, the external change agent gets most of the credit; in case of failure, the teacher gets all the blame (Fullan, 1991²).

In sum, it is important to keep in mind that voluntary curriculum innovations, like AIDS education in the Netherlands, need to be distinguished from those mandated by policy regulations. The former provides more degrees of freedom for adoption on the school/teacher level. It seems fair to conclude that the introduction of school-based AIDS education was, and still is, primarily driven by the operational capacity within the health care system, with rather weak linkages to the formal education support structure. In contrast, curricular materials for secondary education, especially as far as the core curriculum is concerned, generally involves institutions within the formal education support structure and/or private textbook publishers. Unlike in elementary education, health education conient and their advocates, are traditionally distant from Dutch secondary schools. The cultural and structural gap between health and education may have mediated the impact of health educators' efforts to induce the innovation process in secondary schools.

\section{Characteristics of the innovation}

As previous addressed, early innovation research generally emphasized program attributes affecting adoption, like the ones identified by Rogers (1983): relative advantage, compatibility, complexity, trialability, and observability. Except for complexity, the more an innovation can be characterized as having each of these attributes, the more adoption is expected. Educational 
researchers additionally focused on success-enhancing attributes of implementation. According to Crandall's (1989) overview the following attributes appear to be empirically grounded:

- value congruence;

- comprehensiveness;

- quality of materials;

- externally developed validity;

- availability;

- transportability.

What is critical here, as with attempts to identify global categories of adopting units, is that these and other lists of program attributes usually represent post hoc qualifications on the part of the researcher. Their applicability for a specific demonstration project is questionable; these lists hardly provide leads for development and dissemination of specific programs. First, some labels are far from clear about what they actually cover. For example, the label "quality of materials" could as well have been used as a heading of the listed attributes.

Second, the connotation of these labels may vary across different types of information used within distinct decision making areas (cf. Rich, 1991). For example, the brochure disseminated by the DCH's AIDS project outlining a comprehensive school policy on AIDS education may have been congruent with the needs of school principals who are primarily responsible for organizing its implementation: e.g. it provided leads for curriculum planning on the school level, which may have been sufficient for the allocation of resources both between and among teaching departments; it also referred to the availability of expert advice about parent involvement, etc. The same brochure, however, may have been too comprehensive and not nearly a priori explicit enough for the teachers responsible for the innovation's operational character during classroom instruction. 'The teachers' primary need may be the access to exemplary teaching materials providing procedural clarity about classroom practices to be changed.

Third, the application of these lists of innovation attributes to the development of a particular innovation is further complicated since users' response ultimately depends on how these attributes match their pre-existing social and psychological dispositions (Doyle \& Ponder, 1977-78; Fullan, $\left.1991^{4}\right)$. For example, the anount of complexity involved in putting a given change into practice. largely depends on the initial capacity available on the part of the user system (skill, peer support, financial or physical resources). Although some attributes may be more or less inherently linked to particular innovations, it will be the users' perception of these attributes that ultimately direct their investment in modifications of existing practices (cf. Rogers, 1983). The Rand studies even reported empirical examples showing these innovation attributes may have an impact opposite to the hypothesized direction (Berman \& McLaughlin, 1978). Unlike Rogers' generalization, broadly defined innovation projects were more likely to be implemented than were projects with a modest or narrow scope. It was argued that, depending on certain conditions, like the starting point of the individuals involved, complexity resulted in greater change because teachers felt more challenged 
and were willing to invest more effort than in programs attempting less (cf. Crandall, 1989; Fullan, $\left.1991^{2}\right)$.

In the area of curriculum innovation, Doyle \& Ponder (1977-78) provided a promising frame of reference for understanding teachers' response to information intended to modify and improve their classroom practices. According to Doyle \& Ponder, findings from innovation research are misleading because they usually generate images of teaching from highly controlled classroom conditions. Among others, they have stressed the importance of investigating teachers' decision making vis-à-vis an innovation under the prevailing condition where teachers usually operate as the final arbiters of classroom practices. In naturalistic teaching settings, calls for classroom changes need to pass the test of what Doyle \& Ponder have termed the "practicality ethic" of teachers. Despite some overlap, three aspects of meaning are associated with this ethic: instrumentality, congruence, and costs.

Teachers will perceive a given innovation as instrumental when it provides clearly specified procedural referents for classroom practice: how-to-do information. Statements of principle, theory, or specifications of valued outcomes are not practical. Instrumentality means the availability of procedural referents for sequential steps in teachers' educational planning, encompassing the préactive, interactive, and postactive planning stages (cf. Clark \& Peterson, 1986; Borko et al., 1990).

Congruence refers to teachers' estimated compatibility of the change proposals with the prevailing classroom conditions in terms of student reactions (interest, learning) and teachers' preferred mode of relating to students. Congruence emphasizes teachers' beliefs about students as important directives for their educational decision making. It may be indicative for the conserving tendency to maintain classroom routines as they are.

Perceived cost is referred to as the ratio between amount of return to investment. Investment may include financial costs, as well as personal costs (e.g. time, ease). When facing innovations, individual estimates of the cost ratio may be complicated since the innovation's benefits are usually unpredictable beforehand. Potentially rewarding returns may be recognition by peer-teachers, professional status, or students' active involvement and enthusiasm.

In sum, the traditional sets of innovation attributes are by themselves of limited value when investigating the process of decision making about a given innovation. Both the relative importance and meaning of these attributes can be expected to vary across different innovations, as well as across, or even within, different groups of users. The latter is apparently illustrated by research within the tradition of the Concems Based Adoption Model (CBAM). Teachers appear to report differential 'concerns' about the same change proposal (cf. Hall \& Loucks, 1978; Hall \& Hord, 1987). The "practicality ethic" of teachers provides a frane of reference for understanding how new information about classroom practices is processed by teachers. Practical innovations are those addressing salient beliefs about student reactions, matching the prevailing classroom conditions, and meeting teachers' need for explicitness, with strong emphasis on clear procedural referent for instructional planning. 


\section{Characteristics of the adopting unit}

Variability in adoption or implementation essentially refers to the innovation's fit with potential user units. In this section we depart slightly from the innovation itself to the setting in which a curriculum innovation is shaped in practice. The emphasis will be the characteristics of schools and teachers affecting the final innovation outcomes: student achievement.

Several examples in the area of educational improvement have illustrated local contingencies to be superior over innovation characteristics or other factors that are directly controllable by higherlevel policy-makers (cf. Berman \& Mclaughlin, 1978; Crandall, 1989; Rosenholz, 1989; McLaughlin, 1990). Local factors may be even more decisive in highly decentralized education systems, or when innovation utilization is not coerced by any bureaucratic rule, as with classroom AIDS education in Dutch secondary schools. In accordance with Doyle \& Ponder (1977-78), recent developments in research on pedagogical innovations emphasize teachers' social construction of meaning about new classroom practices (cf. Ashton \& Webb, 1986; Eveland, 1987; Crandall, 1989; Rich, 1990; Fullan, 1991"; Cousins \& Leithwood, 1993). This is to say that it is on the classroom level where change does or does not occur, and that change results from teachers' processing of new acquired information within hisher own social context.

Organizational climate conditions. Caution is needed in drawing conclusions from a mixture of innovation research while disregarding the differential character of innovations (e.g. administrative, technical, or social programs), as well as of the organizational setting (e.g. manufacturing companies, schools). Research in public companies have confirmed that adoption processes and related determinants vary across different types of innovations (cf. Damanpour, 1988). In the area of schooling, similar results are found. Although certain curriculum innovations may also require changes in organizational role-behavior, from the perspective of conceptualization and measurement, they are preferably distinguished from innovations that are basically organizational or administrative in nature (Fullan \& Pomfret, 1977; Brown \& Mclntyre, 1982; Fullan, $1991^{\mathrm{a}}$ ). The former refer to the domain that is generally controlled and accounted for by the classroom teacher. This recognition stresses the multi-level character of pedagogical innovations, as well as the delicacy of relying on principal's information when estimating curriculum implementation (Fullan \& Pomfret, 1977). It also provides a basis for explaining the frequently encountered discrepancy between school level adoption and classroom implementation.

One of the most widely recognized success-enhancing factors for curriculum innovations appear to be the interaction teachers have with their colleagues about instructional matters. Collegial interaction may provide the teacher with points of reference outside the classroom for reflection on hisher own practices and effectiveness. This may, in turn, reinforce perceptions of their importance and efficacy toward student learning (Smylie, 1988). Collegial interaction will also increase diffusion because peer-teachers are often the preferred source for innovation information (Crandall, 1989; Fullan, 1991"). Most research, however, has demonstrated that in many schools the frequency of collegial interaction is rather low (cf. Smylie, 1988; Rosenholz, 1989; Fullan, 1991"). 
Besides frequency of peer communication, the quality of these interactions may be just as important. Shared consensus about the goals and means of instruction is frequently associated with innovation, as well as with school effectiveness (cf. Fullan \& Pomfret, 1977; Berman \& McLaughlin, 1978; Rosenholz, 1989; Levine \& Lezotte, 1990; Creemers, 1991). Research by Tjosvold \& McNeely (1988) additionally suggests that shared vision building is, however, indirectly related to innovation outcomes by affecting the quality of communication: unlike faculty members with competitive and independent goals, those with cooperative goals communicated openly and skilfully, made progress in solving innovation-related problems, efficiently used resources, felt positive about the experience, and expected to work with others successfully in the future.

The building principal also appears to play an important role in educational innovation and school effectiveness. Two images of the principal's leadership can be distinguished: educational leadership and change leadership. The former is usually referred to by school effectiveness research. High student academic performance appears to be associated with principals actively emphasizing achievement of instructional objectives toward teachers and students (Levine \& Lezotte, 1990; Creemers, 1991). Regarding innovation, the principal's role is more of a manager who establishes requisite conditions for improvement; e.g. by allocating resources, by facilitating peercommunication and teacher involvement in participative decision making (Berman \& McLaughlin, 1978; Hall \& Hord, 1987; Crandall, 1989). However, as with frequency of collegial interaction, few principals actually engage in these leadership roles (cf. Fullan, 1991 ). Moreover, the impact of the principal's educational leadership still appears to be hardly confirmed by Dutch school effectiveness research (Scheerens, 1989).

Several demographics and organization characteristics are related to organizational innovativeness. Rogers (1983) asserts the following characteristics being positively related to organizational innovativeness: members' expertise, interconnectedness, resource availability, and organizational size. Centralization is assumed to be negatively related with organizational innovativeness, while the impact of degree of formalization appeared to be diffused. It is our judgement that, at least when dealing with innovations in selected content areas such as AIDS education, emphasis on identifying global organizational characteristics hardly contribute to an understanding of the innovation process. There are several grounds for this assertion. First, the empirical evidence for a direct linear association with organizational innovativeness is rather weak. It is assumed that the picture will be partly obscured since the direction of these influences may interact with the distinct stages in the innovation process, types of innovation, as well as with the individuals' position and responsibility in the organization (cf. Rogers, 1983: Damanpour, 1988). Second, it is not realistic to expect that these characieristics are easy to change (e.g. size, expertise, organizational resources); they will at least exceed the potential capacity within most narrow focused curriculum innovation projects. Finally, these organization labels are rather meaningless in the absence of an adequate multi-level theory connecting the operational processes within nested organizational units, as in schools (school management, teaching department, teacher, and students). 
Teachers' planning bebavior and thought processes. Teachers' acquisition of information about new classroom practices will inevitably appeal to their personal ideological orientations toward education, to beliefs about the efficacy of the proposed practices, and to their own capacity for application. Because their innovation response is provoked within the context of an organization, one may expect that the innovation will be judged according to the individual's job performance criteria (Leonard-Barton, 1988). In other words, the proposed curriculum needs to fit with the prevailing characteristics of teachers' educational planning behavior. Therefore, we will first provide a brief overview of research on teachers' planning behavior and related thought processes, before addressing the issue of personal capacity.

Teachers generally tend to engage in instructional planning in order to (1) meet immediate personal needs (e.g. to reduce uncertainty and anxiety, to gain confidence), (2) prepare themselves for instruction (e.g. to leam content, to organize materials and activity flow), and (3) guide the interactive process (e.g. to organize students, to direct activities) (cf. Borko et al., 1990; Clark \& Peterson, 1986). Traditional models for teachers' planning behavior advocated some version of a rational means-end model. The model most often referred to prescribes four sequential steps: (a) specifying (behavioral) objectives, (b) specifying students' entry behavior (knowledge, skills), (c) selecting and sequencing learning activities, and (d) specifying evaluation procedures (cf. Shavelson \& Stern, 1981). Empirical research, however, shows that teachers' planning seldom conforms to these models (Shavelson \& Stem, 1981; Clark \& Peterson, 1986; Porter \& Brophy, 1988; Borko et al., 1990). In practice, teachers' primary focus is on teaching content and activities, not objectives. It appears that most teachers define their success in terms of student irvolvement rather than achievement. As Shavelson \& Stern (1981) stated: "Obviously there is a mismatch between the demands of classroom instruction and the prescriptive planning model. This mismatch arises because teachers must maintain the flow of activity during a lesson or face behavioral management problems. Hence, they are faced first and foremost with deciding what activities will engage students during the lesson or, put another way, the teacher must decide how to entertain his or her audience while attending to the curriculum". Nerertheless, teachers' educational decision making has been shown to be directed by more global images about the ends of education (goals), as well as by the responsibility teachers are willing to take for student performances (Ames, 1983; Cilark \& Peterson, 1986: Borko et al., 1990; Westerman, 1992).

Teachers' ideological long-term goal orientations toward education are often represented by two more or less contradictory images: teacher-centeredness versus student-centeredness (Rich, 1990). Victor (1976; Victor \& Otis, 1980) associated teacher-centeredness with dogmatism (closed to new ideas), emphasis on subject matter and teacher-student social distance. In interaction with students, these teachers appear to under-utilize positive reinforcernent and do not adapt instruction to students' level of development or experience. In contrast, student-centered teachers are more willing to disclose personal information and consider students perspective and psychological wellbeing. They also appear to take more responsibility for student achievement (Brophy \& Rohrkem- 
per, 1982; Ames, 1983). It can be hypothesized that AIDS education will be more acceptable for student-centered teachers than for their teacher-centered counterparts; the goals and means of AIDS education will be more congruent with the ideological dispositions and experiences of studentcentered teachers.

A related field of inquiry has addressed teachers' theories about students, and their perceived responsibility toward students' performance. Teachers' attributions about the causes of students' success and failure have been shown to be a powerful directive for their decision making regarding the goals that they set for students, management of students' classroom behavior, and the type of educational practices they use with their students (Clark \& Peterson, 1986). Teachers' attributions are conceived of as an attempt to reduce complexity in the usually overwhelming amount of information on which the teacher needs to decide (cf. Shavelson \& Stern, 1981). Expectations about students' ability appear to be the single most decisive factor in this regard (Ashton \& Webb, 1986). According to Weiner (1985), attributions about the causes of student performance will vary across three dimensions: stability, controllability, and locus (e.g. whether or not the cause is controllable by the teacher). Since students are usually treated as a whole class for instruction, teachers' decision making about curriculum innovations will be based in group attributes (Shavelson \& Stern, 1981). When applied to AIDS education implementation, one may hypothesize that teachers' aggregated inferences about the causes of students' HIV-related behaviors will affect their willingness to engage in HIV instruction. For example, teachers who perceive the determinants of students' risk behavior as being unstable (changeable) and controllable by instructional means will be more willing to provide AIDS education than those who perceive these causes as being stable and beyond the control of classroom instruction, whatsoever.

It is also suggested that teachers' aggregated attributions, or attributional style (cf. Anderson et al., 1988), will interact with their sense of responsibility. Ames (1983) posited that teacher's value for responsibility involves the beliefs that: (a) teaching is an important activity, (b) teachers engage in intentional acts to produce positive outcomes, and that (c) student success is generally feasible given the situational aids and constraints. Unlike teachers with low value for responsibility, high value teachers view themselves as trying hard and as being responsible for accomplishing student success, even in the face of situational obstacles. Both high and low value teachers will credit students for their successful achievement. In case of student failure, low value teachers will also externalize their attributions to the student (or to inhibiting situations), since they belief that student outcomes are not affected by intentional teacher actions. High value teachers will, however, hold themselves accountable for student failures; primarily because these teachers think they did not invest enough effort. In the area of school health education, high sense of responsibility has shown to be positively related to teachers' willingness to provide a sex education course (Levenson-Gingiss \& Hamilton, $1989^{2}$ ).

Teachers' capacity for application may also determine their innovation-decision making. In accordance with this view, Bandura $(1977 ; 1986)$ suggests that behavioral change is directed not 
only by valued outcomes or contextual factors, but also by self-efficacy estimates regarding the associated behaviors. For example, teachers may value the outcomes of classroom AIDS education, but at the same time be reluctant to engage in HIV instruction because they question whether they can execute required teaching or classroom management strategies. Perceived self-efficacy is defined as people's judgements of their capabilities to organize and execute courses of action required to attain designated types of performances (Bandura, 1986). Self-eflicacy expectations are distinct from response-outcome expectations, just as intentional teacher acts need not be confused with student learning outcomes. As far as innovation diffusion is concerned, perceived self-efficacy is assumed to affect every phase of the change process. Bandura asserts self-efficacy is a situationspecific determinant of behavior, not a global personality trait. Therefore, teachers' self-efficacy concerning curriculum innovations should preferably be conceptualized according the structural units of their educational decision making. Vis-à-vis a given curriculum proposal, teachers will at least make judgements about (a) their ability to guide required learning activities, (b) their ability to adapt content and objectives to students' entry behavior, and (c) their ability to organize and manage the classroom as an efficient and safe learning environment. The latter is of particular interest since school effectiveness research indicates that a certain level of classroom order is an important prerequisite for learning to take place (Doyle, 1986).

Empirical studies have found that high teacher efficacy improves student academic achievement (Gibson \& Dembo, 1984; Ashton \& Webb, 1986; Midgley et al., 1989; Rosenholz, 1989). Brophy \& Evertson (1981) indicated that teachers' estimated self-efficacy mediates the impact of their attributions about student performance on their instructional behavior and subsequent student achievement. Similarly, it has been found that teachers' efficacy expectations mediate the impact of their ideological orientations toward education (cf. Ashton \& Webb, 1986). Moreover, high sense of teacher efficacy also tends to accompany more personal and humanistic beliefs about controlling and relating to students (Woolfolk \& Hoy, 1990).

Teachers' self-efficacy is also positively related to adoption and implementation of educational innovations (Berman et al., 1977; Guskey, 1988; Stein \& Wang, 1988; Smylie, 1988). There also exists a variety of empirical evidence indicating that school level characteristics are just indirectly related to instructional innovations, by affecting teachers' mastery expectation (Ashton \& Webb, 1986). High efficacy teachers may even buffer or defeat school level impediments for change, such as large school size, large numbers of minority students, non-participative climate conditions (cf. Fuller et al., 1982).

\section{Characteristics of the innovation strategy}

In the past few decades, debates about educational innovations have been devoted to two obviously contradicting perspectives: the "fidelity" or "top-down" approach, versus the "mutual adaptation" or "bottom-up" approach. Fidelity orientations put strong emphasis on the development and diffusion of systematically validated practices. The potential user is mainly perceived as a "utility maximizer", who will almost naturally use the innovation when it is instrumental to reaching valued 
goals. These assumptions were challenged by the Rand Corporation studies (cf. Berman \& McLaughlin, 1977; 1978). The studies indicated that externally specified projects were able to achieve adoption. Although temporary funding was essential to these change efforts, implementation and continuation almost entirely depended on local factors, like teachers' initial motivation, expertise, management style. Effective implementation strategies appeared to promote "mutual adaptation", a dominant concept in the literature on curriculum innovation since then.

Later, the results of the DESSI study (Crandall, 1989) gave grounds for reconsidering the implications of the Rand study findings. Unlike Rand, the DESSI project showed that successful implementation can readily be achieved by externally developed programs provided that clearly validated materials and procedural guidelines are coupled with responsive in-person assistance during later implementation. It also made Mclaughlin (1990), one of the Rand authors, revise some of their prior conclusions: "We did not look beyond the policy structure to consider that the embedded structure of greatest import to teachers might have nothing or little to do with policy - it might have to do with professional networks, school departments, or other school-level associations, or colleagues however organized". The results of both projects, however, might be less contradictory than they appear at first glance. Unlike Rand, DESSI looked at implementation of clearly specified proven practices. Moreover, the external support agents did not emphasize mechanistic reproduction, but in fact facilitated adaptive implementation of new materials and teacher practices, remaining consistent with both local contingencies and project's central philosophy (McLaughlin, 1990).

The contemporary view on curriculum innovations stresses the inadequacy of thinking about mutual exclusive strategies, either being top-down or bottom-up (Van den Akker, 1988 ${ }^{2}$; Fullan, $1991^{2}$; Cousins \& Leithwood, 1993). Top-down approaches will fall short because they tend to neutralize or bypass the development of user capacities and congruent belief structures. In contrast, bottom-up projects tend to ignore teachers' need for clarity and practicality. They provide rather abstract guidelines or goals which need to be further specified by the practitioner; often resulting in teacher confusion, frustration, or at best, low-quality changes (cf. Huberman \& Miles, 1984; Fullan, 1991; Cousins \& Leithwood, 1993). As a consequence, there appears to be a growing consensus about combining the merits of the top-down and bottom-up approaches into a more comprehensive strategy. When applied to planned curriculum innovation this strategy should combine at least the following features (Crandall, 1989; Fullan, 1991"):

- Attention to the development of clear and validated materials. It means that prespecified student learning objectives are matched with a focused theory-based framework of pedagogically and didactically sound methods, as well as with a practice-based framework of clearly specified procedural referents for teachers pre-active, interactive, and postactive decision making (cf. Van den Akker, 1988"; $\left.1988^{k}\right)$.

- Selecuve use of external resources (people and materials). The change facilitator should systematically provide access to alternative practices for adoption in order to promote informed, local choices, which in turn fosters greater commitment. It combines mass media and face-to 


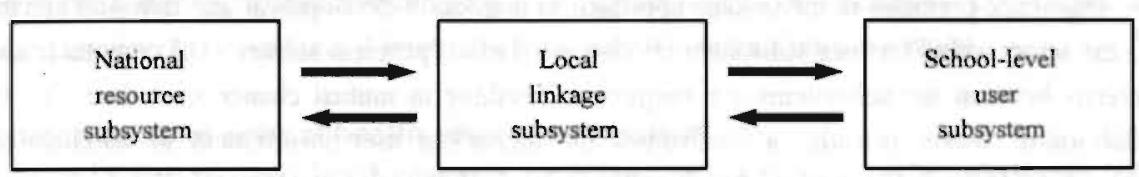

Figure 2.3. Linkage-model for dissemination of Dutcb AIDS curricula.

face communication practices (Bandura, 1986), and exceeds the mere provision of information.

- Focused, ongoing in-service or staff development activities. When curriculum innovation is conceived of as a learning process of teachers, the mere availability of clear statements and validated materials will be insufficient for utilization. Additional pre-implementation training with in-person follow-up assistance during implementation will be necessary to improve teacher learning and understanding. One-shot workshops have clearly proved to fall short (Berman \& Mclaughlin, 1978; Huberman \& Miles, 1984; Fullan, 1991 ${ }^{2}$ ). Effective in-service activities comprise demonstration of good practices (modeling), guided enactment and feedback, and coaching during self-directed application of acquired skills (cf. Bandura, 1986; Joyce \& Showers, 1988).

- Development of interaction-based conditions at the school level. It provides a base for social learning about the innovation. There is no evidence for large-scale participation at the initiation stage. Elaborate pre-action discussions involving many might exhaust the energy needed for implementation (Huberman \& Miles, 1984; Fullan, 1991 ${ }^{5}$ ). Growing peer-participation becomes important after the pre-implementation stages. Since teachers appear to value congruent models, overt successful applications by peers will improve other teachers' motivation and commitment to the innovation (cf. Bandura, 1986).

- Active administrative support and leadership at the district and especially the school level. Because this recommendation is strongly rooted in U.S. research, it may be de-emphasized when dealing with less centralized education systems (cf. Louis, 1992). For example, in the Netherlands schools are not linked to any district or local government authority. As previously mentioned, the building principal may, however, be an important promoter for ongoing change efforts by emphasizing directions for change, and facilitating participative climate conditions.

In order to orchestrate these support initiatives effectively, the central change agent will also need a management framework for linking actors operating at different organizational levels. When applied to the introduction of school-based AIDS education in the Netherlands, these interrelating actors can be roughly subdivided in a national resource subsystem, local linkage subsystem, and school-level user subsystem. The "Linkage-model", initially described by Havelock (1969), provides a framework for linking these multi-level actors; see Figure 2.3. 
Important premises of the linkage approach to innovation development and diffusion are that (a) the actors within the user subsystem are conceived of as "problem-solvers"; (b) communication patterns between the subsystems are reciprocal, resulting in mutual change over time; (c) the collaborative system provides a mechanism for increasing user involvement in development, research and dissemination, and for the allocation of additional resources (cl. Havelock, 1969; Lagerweij, 1987; Orlandj et al., 1990; Schinke et al. 1991). In order to operate effectively, the resource subsystem should best take a social marketing perspective (Orlandi et al., 1990; Schinke et al. 1991). For maintaining effective communication among collaborating parties, the resource subsystem needs to monitor user group preferences, needs, limitations, and expectations. This will provide leads for segmentation, so the innovation can be tailored to relevant subgroups into the target user system (Orlandi, 1990). A formative monitor system rnay provide useful information for the support activities initiated by linkage agents. Effective roles of local facilitators encompass the identification of school/teachers' needs, providing access to relevant information through print materials and demonstration, working with the resource subsystem to arrange for requisite training, helping schools secure resources, assisting teachers during implementation and reassuring adopters (Crandall, 1989).

\section{Research on school health education innovation}

\section{Effectiveness of school health education}

There is a considerable amount of research evidence indicating positive effects of school health programs on students' health behaviors; including the use of drugs, alcohol, cigarettes, nutrition, and sexual behavior. These programs may have been tailored at categorical behaviors ( $\mathrm{cf}$. Gilchrist \& Schinke, 1983; Flay, 1985; Parcel et al., 1989'; Stone et al., 1989; Hansen, 1992), or may have been more or less comprehensive in nature when addressing multiple health behaviors simultaneously (cf. Connell et al., 1985; Errecart et al., 1991). Systematic evaluations of Dutch school health education programs are hardly available. De Vries (1989) reported positive effects of a smoking prevention curriculum on secondary school students' behavior and related determinants. The impact of a comprehensive health curriculum for Dutch elementary schools (Van Weerden, 1990), proved to be rather disappointing; the curriculum only appeared to affect students' health knowledge. The limited impact on attitudes, control beliefs, and behavior was attributed to teachers' poor implementation of the curriculum (Van Weerden, 1990).

Others also associated student learning outcomes with teachers' implementation of health education curricula. Taken as a whole, there appears to be one logical conclusion: without adequate curriculum implementation, improvement in student learning cannot be expected, no matter how efficacious the curriculum might be. Next, we will discuss research on a variety of health curriculum innovationș and associaled determinants. We do not pretend to provide a complete review of the 
literature; rather we refer to research projects exemplary for the development in this particular field of inquiry. Finally, we will review research on sex and AIDS curriculum innovations.

\section{Antecedents to school health education innovation}

In the area of school health education, the issue of implementation has become slightly higher on the research agenda since in the U.S. the School Health Education Evaluation project (SHEE) was carried out. This massive project, involving more than 30,000 pupils in 1,071 classrooms from 20 states, focused on the effectiveness of four elementary school health curricula (Connell, 1985). It showed that program implementation contributed significantly to an increase in pupils' healthrelated knowledge, attitudes and behavior. The results also indicated that relatively few (10-15) hours of instruction can produce large knowledge effects, while more instruction time is needed for affecting attitudes and practices. Stable effects within all these three outcome domains appeared to be established after 40-50 hours of instruction. Amount of teacher in-service training was positively associated with degree of curriculum implementation.

Similarly, others assessed the impact of implementation on students' program-related learning outcomes. For example, in a three-year follow-up study of a school-based cardiovascular prevention program (Resnicow et al., 1992), it was found that students who were exposed to high implementation teachers had significantly lower cholesterol levels, blood pressure, and higher knowledge about and intake of "heart healthy" food. Only a few positive effects were detected in the low and moderate exposure conditions. Previous research on the same program reported comparable results (Bush et al., 1989). In no classroom was the program implemented as intended, in terms of either quality or quantity. Pentz et al. (1990) thoroughly tested dose-response effects concerning school-based drug use prevention. Degree of implementation was negatively associated with the usual increase in students' drug use from base-line to one year. Parcel et al. (1989) also reported mediating effects of teacher implementation on the outcomes of a school health promotion program on healthful diet and physical activity. Fidelity implementation was rare, in spite of the presence of administrative support and staff training. Post-implementation interviews indicated that teachers tended to attribute their implementation failures to lack of time, and their greater emphasis on academic subject matters.

Research actually testing the antecedents to school health education innovation is scarce; especially those that go beyond the mere incorporation of bivariate estimates of teachers' programrelated training status (training versus no training). The successor of SHEE, the Teenage Health Teaching Modules (THTM) Evaluation project, also fell short in this respect. It was demonstrated that teacher training (training versus no training) had a significantly positive effect on self-reported preparedness to teach THTM, and, to a lesser extent, on fidelity implementation (Ross et al., 1991). There also appeared to be a significant direct association between teacher training and student learning outcomes, although degree of classroom implementation only affected improvement in students' knowledge, not attitudes or behavior (Parcel et al., 1991). As previously mentioned, from a theoretical point of view, direct associations between teachers' training status and student 
outcomes are rather meaningless. Teacher training is usually assigned to improve classroom performances, while student outcomes will, among others, depend on the extent to which teachers succeed in changing their classroom practices accordingly.

A slight step ahead is described by Tortu \& Botvin (1989) who found implementation of schoolbased smoking prevention to be affected by (1) teachers' attitudes toward students, the curriculum, and teaching in general, and (2) teachers' estimated ability to communicate with students, stimulate classroom discussion, and maintain order. Moreover, Perry et al. (1990) explored the combined impact of variability in curriculum explicitness and training workshops on teachers' implementation of smoking prevention curricula. The results indicated that teachers who received a prespecified curriculum program together with training assistance implemented the curriculum to a significantly higher degree than teachers who received a prespecified curriculum program without training, or those who were only assigned to in-service training. Teachers in all these three conditions were, however, still significantly more compliant to the prescribed program components than teachers in the naturalistic control condition.

Research findings generated by the School Health and Tobacco Education Project (SHTEP), have confirmed some of the critical factors also associated with the implementation of non-health curricula. McCormick (1992) found that estimates of teachers' prior awareness, concern or interest regarding the curricula were not related to actual implementation. Quantity and quality of teachers' implementation was improved by participation in teacher training and positive climate conditions, expressed by teachers satisfaction with their job and superiors, and involvement in initial decision making. Results reported by Smith et al. (1993) showed that at the onset of the project, initial degree of implementation was positively associated with the presence of a school health coordinator, a supportive administrator, and which of the three exemplary curricula was used by teachers. During the continuation stage, degree of implementation was only related to the curriculum taught. These results at least confirm the critical impact of teachers' immediate task environment, and that (perceived) innovation attributes, among others, are related not only to the stage of adoption, but also to subsequent applications in practice.

School-based sex education. Recently, Kirby (1992) reviewed several school-based sex education programs addressing a variety of outcomes, ranging from promotion of sexual abstinence to dispensing of contraceptives. It was found that most programs were rather poorly evaluated, if evaluated at all. Only a few evaluated programs produced promising outcomes. According to his overview, five generations of sex education programs have emerged historically:

- Curricula emphasizing student knowledge, risks and consequences of pregnancy. The impact of these programs appeared to be restricted to knowledge gains. Their limited impact was explained by referring to a meta-analysis indicating generally low correlations $(r=.17)$ between knowledge and contraceptive behavior (Whitley \& Schotield, 1985; quoted by Kirby, 1992).

- Curricula emphasizing value clarification and communication/decision making skills. These programs address generic human values and social skills. Evaluation studies have demonstra- 
ted attitude changes, however, only when specific value structures were given prominent emphasis. These programs did not affect initiation of intercourse, nor did they reduce sexual risk-taking or teenage pregnancy.

- Curricula emphasizing sexual abstinence. Although some short-term attitude shifts were reported, "abstinence only" programs did not appear to delay or reduce frequency of intercourse.

- First generation HIV/AIDS curricula. These programs were not built on the successes and failures of previous sex education programs. They relied heavily on classroom discussions, and rarely incorporated skill-oriented activities. Consequently, the programs' impact appeared to be restricted to a reduction of students' misconceptions about the ADS risk, but did not affect risk-taking behaviors.

- Theory-based curricula with demonstrated effectiveness. Most effective programs combined modeling and practising of desirable behaviors (e.g. by role-play), and demonstrated related benefits. These programs appeared to contribute to students' reduction of unprotected intercourse, and to a delay of the onset of intercourse, especially when students are reached before they have initiated intercourse.

Kirby (1992) concluded that the efficacy of school-based sex or AIDS education is determined by the same elements constituting the success of programs tailored at other health-related behaviors. Efficacious programs are based on genuine insights in students' behavioral determinants and related theory-based learning methods, e.g. derived from Social Learning Theory (Bandura, 1986; 1989) and Communication-Persuasion Theory (McGuire, 1974; 1985).

Regarding factors determining teachers' implementation of general sex education, little empirical research is available. Hammonds \& Schultz (1984) found that the applied instructional strategies by secondary teachers providing sex education are generally the same as those preferred by students: large group discussion, educational media, guest speaker, case study, lecture, and small group work. Students' preference for lecture techniques was most prominent when addressing sensitive social and emotional aspects of sexuality. Schultz \& Boỵd (1984) related distinct teachers' beliefs with topics they had covered during classes on sex education. Perceived competence and social support, from school administration, colleagues and community, appeared to be positively related to the range of sexuality topics taught. In turn, the more positive teachers felt about their own sexuality and the more permissive their own perceived sexual behavior, the more competent they felt to teach and the more likely they went beyond teaching the physiological aspects of human reproduction. Demographics, like age, sex, years of teaching experience, religious affiliation, were generally unrelated to teacher beliefs toward providing sex education. Based on their study of the impact of three family life educational programs, Herz et al. (1986) concluded that (1) five hours or less of in-class exposure is unlikely to produce much change in student outcomes (knowledge, attitudes, intentions), (2) utilization of participative teaching formats (e.g. role-play) only facilitate 
learning when students do not resist these formats, and (3) teachers' ability to communicate effectively about sex and birth control with teens is a prerequisite for success.

As with other health content, the impact of teacher training is also addressed. Smith et al. (1984) found rather disappointing long-term effects of a sexuality teacher training program. Despite significant short-term increases in trainees' knowledge and attitudes, these shifts were not maintained over time. The most drastic decrease occurred in teachers who, while trained, did not apply the teaching materials in practice. Levenson-Gingiss and Hamilton $\left(1989^{\mathrm{b}} ; 1989^{\mathrm{b}}\right)$ also studied the short- and long-term impact of teacher training. Differences between pre- and post-training estimates showed significant increases in teachers' knowledge, perceived importance to teach, level of comfort and intention to teach a sex education curriculum. Teachers' sexual morality (liberal versus conservative) and perceived responsibility for student outcomes were unaffected. Teachers with lower sense of responsibility, importance, comfort and intention to teach sexuality, anticipated most negative responses of students, colleagues, administrators, parents, and community (LevensonGingiss \& Hamilton, $1989^{b}$ ). One-year follow-up assessments showed that teachers' willingness to continue to teach the course was significantly affected by their sense of responsibility and importance, and by perceived comfort to present factual information and to guide value-laden discussions. Three more general estimates also accounted for significant variability in teachers' intentions to continue: years of teaching experience, gender, and their moral orientations toward sexuality (Levenson-Gingiss \& Hamilton, 1989²).

School-based ADS education. In 1988, the state of affairs regarding AIDS education in Dutch secondary education was assessed by Mellink (1989). The results of this inventory are summarized in Chapter 1 (Part One). The antecedents to implementation of school-based aIns education attracted even less attention in the research community than did general sex education. According to our search of the literature ${ }^{2}$, empirical studies associating program implementation with student learning outcomes are even lacking, in the Netherlands and abroad. The literature still appears to be dominated by prescriptive writing about the ends and means of school-based ADS education, mostly emphasizing what schools or teachers need to change, rather than how these changes can be acconiplished. Only descriptive research will be summarized as far as they have addressed factors with the potential of affecting the process of school-based AIDS education innovation.

In 1987, Brucker et al. (1989) assessed teacher attitudes toward colleagues and students infected with HIV, and schools' test policies in this regard. The responding teachers appeared to be in support of providing "appropriate" education about AIDS for students, parents, and themselves. The school district was seen as primarily responsible for providing these educational programs. Four years later, the same questionnaire was administered to another sample (Brucker \& Hall, 
1991). It was found that these teachers felt less threatened by and less negative toward these AIDSrelated issues than their colleagues in 1987. Gold \& Kelly (1991) used six focus groups, including white, black, and Hispanic teachers and students, to explore the need for culturalizing AIDS education interventions. It was concluded that (a) accurate facts about AIDS were perceived as more important than the cultural milieu within which the material are presented, (b) teacher training was perceived as most effective for curriculum implementation, (c) strategies directed at sexual abstinence were seen less appropriate than those that involve decision making skills, and (d) effectiveness of the curricula should be enhanced by including visual materials. Ellis \& Torabi (1992) reported on the state of affairs in Indiana (U.S.) secondary schools. Based on information provided by the school principal, it appeared that factual information about HIV/AIDS dominated classroom content, while affective and behavioral issues were less frequently addressed. AITS education was provided by teachers with a variety of professional backgrounds, most of them without any specific health education preparation. Most principals believed their students were at risk for HIV, and emphasized the importance of comprehensive school health education in this respect.

A nationwide needs assessment has been conducted by the American School Health Association (ASHA), involving teachers, presidents of parent associations, school administrators, school nurses, school board members, school counselors, and physicians (Kerr et al., 1989). Most respondents (87\%) appeared to believe that school-based health education is effective in preventing the spread of HIV. Overall, teachers were held most responsible for providing AIDS education (36\%), followed by parents $(27 \%)$, and school nurses $(26 \%)$. The ranked order, however, paralleled the respondents' professional affiliation, each group ranking their own profession or role first. Most respondents $(51 \%)$ indicated they needed in-service programs on HIV, while only $42 \%$ claimed to have received specific preparation for providing HIV information. Discussing homosexuality, bisexuality, safer sex practices, and death and dying, appeared to induce most discomfort. Among other things, respondents indicated a need for model HIV policies on confidentiality, grade level appropriate HIV education, attendance for infected staff and students, and handling blood or body fluids.

Recently, Remafedi (1993) conducted research on the impact of a teacher training course addressing HIV/ADS and adolescent homosexuality. When compared to their counterparts who did not attend to the course, trainees appeared to be significantly more knowledgeable about HIV and adolescent homosexuality. They also reported applying more activities to student instruction about homosexuality, and improving the milieu for homosexual students. They were also least reliant on informal sources of information.

It seems fair to conclude that research on school-based health education innovation is still in the early stages of development, while studies addressing the antecedents to sex and AIDS education innovation are typically absent. The review of the literature does suggest that health education programs will produce desirable student outcomes provided the programs are clearly grounded in students' behavioral determinants and related learning theories, and when appropriately imple- 
mented. In so far as research on school health education addressed the issue of implementation, it is usually treated as an independent factor or experimental condition in relation to students learning outcomes. The innovation process is hardly accounted for as an entity in its own right. Nonetheless, there is a vast amount of prescriptive literature about what the ends of change in schools should look like. With only a few promising exceptions, the range of process variables that are actually tested in relation to school health innovation is rather small; often restricted to teachers' training status (training versus no training). Research on other teaching contents, however, have demonstrated successful innovations to be largely dependent on the development of meaning about the proposed change by those most directly involved, while the transactional process between the user and resource system is mediated by a configuration of many interrelated variables (cf. Crandall, 1989; Levenson-Gingiss \& Hamilton, 1989; Fullan, 1991; Cousins \& Leithwood, 1993).

\section{Toward a conceptual framework}

The review of the literature addressing curriculum innovations, teachers' planning behavior and related thoughts, and health education innovations suggested numerous factors with the potential of affecting teachers' innovation-decision making about classroom AIDS education. An additional frame of reference will, however, be needed to integrate these variables into a manageable research framework.

As yet, it seems fair to conclude that a framework that solely accounts for variability in teachers' implementation behavior, but disregards their intentions, goals, judgements, or planning concerns, will hardly provide insight into teachers' learning about a given curriculum innovation ( $\mathrm{cf}$. Shavelson \& Stern, 1981). Teachers' social and psychological dispositions toward the innovation will ultimately mediate the impact of any externally initiated attempt to change classroom practices, no matter how successful the innovation proved to be during efficacy testing. In order to account for the process of teachers' learning about classroom AIDS education, some requirements regarding the research framework were defined in advance:

- the model should account for teachers' social construction of meaning regarding classroombased ADS education; thus, boch personal factors and factors in teachers' task environment needed to be treated;

- it should incorporate practice-based teacher concerns about providing AIDS education in general and the application of the AIDS curricula in particular;

- in order to generate focused leads for improvement of support policies, the process variables should be highly specific to the structural units of teachers' educational decision making.

For the purpose of the present research on diffusion of the Dutch exemplary AIDS curricula, it was assumed that the sociopolitical context of schools needed no further attention. The ADS curricula 


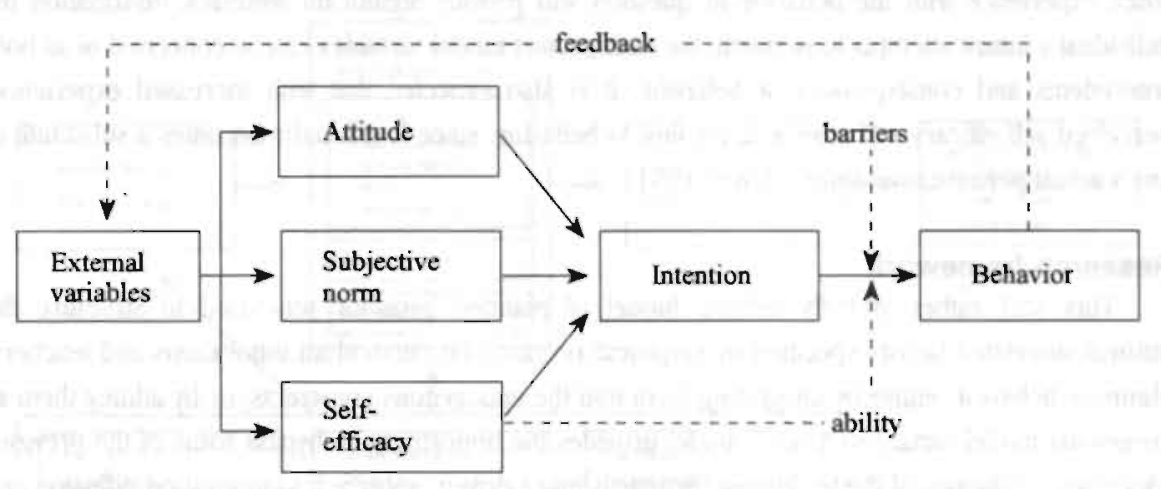

Figure 2.4. Determinants of planned behavior (cf. Ajzen, 1991; Bandura, 1986).

were targeted at Dutch secondary schools which were, and still are, all functioning within the same education system, as previously described in the section "characteristics of the sociopolitical context".

\section{Theory of Planned Behavior}

The Theory of Planned Behavior (Ajzen, 1987; 1991) was expected to suit the prespecified requirements, although the model has, as far as we know, never been applied within the context of curriculum innovations. This behavioral model integrates the Theory of Reasoned Action (Fishbein \& Ajzen, 1975; Ajzen \& Fishbein, 1980) and Bandura's self-efficacy theory (1977; 1986), and is graphically represented in Figure 2.4. According to the Theory of Reasoned Action, behavior is best predicted by the individual's intention to engage in that behavior. In turn, behavioral intentions are best predicted by corresponding measures of attitudes and subjective norms, especially when these measures capture individual's most salient beliefs about the behavior in question. Tihese determinants refer to a specific behavioral context and not to a generalized predisposition, and need to be specified accordingly (Ajzen, 1991). Attitudes are conceptualized as a weighted result of the perceived behavioral consequences and one's evaluation of these consequences. Perceived subjective norms are conceptualized as a weighted result of the attributed normative beliefs of important social referents and one's motivation to comply to these socially induced expectations.

Self-efficacy is added to the model because it was recognized that self-directed behavioral change is beyond attitudinal or normative control in case one lacks the means to perform. Response-outcome expectations, according to Bandura also an important behavioral directive, need no further attention since they are already accounted for by the attitude construct as defined by the Theory of Reasoned Action. According to the model's original definition, the impact of other variables are expected to be mediated by the attitudinal, normative, and control beliefs. Moreover, 
since experience with the behavior in question will provide significant feedback information for individual's future attempts to perform, the endogenous model variables can be conceived of as both antecedents and consequences of behavior. It is also expected that with increased experience, perceived self-efficacy will have a direct link to behavior, since it gradually becomes a substitute of one's actual performance ability (Ajzen, 1991).

\section{Research framework}

This still rather globally defined model of planned behavior was used to structure the innovation-related factors specified by empirical research on curriculum innovations and teachers' planning behavior, either by integrating them into the endogenous constructs, or by adding them as exogenous model variables. Ajzen's model provides the opportunity to bypass some of the previous addressed limitations of the traditional, primarily input-driven, approach to innovation diffusion and adoption. Research within the context of curriculum innovations have clearly demonstrated that adoption does not necessarily imply real change in practice, while implementation appeared to be dominated by teachers' pre-existing social and psychological dispositions (cf. Crandall, 1989; Mclaughlin, 1990). Unlike the traditional approach, the present conceptual model was developed from the perspective of teachers' planning behavior and related concens under the prevailing environmental conditions (cf. Doyle \& Ponder, 1977-78; Shavelson \& Stern, 1981; Clark \& Peterson, 1986; Porter \& Brophy, 1988; Borko et al., 1990). In accordance with the Theory of Planned Behavior, teachers' innovation-decision making will be best predicted by determinants referring to the specific context in which the innovation is shaped in practice, not by generalized innovation attributes or user segments. The resulting research framework that was applied to teachers' adoption and implementation of four nationally disseminated AIDS curricula is graphically presented in Figure 2.5.

Endogenous model variables. The curriculum-related beliefs account for the recognition that teachers' response to a given innovation will be directed not only by valued outcomes (attitudes), but also by normative and pragmatic concerns.

The attitudinal constructs elaborate on Doyle \& Ponder's (1977-78) analysis of the critical linkage between an externally initiated attempts to change classroom practices and the "practicality ethicm of teachers, which appears to be governed by instrumentality, congruence, and costs. According to Doyle \& Ponder (1977-78), instrumentality refers to teachers' need for explicitness about the proposed classroom procedures. Congruence stresses the impor-tance of distinguishing teachers' beliefs about learning outcomes and their anticipated students' reactions to the proposed activities during classroom interaction (enthusiasm, involvement), which is also confirmed by empirical research on teachers' planning behavior (cf. Clark \& Peterson, 1986; Porter \& Brophy, 1988; Borko et a., 1990). Another aspect of congruence involves perceptions of the change initiator. The costs of innovation refer to both financial and personal investments (time, ease), relative to its potential retum (recognition, student enthusiasm). In the present framework, the 


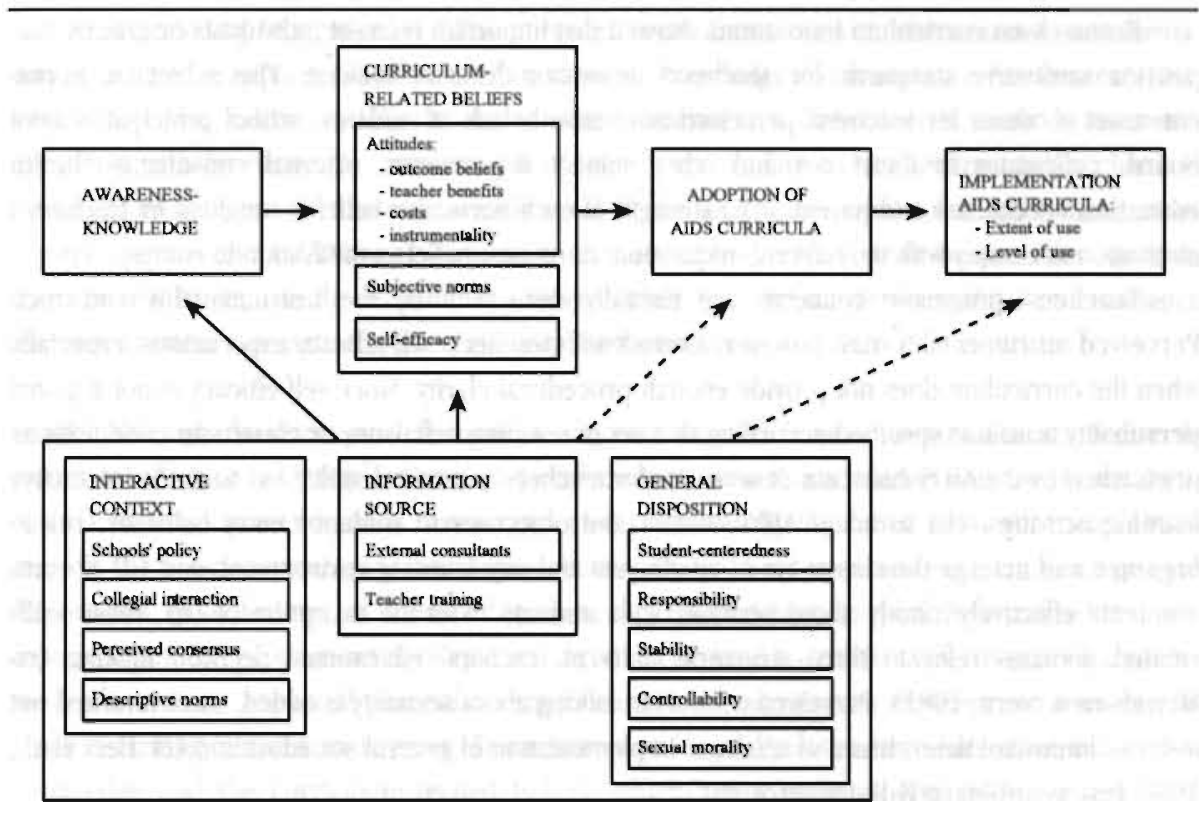

Figure 2.5. Framework for investigating the process of teachers' innovation-decision making about the nationally disseminated AIDS curricula.

approach to the concepts of instrumen-tality and costs differs slightly from their original definition (cf. Doyle \& Ponder, 1977-78). Congruence is not incorporated as a separate entity, but is integrated into instrumentality (student reactions), outcome beliefs (learning objectives), and subjective norms (perceptions of change initiator).

In the present framework, instrumentality accounts for the extent to which an AIDS curriculum is believed to be instrumental in meeting teachers' primary planning concerns, including expectations about time/ease of pre-active planning, about students' enthusiasm/involvement during classroom interaction, and about the extent to which the curriculum provides clearly defined procedural referents. Costs only refer to teachers' expectations whether financial costs are an impediment for purchasing the curriculum. The teacher benefits construct refers to the anticipated outcomes of curriculum utilization favoring the teacher. It accounts for improvements teacher-student relation (recognition), and what utilization researchers might term 'conceptual use', namely, increased insight into ways to improve the teachers' own education efforts (not necessarily within the context of AIDS education). The outcome beliefs construct accounts for teachers' perceived value of the student learning outcomes as specified by the curriculum, and is indexed according to the expectancy-value model of attitudes: perceived feasibility $\mathrm{x}$ importance. 
Research on curriculum innovations showed that important referent individuals or groups may provide normative standards for teachers' innovation-decision making. 'The subjective norms construct accounts for teachers' perceived normative beliefs of students, school principal, school board, colleagues in their own and other subject departments, external consultants (health education specialists) and parents. The strength of each normative belief is weighted by teachers's motivation to comply with the referent in question: normative beliefs $\mathrm{x}$ motivation to comply.

'Teachers' pragmatic concerns are partially dealt with by the instrumentality construct. Percejved instrumentality may, however, interact with teachers' self-efficacy expectations; especially when the curriculum does not provide enough procedural clarity. Since self-efficacy is not a global personality trait, it is specified according to a set of teaching behaviors or classroom conditions as prescribed by the AIDS curricula. It accounts for teachers' perceived ability (a) to guide interactive learning activities, (b) to adapt AIDS content and objectives to students' entry behavior, (c) to organize and manage the classroom as an efficient and safe learning environment, and (d) to communicate effectively/frankly about sexuality with students. With the exception of (d), these skillrelated domains refer to three structural units of teachers' educational decision making (cf. Shavelson \& Stern, 1981). Perceived comfort in talking about sexuality is added, since it turned out to be an important determinant of teachers' implementation of general sex education (cf. Herz et al., 1986; Levenson-Gingiss \& Hamilton, $1989^{5}$ ).

Exogenous model vartables. The exogenous variables are added to the model because empirical research indicated their potential relevance to the present context. Unlike the endogenous constructs, they are not specified in direct relation to any of the exemplany AIDS curricula. Because of their more generic nature, they are expected to be external to the primary process of teachers' innovation-decision making. There also appears to be empirical evidence for this claim. For example, Brophy \& Evertson (1981) found that the impact of teachers' attributions about the causes of students' achievement (controllability, stability) on their instructional planning behavior was Inediated by teachers' self-efficacy. Ashton \& Webb (1986) reported similar mediating effects of teachers' self-efficacy with regard to the impact of teachers' ideological orientations toward education (like student-centeredness), and the impact of school level characteristics (like policy regulations, collegial interaction, perceived consensus).

The descriptive norms construct is added to the framework because the interactive climate conditions in schools that are often associated with successful innovations seem to be more the exception than the rule (cf. Fullan, 1991 $)$. Therefore, perceived colleague behavior may operate as a descriptive norm to teacher's own curriculum-decision making instead (cf. Grube et al., 1986).

Teachers' sexual morality (restrictive versus permissive) and their sense of responsibility toward providing AIDS education are entered in the framework since these personal dispositions have proved to be positively related to curriculum innovation within the context of classroom sex education (Levenson-Gingiss and Hamilton, 1989²). 
As indicated by (educational) diffusion research, the directness with which innovation information is obtained may positively affect user's awareness-knowledge and acceptance ( $c$. Rogers, 1983; Crandall, 1989; Fullan, 1991 ). In the present framework, a distinction is made between the provision of infonnation by mass media channels, versus face-to-face dissemination channels (external consultants, in this case usually local health and/or sex educators). Attendance at inservice courses about AIDS/sex education is also added to the framework because the curricula were usually brought to the attention of trainees, while the courses' primary aim was to enhance teachers' mastery expectation about classroom ALDS education.

Finally, although the conceptual framework suggests that the exogenous variables are indirectly linked to adoption and implementation by affecting awareness-knowledge and the curriculumrelated beliefs, some exceptions may be expected (indicated by the dotted arrows). Ajzen (1991) recently discussed some empirical examples showing that, at least in certain contexts, more general dispositions (like feelings of moral obligation and responsibility to perform) can additionally capture significant proportions of unique variance in behavioral intentions. According to educational research, a direct impact of particular context conditions may also be expected. An exception is made regarding information sources. These factors are logically assumed to only affect awarenessknowledge and the curriculum-related beliefs, which are assumed to be central to teachers' processing of acquired information about the exemplary AIDS curricula. 
Chapter 3

\section{Antecedents to adoption of classroom-based AIDS-education in secondary schools}




\section{Abstract}

This paper describes the results of a cross-sectional survey of 956 Dutch secondary teachers. It explores the determinants of adoption of classroom-based AIDS education. The results sboued that teachers' decision making was most strongly related to bigbly specific adoption-related beliefs (outcome beliefs, subjective norms, self-efficacy). Adoption was additionally related to more generic dispositions (sense of responsibility and sexual morality) and environmental conditions (school policy and frequency of collegial interaction about HIV instruction). Past experience with AIDS education appeared to be positively associated with teachers' intentions and related determinants. It is concluded that additional support needs to address teachers anticipated ideological and practical constraints, both by mass media interventions and responsive in-person assistance.

\section{Introduction}

School-based AIDS education in the Netherlands appears to have limited impact on adolescents' sexual behaviors (Vogels \& Van der Vliet, 1990; Richard \& Van der Pligt, 1991, Schaalma et al. 1993). Similar results are found in other countries (e.g. Becker \& Joseph, 1988; Ross \& Rosser, 1989; Memon, 1990; Kirby, 1992). It is suggested that newly developed curricula should be more theory-based and should focus on the most determinative factors of adolescents' AIDS-related behaviors: e.g. social norms, skills to negotiate condom use (Kirby, 1992; Basen-Engquist \& Parcel, 1992; Schaalma et al., 1993). There is reason to expect that these new programs should bring about more desirable outcomes, especially while teachers work in the highly controlled conditions that usually accompany field testing; e.g. additional funding, training, classroom observation. However, in order to survive in the long run, the programs also need to take into account the subjective reality of teachers who are expected to use them in the absence of these supportive conditions (cf. Doyle \& Ponder, 1977; Fullan, 1991"). In this article we will attempt to conceptualize the decision making process underlying teachers' adoption of classroom AIDS education within a naturalistic teaching environment. In addition, the impact of teachers' past experience on specific adoption-related beliefs will be explored.

\section{Theoretical background}

Although many innovation attributes are expecied to determine ieachers' adoption decision, their response will largely depend on how these attributes match their social and psychological dispositions (Doyle \& Ponder, 1977-78; Rogers, 1983; Fullan, 1991). The Theory of Planned 
Behavior (Ajzen, 1991) was used to structure these dispositions toward providing AIDS education. It emphasizes attitudes, subjective norms, and control beliefs (self-efficacy; Bandura, 1986) for explaining behavioral intentions. Although this model is not commonly applied to curriculum innovations, there is good reason to expect that it suits the problem at hand since teaching is conceived of as an intentional act which is guided by teacher beliefs and thoughts (Shavelson \& Stern, 1981; Clark \& Peterson, 1986; Borko et.al, 1990). Moreover, in the Dutch education system the autonomy of schools and teachers is the prevailing norm; no external authority can interfere in the details of the curriculum in schools (cf. Louis, 1992). Sex education is also provided on a voluntary bases, mostly by teachers of biology, social studies, religious education, or health education.

Perceived importance and feasibility of student learning outcomes were assumed to capture teachers' attitudes toward classroom AIDS education. In tum, (dis)approval of specific objectives may refer to more general goal-orientations which are often contrasted by two ideological images: teacher- versus student-centeredness (Rich, 1990). Victor (1976; Victor \& Otis, 1980) associated teacher-centeredness with dogmatism (closed to new ideas), emphasis on subject matter and teacher-student social distance. Student-centered teachers also appear to take more responsibility for student outcomes (Brophy \& Rohrkemper, 1982). Levenson-Gingiss and Hamilton (1989) showed that high responsibility teachers were more willing to continue providing sex education. Also teachers indicating a permissive sexual morality appeared to be more willing to continue teaching a sex education course. Teachers' attributions for the causes of student performance may also affect their decisions about goals, activities and classroom management strategies (Brophy \& Rohrkemper, 1981; Ames, 1983; Clark \& Peterson, 1986). Most studies confirmed Weiner's three dimensional solution (1985): locus, stability, and controllability. One may hypothesize that teachers who belief the causes of students' AIDS-related behaviors are unstable and controllable, will be more willing to provide AIDS education than those believing these causes are stable and beyond the control of classroom instruction.

According to Bandura (1986), behavioral change is not only directed by valued outcomes, but also by self-efficacy. For example, teachers may value the proposed student outcomes, but at the same time be reluctant to provide AIDS education because of perceived lack of control over required teaching- or management strategies. Teachers' self-efficacy appeared to be positively related to students' achievement (Gibson \& Dembo, 1984; Ashton \& Webb, 1986; Midgley et al., 1989; Rosenholz, 1989), and innovation implementation (Berman \& Mclaughlin, 1978; Guskey, 1988; Stein \& Wang, 1988; Smỵlie, 1988).

Important referents in teachers' task environment (e.g. colleagues, principals, students) may provide standards for their innovation-decision making (Fullan, 19912). Principal's "educational leadership" showed to be a facilitating factor in American school effectiveness research (cf. Levine \& Lezotte, 1990), but is still not clearly confirmed by research in Dutch schools (Scheerens, 1989). 


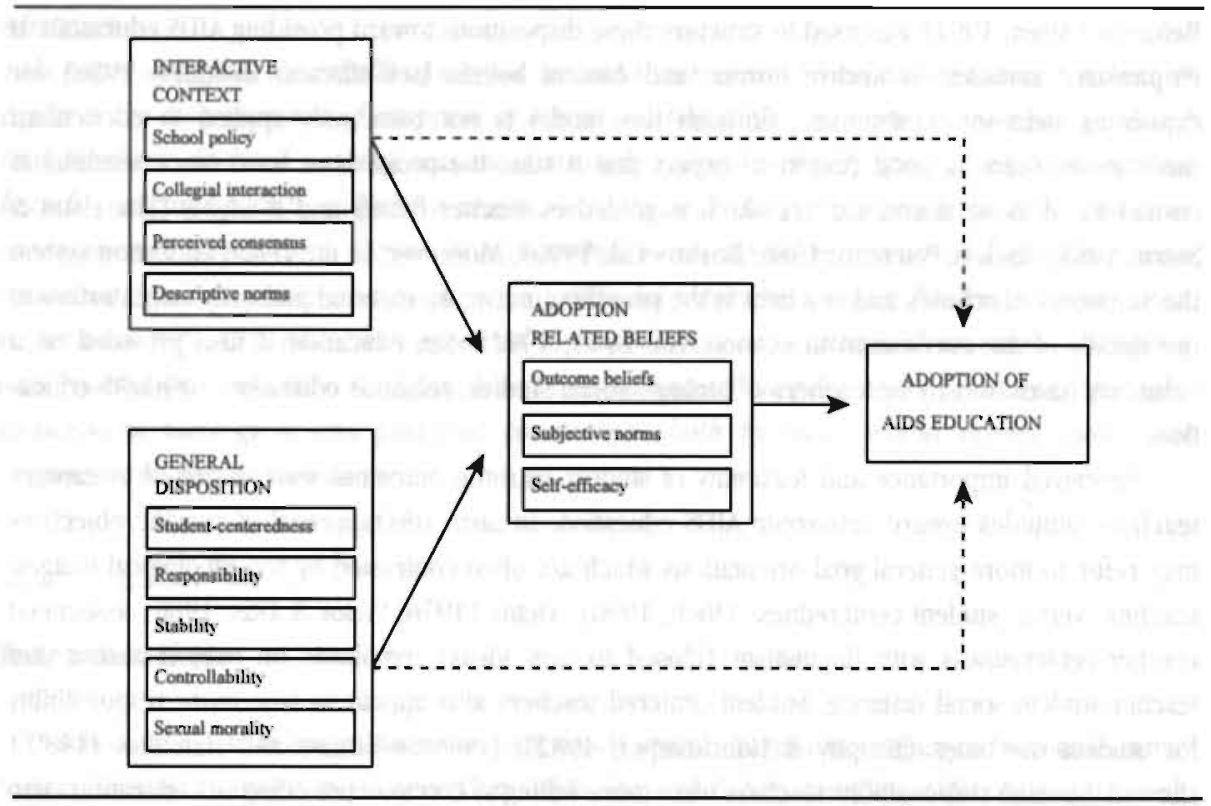

Figure 3.1. Model for explaining teachers' adoption of classroom-based AIDS education.

Schools' formal policy and collaborative climate conditions may contribute to the clarity of change and reinforce teachers' adoption (Snylie, 1988; Crandall, 1989). Frequency of collegial interaction and participative decision raking are frequently associated with teachers' acceptance of curriculum innovations (Fullan \& Pomfret, 1977; Huberman \& Miles, 1984; Rosenholtz, 1989). Since these favorable conditions are not obvious in schools (Fullan, 1991*), perceived colleague behavior may operate as a descriptive norm for teacher's own adoption decision (cf. Grube et al., 1986).

The key-factors briefly described so far were applied to Ajzen's model (1991), either by integrating them into the basic constructs or by adding them as exogenous variables (see Figure $3.1)^{2}$. The Theory of Planned Behavior suggests that behavioral intentions are best predicted by specific outcome, nornative and control beliefs; other factors only indirectly affect intentions. However, Ajzen (1991) recently argued that more general preferences, like feelings of moral obligation and responsibility to perform, can additionally capture significant proportions of variance in intention. According to educational research, also a direct impact of certain context conditions

The rational for ignoring otber fuctors in the overall framework is described in the introduction to the results section of Cbapter 1. 
may be expected. Moreover, it is assumed that experience with AIDS education will provide significant feedback information for teachers' present adoption decision.

\section{Methods}

\section{The questionnaire}

The questionnaire was based on the reviewed literature, and on qualitative preliminary research among 21 teachers and the designers of four nationally disseminated AIDS curricula. Cronbach's $\alpha$ was used to test internal-consistency of scaled variables.

Adoption/initial implementation. Teachers' adoption was assessed by a 5-point scaled item: "Do you plan to provide classroom AIDS education during the next school year?" Also questions were posed about past implementation, the number of lessons spent on AIDS education and what curricular material(s) were used during these courses.

Adoption-related beliefs. Outcome beliefs were measured as a weighted result of perceived importance and feasibility of the learning outcomes proposed by the nationally disseminated AIDS curricula; using eighteen 5-point scaled items (see Table 3.3; $\alpha=88$ ). Teachers responded to the normative beliefs of students, principal, school board, colleagues in their own and other departments, external consultants and parents; each weighted by their motivation to comply to these referents $(\alpha=84)$. Self-efficacy was measured by twenty-four 5 -point scaled items, each referring to a teaching behavior or classroom condition as prescribed by the teaching guides appended to the AIDS curricula. Four skill-related domains were represented: (a) application of interactive teaching strategies, (b) talking frankly about sexuality, (c) adaptation of AIDS content and objectives to own educational context, and (d) application of classroom management strategies for creating a minimal level of orderliness and safety for students (see Table 3.4; $\alpha=.92$ ).

Exogenous model variables. Regarding schools' policy, teachers were asked whether the outline of content and organization of AIDS education was formally prescribed by the school work plan or their own curriculum work plan. Teachers also indicaled whether colleagues in their school already provided AIDS education (descriptive norm). A 6-point scaled item assessed the frequency of collegial interaction about HIV instruction. A 5-point scaled item assessed the degree to which teachers achieved consensus with their colleagues about the goals and requirements for classroom AIDS education. Student centeredness was indexed on ten 5-point scaled items developed by Den Hertog (1990; $\alpha=80$ ). Fourteen 5-point scaled items, adapted from Luijkx et al. (1987), assessed teachers' sexual morality $(\alpha=.88)$. Sense of responsibility was measured by seven 5-point scaled items ( $\alpha=75$ ), such as: "I feel responsible because one can never be sure about the quality of AIDS 
education provided by parents," or "I do not feel responsible because time pressure forces me to select other subject priorities." Three 4-point scaled items measured perceived stability and controllability of factors teachers assumed to cause students' lack of knowledge, negative attitudes and lack of social skills toward AIIS preventive behaviors ( $\alpha=.70$ and $\alpha=.71$, respectively).

Finally, teachers were asked about their age, religious affiliation, gender, years of teaching experience, subject area, school's denomination (Catholic, Protestant, Public), and educational level. Educational level was classified into junior level (junior vocational and junior general secondary education) and senior level (senior general and pre-university education).

\section{Sample procedure}

A stratified multistage sample of 988 secondary schools was used to select teachers; Catholic, Protestant and public schools were represented equally. The school principal was requested to distribute one questionnaire in each of the following departments: biology, social studies, religious education, and health education (the latter is only present in some junior vocational schools). When in a given department no one provided AIDS education, the principal still randomly selected one teacher. From the 3564 distributed copies, 1133 teachers $(32 \%)$ from 620 schools $(63 \%)$ returned a questionnaire. Since the principal acted as a go-between, the response rate may not be very accurate. Based on principal's information obtained during initial telephone contact, school level response appeared to be independent of denomination and educational level. Schools not providing AIDS education were slightly over-represented in the attrition group. On the teacher level, attrition appeared to be independent of subject area. Additional information about non-responding teachers was not available.

\section{Data analysis}

The number of subjects further decreased to 956 teschers (27\%) from 532 schools (54\%) since respondents with missing data were excluded from the analyses. Absence of valid data in single variables, and the tendency in this absence, appeared to be unrelated to teachers' intentions and implementation of AIDS education ( $p>10$ ). The assumption of randomness in relation to teachers' intentions was also confirmed by multiple regression using the "missing-data plus plugged-blanks" method (Cohen \& Cohen, 1983).

Because of the large number of respondents, univariate differences were interpreted as significant at $\mathrm{p}<.01$. Determinants of teachers' adoption were explored by stepwise multiple regression analysis. F-probability to enter was set at $p<.01$. The impact of past experience on teachers' adoption and its antecedents was assessed by MaNova. Univariate differences on scaleitems were interpreted as significant when $\mathrm{p}<.001$, and as highly relevant when differences exceeded $10 \%$ of the scale range. 


\section{Results}

\section{Sample description}

About $64 \%$ of the respondents were involved in junior secondary education; $36 \%$ in senior secondary education. Regarding schools' denomination, $29 \%$ taught in public schools, 36\% in Catholic schools, and 35\% in Protestant schools. Teachers were divided into four subject areas: biology $(39 \%)$, social studies (30\%), religious education (16\%), and a category 'HF/counselors' ( $16 \%$, consisting of health educators and student counselors). Males comprised $71 \%$ of the sample and females $29 \%$. Mean age was 42 years $(s d=7.28$; range $=23 / 63$ ). Years of teaching experience varied from 1 to 40 years $(\bar{x}=17, s d=7.79)$. Religious affiliation was divided into four categories: Roman Catholic (34\%), Protestant (32\%), "others" (7\%), and no religious conviction ( $27 \%$ ).

\section{Past implementation of AIDS education}

School level aggregates showed that on $82 \%$ of the responding schools at least one teacher provided classroom AIDS education. When summed up over all grade-levels, these schools spent an average of 5.2 lessons on AIDS education $(\mathrm{sd}=3.47$; range $=1 / 20)$. Past implementation and the number of lessons taught appeared to be independent of schools denomination and educational level.

On the individual level, $68 \%$ of the respondents already provided AIDS education; $62 \%$ of them used the nationally developed curricula. Most respondents (77\%) never participated in in-service training on AIDS/sex education. When compared to male teachers, more female teachers provided AIDS education ( $66 \%$ vs. $\left.77 \% ; \chi^{2}(1)=9.66, p<.001\right)$. In contrast with teachers who reported on any other religious affiliation (28\%) or no religion (22\%), more teachers admitting Catholicism $(34 \%)$ or Protestantism (36\%) already provided AIDS education $\left(\chi^{2}(3)=13.93, p<.01\right)$. More teachers in senior education provided AIDS education than teachers in junior education ( $76 \%$ vs. $\left.65 \% ; \chi^{2}(1)=9.02, p<.01\right)$. When compared to teachers in social studies $(65 \%)$ and religious education (38\%), AIDS education was more prominent among teachers in biology (78\%) and within the category 'HE/counselors' $\left(85 \% ; \chi^{2}(3)=95.11, p<.001\right)$. Past implementation of AIDS education was unrelated to age, years of teaching experience, and schools' denomination.

\section{Determinants of teachers' Intentions to provide AIDS education}

Table 3.1 presents descriptive statistics and zero-order correlations of the variables in the research framework. All variables, except descriptive norms, significantly correlated with teachers' intentions; ranging from .11 (perceived consensus) to .56 (subjective norms).

Table 3.2 shows the results of the multiple regression on teachers' intentions to implement classroom ADS education. Predictors were entered according their theoretically expected order: adoption-related beliefs were entered in the first step, exogenous model variables were entered in the second step. 
Table 3.1. Mean, standard deviation and zero-order correlations' of determinants of teachers adoption decision $(N=956)$. Ranges in parentheses.

\begin{tabular}{|c|c|c|c|c|c|c|c|c|c|c|c|c|c|c|}
\hline & mean & sd. & 1 & 2 & 3 & 4 & 5 & 6 & 7 & 8 & 9 & 10 & 11 & 12 \\
\hline 1 Intention $(-2 /+2)$ & 1.01 & 1.31 & - & & & & & & & & & & & \\
\hline 2 Outcome beliefs $(+1 /+25)$ & 12.91 & 3.28 & .36 & - & & & & & & & & & & \\
\hline 3 Subjective norms $(-8 / 4-8)$ & 2.3 .4 & 2.30 & .56 & .38 & - & & & & & & & & & \\
\hline 4 Self-efficacy $(-2 /+2)$ & 311 & .63 & .36 & .59 & .34 & -. & & & & & & & & \\
\hline 5 Schools' policy? & - & - & .34 & .17 & .29 & .16 & - & & & & & & & \\
\hline 6 Perceived consensus $(-2 /+2)$ & .39 & .97 & .11 & .16 & .21 & .13 & .18 & - & & & & & & \\
\hline 7 Descriptive social norm 2 & - & - & ns & $\mathrm{ns}$ & .14 & ns & .20 & .20 & -. & & & & & \\
\hline 8 Collegial interaction $(0 /+5)$ & 1.25 & 1.02 & .28 & .18 & .28 & .20 & .27 & .26 & .26 & -- & & & & \\
\hline 9 Controllability $(+1 /+4)$ & 2.62 & .56 & .38 & .50 & .40 & .45 & .15 & .12 & ns & .18 & - & & & \\
\hline 10 Stability $(+1 /+4)$ & 2.66 & .59 & .23 & .48 & .20 & 39 & .11 & .12 & ns & .13 & .56 & - & & \\
\hline 11 Sexual morality $(-2 /+2)$ & .51 & .68 & .24 & .28 & .16 & .30 & ns & -.11 & ns & ns & .25 & .15 & - & \\
\hline 12 Responsibility $(-2 /+2)$ & 1.29 & .57 & $.4 !$ & .51 & .39 & .46 & .18 & .14 & .12 & .21 & .46 & .40 & 36 & - \\
\hline 13 Student-centeredness $(-2 /+2)$ & 1.01 & .51 & .12 & .37 & .17 & .36 & ns & .12 & ns & $\mathrm{ns}$ & .20 & .21 & ns & .31 \\
\hline
\end{tabular}

'printed comelations are significan at $p<.00 y_{;}^{2}$ binan' coded wariables.

Table 3.2. Results of stepwise regression analysis on teachers' intentions to implement classroom AlDS education $(N=956)$.

\begin{tabular}{llllll}
\hline & R & $\mathbf{R}^{2}$ & BETA & P< & r \\
\hline 1. Subjective social norms & .56 & .31 & .38 & .001 & .56 \\
Self-efficacy & .58 & .34 & .08 & .01 & .36 \\
$\quad$ Learning outcome beliefs & .59 & .35 & .05 & $\mathrm{~ns}$ & .36 \\
2. Formal school policy & .61 & .37 & .15 & .001 & .34 \\
Sense of responsibility & .62 & .39 & .13 & .001 & .41 \\
Collegial interaction & .63 & .40 & .08 & .01 & .28 \\
Sexual morality & .64 & .41 & .08 & .01 & .24 \\
\hline
\end{tabular}

After the first step, subjective norms, self-efficacy, and outcorne beliefs all accounted for a significant proportion of unique variance in teachers' decision to implement AIDS education. However, after inclusion of exogenous model variables, the regression coeflicient of outcome beliefs became insignificant $(p=17)$. Examination of the subsequent steps indicated that this was affected by the common variance of outcome beliefs and sense of responsibility $(r=.51)$. Sense of responsibility, sexual morality, schools' formal policy and frequency of collegial interaction, added $6 \%$ to the variance in intention already captured by subjective norms, self-efficacy, and outcome beliefs $(35 \%)$. None of the demographics significantly improved the final model's solution. 


\section{The impact of experience with classroom AIDS education}

The impact of experience on teachers' intention and related determinants was assessed by comparing teachers who implemented AIDS education $(n=647)$ to those who did not $(n=309)$. Multivariate analysis of variance indicated that initial implementation significantly affected teachers' intentions, as well as its antecedents $(F(8,947)=124.86, p<.001)$.

Before addressing differential responses to specific adoption-related beliefs, we first present the univariate association of experience with intention and the exogenous model variables. Experienced teachers appeared to be far more intended to provide ADS education the next year than inexperienced teachers $(\bar{x}=1.62$ vs. $\bar{x}=-31 ; t(428.86)=-25.44, p<.001)$.

Only $34 \%$ of all teachers reported the presence of a formal school policy on AIDS education. Most teachers who already provided AIDS education were teaching in schools that defined their policy in this regard, while nearly all inexperienced teachers worked in schools where such regulations were absent $\left(55 \%\right.$ vs. $\left.91 \% ; \chi^{2}(1)=120.67, p<.001\right)$. Frequency of collegial consultation about HIV instruction appeared to be generally low; $19 \%$ never discussed it in an official meeting with colleagues, and $53 \%$ reported on having such a meeting less than once a year. The frequency of collegial interaction appeared to be significantly higher among experienced teachers $(\overline{\mathrm{x}}=1.51)$ than among teachers who never provided AIDS education $(\tilde{\mathrm{x}}=.72 ; \mathrm{t}(869.40)=-13.86, \mathrm{p}<.001)$.

When compared to their counterparts, experienced teachers expressed a more permissive sexual morality $(\bar{x}=.27 \mathrm{vs}, \overline{\mathrm{x}}=.62 ; \mathrm{t}(553.64)=-6.98, \mathrm{p}<.001)$. They also felt more responsible to teach about AIDS $(\bar{x}=1.01$ vs. $\bar{x}=1.42 ; t(474.00)=-9.25, p<.001)$. Inspection of the responsibilityitems showed that most teachers endorsed the importance of dealing with young peoples' misconceptions about the risks of HIV. Teachers not providing AIDS education were, however, far more inclined to push aside their responsibility by referring to other subject matter priorities, and to the incompatibility of AIDS education with their perceptions of the nature/purpose of their teaching subject. Additional analysis of variance showed that teachers' response to these responsibility statements were not affected by subject department.

Outcome beliefs. Teachers' attitudes toward the learning outcomes were generally moderate (Table 3.3). They most positively responded to cognitive oriented outcomes, such as improving students' insight in distinct HIV-risk behaviors, in differences between AIDS and HIV-positive, and that STDs/HIV are not restricted to specific risk groups. They were also positive toward increasing students confidence in choosing their own preferred mode of coping with STD/HTV-risks. Teachers responded least positive to outcomes that are often defined within the context of general sex education, such as learning to make contact with someone you like, or to cope with conflicts in intimate relationships. They also felt reserved toward developing students' opinions about sex-role stereotypes and learning how to respond in case STD-infection is suspected; mainly due to low achievement-expectations. Their relatively low attitude toward enhancing students' awareness of own sexual preferences mainly resulted from teachers' perceived importance. 
Table 33. Mean differences in perceived feasibility and importance of student learning outcomes between inexperienced (IT, $n=309)$ and experienced teachers (ET, $n=647)$.

\begin{tabular}{|c|c|c|c|c|c|c|}
\hline \multirow[b]{2}{*}{ Learning outcomes } & \multicolumn{2}{|c|}{$\begin{array}{c}\text { Feasibility (F) } \\
\qquad(+1 /+5)\end{array}$} & \multicolumn{2}{|c|}{$\begin{array}{c}\text { Importance } \\
\text { (I) }\end{array}$} & \multicolumn{2}{|c|}{$\begin{array}{c}F \times I \\
(+1 /+25)\end{array}$} \\
\hline & IT & ET & IT & ET & IT & ET \\
\hline comfort in discussing sexuality & 3.23 & $3.78^{m=0}$ & 2.99 & $3.49^{* *}$ & 10.06 & $13.49^{\text {** }}$ \\
\hline awareness of own sexual preferences & 3.18 & $3.44^{*}$ & 3.00 & $3.22^{*}$ & 9.75 & $11.38^{*}$ \\
\hline knowing to make contact with someone you like & 2.89 & 3.09 & 2.83 & 2.98 & 8.51 & 9.56 \\
\hline taking position toward sex-role stereotypes & 2.97 & $3.33^{\circ}$ & 3.25 & $3.49^{*}$ & 10.00 & $11.82^{*}$ \\
\hline assertiveness toward unwanted approaches & 3.28 & 3.51 & 3.60 & $3.81^{*}$ & 12.09 & $13.58^{\circ}$ \\
\hline confidence about choosing own sexual lifestyle & 3.33 & 3.54 & 3.76 & 3.95 & 12.73 & $14.16^{*}$ \\
\hline coping with conflicts in intimate relationships & 2.71 & 2.86 & 3.27 & 3.36 & 9.15 & 9.86 \\
\hline knowledge about HIV-risk (reducing) behaviors & 4.06 & $4.41^{*}$ & 3.95 & $4.22^{*}$ & 16.24 & $18.67^{*}$ \\
\hline correct descriptions of safe(r) sexual behaviors & 3.64 & $4.08^{*}$ & 3.10 & $3.49^{*}$ & 11.59 & $14.48^{* *}$ \\
\hline choosing own preferred STD preventive behavior & 3.49 & $3.99^{* * 1 *}$ & 3.61 & $3.99^{*}$ & 12.95 & $16.09^{* *}$ \\
\hline insight in arguments used to refrain from safe sex & 3.31 & $3.61^{\text {*k }}$ & 3.56 & 3.69 & 11.97 & $13.41^{*}$ \\
\hline confidence in purchasing/using condoms & 3.30 & $3.73^{*}$ & 3.37 & $3.69^{*}$ & 11.50 & $13.96 *$ \\
\hline knowing differences AIDS and HIV-positive & 3.76 & $4.19^{*}$ & 3.35 & $3.61^{*}$ & 12.74 & $15.30^{* *}$ \\
\hline insight in consequences of HIV-tests & 3.46 & 3.62 & 3.29 & 3.39 & 11.64 & 12.49 \\
\hline insight in personal/social consequences AIDS/HIV & 3.12 & 3.36 & 3.40 & 3.49 & 10.93 & 12.02 \\
\hline knowing to respond if STD-infection is suspected & 2.86 & 3.02 & 3.33 & 3.47 & 9.81 & 10.76 \\
\hline recognize STD is not restricted to specific groups & 4.08 & $4.43^{\circ}$ & 3.91 & $4.11^{*}$ & 16.15 & $18.27^{\phi}$ \\
\hline respect for different sexual lifestyles/preferences & 3.35 & $3.64^{*}$ & 3.30 & $3.55^{*}$ & 11.50 & $13.26^{*}$ \\
\hline Total & 3.33 & $3.65^{\circ}$ & 3.38 & $3.61^{*}$ & 11.60 & $13.48^{*}$ \\
\hline
\end{tabular}

"p<.001; " $p<.001$ and diflerence $>10 \%$ of scale-range.

Differences between teachers with and without past experience were most evident regarding the feasibility of these outcomes. Apart from 'feeling comfort in discussing sexuality', teachers' perceived importance never exceeded the relevance criterion ( $>10 \%$ of scale-range). After feasibility was weighted by importance, 13 out of 18 learning outcomes significantly discriminated experienced from inexperienced teachers. Most relevant differences were expressed by 'feeling comfort in discussing sexuality', 'confidence in choosing own preferred mode of coping with STD/HIV', 'providing correct descriptions of safe(r) sexual behaviors', and 'knowing differences between AIDS and HIV-positive'.

Subjective norms. When compared to their counterparts, experienced teachers perceived significantly more positive social pressure from all referent groups (Table 3.4). Although these differences generally resulted from differential normative beliefs, experienced teachers were also more willing to act according to their students' expectations, and were less motivated to comply to parents and the school board. 
Table 3.4. Mean differences in normative beliefs and motivation to comply between inexperienced (IT, $n=309)$ and experienced teachers (ET, $n=647$ ).

\begin{tabular}{|c|c|c|c|c|c|c|}
\hline \multirow[b]{2}{*}{ Social referents } & \multicolumn{2}{|c|}{$\begin{array}{c}\text { Normative Beliefs } \\
\text { (NB) }(-2 /+2)\end{array}$} & \multicolumn{2}{|c|}{$\begin{array}{l}\text { Motivation to Com- } \\
\text { ply (MC) }(1 /+4)\end{array}$} & \multicolumn{2}{|c|}{$\begin{array}{c}N B \times M C \\
(-8 /+8)\end{array}$} \\
\hline & IT & ET & IT & ET & IT & ET \\
\hline Students & .29 & $1.35^{\text {*a }}$ & 3.02 & $3.21 *$ & & $4.41^{* 0}$ \\
\hline School principal & .24 & $1.38^{* * *}$ & 2.53 & 2.47 & .92 & $3.49^{* m}$ \\
\hline Colleagues in own department & .22 & $1.39^{* * *}$ & 2.76 & 2.82 & .78 .86 & $4.18 *$ \\
\hline Colleagues in other departments & .13 & $.95^{* *}$ & 2.22 & 2.13 & .33 & $2.13^{* * *}$ \\
\hline External consultants & .76 & $1.23^{*}$ & 2.55 & 2.42 & 2.05 & $3.11^{*}$ \\
\hline Parents & .00 & $.95^{* *}$ & 2.59 & $2.39^{*}$ & .16 & $2.36^{\text {tata }}$ \\
\hline School board & -.09 & $.90^{* * *}$ & 2.10 & $1.82^{*}$ & -.07 & $1.80^{\text {th }}$ \\
\hline Total & .20 & $1.17^{* * *}$ & 2.54 & 2.47 & .67 & $3.07^{* * *}$ \\
\hline
\end{tabular}

" $p<.001$; *t" $p<.001$ and difference $>10 \%$ of scale-range

Students appeared to be most influential on teachers' decision to provide AIDS education; followed by colleagues in their department and the school principal. Although still significant, experience with AIOS education was least associated with subjective norms of parents, colleagues in other departments, school board and external consultants.

Self-efficacy. According to the absolute mean-scores (Table 3.5), teachers generally expected the lowest 'skill-power' toward applying student-centered teaching strategies. They were negative about their ability to apply role-play or group assignments aimed at purchasing condoms. Within the classroom management domain, many teachers questioned their ability to guarantee that personal information exchanged during course time will not be spread outside the classroom (confidentialiw).

The biggest differences between experienced and inexperienced teachers refer to their confidence in talking about sexuality with students; most evident when it comes to demonstrating condom use. Inexperienced teachers also felt much more insecure in guiding small group discussion about the impediments to students' preferred sexual lifestyle, as in creating an open and safe classroom atmosphere and controlling students' disruptive behaviors. Within the adaptation domain, teachers displayed the biggest contrast regarding their ability to match AIISS content and objectives to students' needs and experiences. 
Table 3.5. Mean differences in self-efficacy between inexperienced $(I T, n=309)$ and experienced teachers (ET, $n=647)$.

Self-efficacy assessments regarding: $(-2 /+2)$

IT ET

Teaching strategies:

role-play in which students take certain positions toward sexulity

role-play on coping with secondary prevention of STD

$-.35 \quad-.16$

$\begin{array}{rr}-.42 & -.17\end{array}$

role-play negotiating about condom use

$-.44 \quad-.19$

creative tasks/exercises exploring own preferences in relationships

$.07 \quad .19$

creative tasks/exercises exploring different sexual lifestyles

$.18 \quad .35$

small group discussions about impediments to preferred sexual life style $\quad-.04 \quad .49^{* \rightarrow}$

creative exercises about own preferences regarding attractiveness

small group assignment purchasing condoms

class discussion about students' own questions regarding sexuality

$.20 \quad .42$

$-.88-.65$

class discussion not prescribed by teachers' own opinions on sexuality

$-.12 \quad .30^{*}$

Classroom management:

create open/safe classroom atmosphere for student to participate

$.11 .48^{* \prime}$

preventing torment of students with minority opinions

$.20 \quad .70^{* *}$

$.01 \quad .25$

guarantee confidentiality

$-.45-.02^{*}$

guarantee that students listen respectfully to others' opinions

$.53 .90^{*}$

controlling disruptive behavior during classes on sexuality/AIDS

$.19 \quad .77^{\text {*⿻一 }}$

coping with students who (might) express personal uncertainty/problems

$.39 \quad .76^{*}$

Adaptation of activities/objectives:

making choices congruent with educational goals/policy own school

using strategies/techniques for reviewing students' knowledge/attitudes

$.47 .94^{*}$

stating clear expectations about what students need to accomplish (outcomes/means) $\quad .27 \quad .73^{*}$

adapting subject matter contentrobjectives so it fits in with students'

needs/experiences

translating drama/video fragments to students' life experiences

$.25 .85^{\text {tot }}$

Talking about sexuality issues:

providing clear/concrete descriptions of different sexual behaviors

$.26 \quad .66^{*}$

demonstration on how to use a condom

$.04 \quad .85^{\text {tw* }}$

talk frankly about sex while refraining from words students are not familiar with

$-.47 \quad .43^{* * *}$

$.80 .80^{* * *}$

Total

$.02 \quad .44^{*}$

$" p<.001 ; " * p<.001$ and difference $>10 \%$ of scale-range.

\section{Discussion}

Generalization of the present data is restricted because the school principal selected one teacher in four departments (when present). Moreover, the final teacher sample represented only $27 \%$ of all questionnaires initially sent. Although, correlational analyses are expected to be less vulnerable to possible selective attrition, this may have resulted in inaccurate prevalence or absolute mean scores. 
Given these limitations, the study showed that the Theory of Planned Behavior can effectively be applied to teachers' innovation-decision making. AIDS education adoption was strongly related to specific outcome, normative, and control beliefs. The assumption that these determinants would also account for the impact of other factors must tentatively be rejected. Sense of responsibility, sexual morality, school policy and frequency of collegial interaction, significantly improved the model's solution.

Teachers' estimated feasibility and importance of student learning outcomes were generally moderate. Teachers more favored STD/AIDS-related knowledge outcomes than learning outcomes of general sex education. The reduced impact of outcome beliefs appeared to be caused by the somewhat broader scope of the responsibility construct. Sense of responsibility may have covered other outcome-related concerns which are absent in the outcome belief construct. For example, "I do not feel responsible because time pressure forces me to select other subject priorities" also refers to perceived costs which, according to the Theory of Planned Behavior, is part of the attitude construct.

Alternatively, the limited impact of outcome beliefs is supported by research on teachers' planning behavior which emphasize the primacy of content and activities, not objectives (Shavelson \& Stern, 1981; Clark \& Peterson, 1986; Borko et al., 1990). Teachers' planning appears to be primarily directed by their estimated ability to maximize student participation and enjoyment. Students as most influential referents for AIDS education adoption may be indicative for this tendency. Nevertheless, we still need to be cautious in concluding that learning objectives are generally irrelevant. Zero-order correlation between outcome beliefs and teachers' intentions was still significant at $\underline{\mathbf{r}}=36$. It is also argued that this association may be moderated by experience, conceptions of the teaching-learning process, or the context of instruction, including student background (Clark \& Peterson, 1986; Porter \& Brophy, 1988).

Although all referent groups appeared to affect teachers' motivational state, there are some clear differences. Social distance may be an eminent factor for explaining these diffe-rences. Students, colleagues in own department, and the school principal were most influential. Students even seem to have most potential in affecting AIDS education adoption. Teachers not only anticipated students' approval, they also referred to students' expectations as a powerful incentive for their adoption decision.

Beside negative subjective norms, teachers may be restricted to provide AIIS education by the absence of a school policy and/or regular meetings with colleagues. The reverse may also be found. When these conditions turn out to be positive, teachers may feel compelled to perform. This is of specific concern since many teachers doubted their ability to talk about sexuality or to apply required teaching- and management strategies. Neither students nor teachers will benefit from situations in which teachers are coerced to continue by policy or collegial pressure, and still anticipate being unsuccessful. They may fail to attribute the problem to inappropriale knowledge of successful classroom practices, but rather to their own inability to teach or students' inability to learn, irrespective of the method applied (Smylie, 1988). 
Above all, self-efficacy was constituted by perceived ability to talk frankly about sexuality with students. Teachers also appeared to anticipate particular situations in which they might fail. For example, in situations which appeal to their ability to take care of students ex-pressing personal problems with their sexuality, or to their management skills for controlling disruptive classroom behaviors, or to guard against insulting students expressing minority opinions. Experienced teachers felt more confident in dealing with these situations. Athough perceived mastery of skill-oriented teaching formats was generally low, it appeared to be less determinative for teachers' planning decisions when compared to the other three efficacy-domains: talking about sex, adapting AIDS content and objectives, and applying classroom management strategies.

Some final remarks need to be made concerning method and scope. First, variance in adoption accounted for by the model (41\%), may be limited by inter-correlations among predictors. We already addressed the common variance in the attitudinal constructs. Second, the research model was applied to AIISS education adoption. Adoption, and its antecedents, will not necessarily predict effective implementation. Moreover, because the results are based on cross-sectional data, conclusions about importance and sequence of predictors are only tentative. Future longitudinal or intervention studies are needed to determine the sequence, and which variables are most predictive for transition to the stage of implementation, or whether new determinants may come into prominence.

\section{Implications}

The present results do suggest that promotion of classroom AIDS education needs to be tailored at positive norm setting, inducing collaborative climate conditions in schools, and increasing teachers' self-efficacy. When also anticipating successful implementation, the innovation strategy should take a combined format of mass media and face-to-face communication (Crandall, 1989; Fullan, $\left.1991^{2}\right)$. We should, however, be reluctant to put too much pressure on teachers whose ideological and practical concerns are (still) incompatible with HIV instruction. Support for these teachers better focuses on their incongruent ideologies (sexual morality, perceived responsibility), before enhancing anticipated practicality or self-efficacy (Rich, 1990).

Mass media promotion of AIDS education may be of little help when it merely emphasizes the desirability of achieving specific learning outcomes. Persuasive communication also needs to anticipate teachers' subjective norms and self-efficacy; for example by incorporating symbolic modeling (Bandura, 1986). Parcel et al. (1989) $)$ elaborated on this incentive by using video-based modeling for disseminating tobacco-use prevention programs. When applied to AIDS education, subjective norms and self-efficacy may be changed by observation of congruent role model(s) demonstrating short term benefits, effective classroom practices, and positive student outcomes. Short term benefits can be made salient by showing students' success in discussing sexuality, as with 
communicating students approval of applied activities by showing their active involvement and enjoyment. Anticipated practicality will be enhanced by demonstrating requisite teacher skills for talking about sexuality, and for applying student-centered-and classroom management strategies.

External consultants from local health and education support services need to strengthen personal contacts with schools and teachers. Effective roles of local facilitators encompass identification of schools'teachers' needs, providing access to alternative practices through print materials and demonstration, arrangement of training facilities, and providing in-person assistance during later implementation (Crandall, 1989).

External consultants should help teachers to develop a plan for proceeding through the distinct stages of change (cf. Hall \& Hord, 1987; Crandall, 1989; Mclaughlin, 1990). Such an implementation schedule defines the magnitude of change over time in order to gain early rewards and some tangible success, which are critical incentives for increasing teachers' self-efficacy. There is little evidence for large-scale participation at the initiation stage; one better starts with small groups of teachers and, if successful, build momentum (Huberman \& Miles, 1984; Fullan, 1991²). Since teachers appear to value congruent models, overt success of colleagues may induce and reinforce other teachers' commitment to the innovation. One also needs to assure principal's support since he/she may contribute to positive norm setting, and is in the position to shape the participative climate conditions conducive for long-term success.

Training might be part of this programmed change to meet the skill-related problems of teachers initially implementing AIDS education. Beside presentations of theory, effective in-service training should provide demonstration of good practices (direct modeling), oppor-tunities for guided enactment, feedback, and follow-up assistance during self-directed application (Bandura, 1986; Joyce \& Showers, 1988; Smylie, 1988). One-shot workshops or occasional visits have shown to fall short in this respect (Berman \& Mclaughlin, 1978; Huberman \& Miles, 1984; Fullan, 1991²).

Special attention is needed for schools and teachers in junior education. Not only because AIDS education was less prevalent in these schools, but also because their students appeared to be more in need of AIDS education than students in senior levels (Vogels \& Van der Vliet, 1990). This discrepancy may result from the interaction between classroom composition and teachers' planning behavior (Clark \& Peterson, 1986; Borko et al., 1990). For example, "low-achieving" students may affect adoption by directing teachers' self-efficacy (Smylie, 1988). Future research is needed to address these classroom contingencies. 
Chapter 4

\section{Diffusion of AIDS curricula among Dutch secondary school teachers}

Suhmitted for publication as: Paulussen, Th.G.W., Knk. G,I. Schaalmu. H.P. G. Parcel, G.S. Diffustom of AlDs curricula among Dufb secondany scbool teaihers. 


\section{Abstract}

This study reports data from a sample of 698 Dutch secondary scbool teachers intending to provide classroom AIDS education. The study addresses determinants of awareness-knowledge about and adoption of four nationally disseminated AIDS curricula. The results indicated that knowledge acquisition largely depended on diffusion networks witbin schools. Transition from aurareness-knowledge to adoption appeared to be mediated by perceived instrumen-tality, subjective norms, perceived colleague bebavior and teacbers' sexual morality. Preferences for using one curriculum rather than another were related to the same variables, although financial costs became slightly more decisive. It is concluded that effective dissemination strategies should combine (a) development of validated materials with maximum procedural clarity, (b) focused mass media communication, (c) close colla-boration of curriculum designers, linking agents, and teachers, and (d) access to in-person assistance.

\section{Introduction}

In order to facilitate the introduction of classroom AIDS education in the Netherlands, many efforts have been devoted to the development of curricular materials. Since 1989, four AIDS curricula have been disseminated among Dutch secondary schools. Two years after their initial release, an evaluation was conducted to assess the acceptability of the curricula among Dutch secondary teachers. In this paper, we address the determinants of teachers' decision making about using these AIDS curricula. In addition, we will explore factors constituting teachers' choice intentions, the intentions to use one curriculum rather than another.

\section{Curriculum characteristics}

Although sex education in Dutch secondary schools is usually provided by teachers in biology, social studies, religious education, and health education, the AIISS curricula were not targeted at specific subject areas. Table 4.1 provides an overview of the curriculum features. Curriculum $A$, the one that became available first, was extensively criticized by representatives of Protestant schools. According to their ideological concern, it too narrowly focused on ADS and condom use instead of promoting sexual abstinence. This resulted in additional governmental funding of a specific curriculum for Protestant schools (Curriculum B). Later on, it was assumed that these curricula did not properly match differential interests and cognitive ability of students in different educational levels. Therefore, Curriculum $\mathrm{C}$ was developed or senior levels (seniorgeneral and pre-university education), and Curriculum D for junior levels (junior vocational and junior general secondary 


\begin{tabular}{|c|c|c|c|c|}
\hline & Curriculum A & Curriculum B & Curriculum C & Curriculum D \\
\hline Products & $\begin{array}{l}\text { - student magazine } \\
\text { - teacher manual } \\
\text { - video }\end{array}$ & $\begin{array}{l}\text { - student magazine } \\
\text { - teacher manual } \\
\text { - video }\end{array}$ & $\begin{array}{l}\text { - student magazine } \\
\text { - teacher manual } \\
\text { (no video) }\end{array}$ & $\begin{array}{l}\text { - student magazine } \\
\text { - teacher manual } \\
\text { - video }\end{array}$ \\
\hline $\begin{array}{l}\text { Target } \\
\text { group }\end{array}$ & all secondary schools & $\begin{array}{l}\text { all Protestanı } \\
\text { secondary schools }\end{array}$ & $\begin{array}{l}\text { senior general and } \\
\text { pre-university schools }\end{array}$ & $\begin{array}{l}\text { junior vocational and } \\
\text { junior general schools }\end{array}$ \\
\hline \# lessons & 4 lessons & 6 lessons & $\begin{array}{l}8 \text { lessons ( } 4 \text { basic and } \\
4 \text { optional) }\end{array}$ & $\begin{array}{l}\text { not specified; provides } \\
21 \text { learning activities }\end{array}$ \\
\hline Content & $\begin{array}{l}\text { AIDS: testing, safe sex, } \\
\text { purchase/use condoms, } \\
\text { anti-discrimination }\end{array}$ & $\begin{array}{l}\text { intimate relationships: } \\
\text { attractiveness, love, } \\
\text { sexuality }\end{array}$ & $\begin{array}{l}\text { STD/AITS: response to } \\
\text { STD-infection, purchase' } \\
\text { use condoms, } \\
\text { anti-discrimination }\end{array}$ & $\begin{array}{l}\text { AIDS/sexuality: inter- } \\
\text { ethnic differences, } \\
\text { physical/emotional } \\
\text { attractiveness }\end{array}$ \\
\hline $\begin{array}{l}\text { Learning } \\
\text { objectives }\end{array}$ & $\begin{array}{l}\text { knowledge, values, } \\
\text { communication skills }\end{array}$ & norms and values & $\begin{array}{l}\text { knowledge, values, } \\
\text { communication skills }\end{array}$ & knowledge and values \\
\hline $\begin{array}{l}\text { Learning } \\
\text { activities }\end{array}$ & $\begin{array}{l}\text { group discussions, role- } \\
\text { play, questionnaire, } \\
\text { demonstration, } \\
\text { buying condoms }\end{array}$ & $\begin{array}{l}\text { group discussions, } \\
\text { reading articles, optional } \\
\text { creative assignments }\end{array}$ & $\begin{array}{l}\text { group discussions, role- } \\
\text { play, demonstration, } \\
\text { buying condoms, } \\
\text { writing assignments }\end{array}$ & $\begin{array}{l}\text { group discussions, } \\
\text { interviews, role-play, } \\
\text { drawing cartoons, writ- } \\
\text { ing assignments }\end{array}$ \\
\hline Costs & $\begin{array}{l}\text { video: Dfl. } 72,50 \\
\text { manual: Dfl. } 4,- \\
5 \text { magazines: Dfl. 4,- }\end{array}$ & $\begin{array}{l}\text { video: Df. } 30,- \\
\text { manual: Dfl. } 15,- \\
\text { magazines: Dfl. } 9,50\end{array}$ & íree of charge & $\begin{array}{l}\text { Complete packige } \\
\text { (video included): } \\
\text { Df. } 19,50\end{array}$ \\
\hline
\end{tabular}

education).

All curricula attempt to keep the transfer of knowledge to a minimum and emphasize active forms of learning. They mainly differ in content and design. Curriculum B primarily focuses on norms and values in intimate relationships; AIDSSID preventive behaviors are minor themes. Curriculum A primarily addresses AIDS-related hehaviors, while Curriculum C broadens the scope to other STDs, and Curriculum D addresses the cultural determination of sexual lifestyles. When compared to the other curricula, Curriculum D is more visually designed, keeping the use of textformats to a minimum. Only Curriculum $\mathrm{C}$ is not accompanied by a dramatized video. All curricula were diffused without any deliberate guidance, apart from mass media promotion: advertisements in newspapers and specialist journals, and direct mail of overviews or complimentary copies. 


\section{Theoretical background}

Teachers were conceived of as the primary unit for adoption since Dutch teachers are by no means mandated to provide AWS education. The Theory of Planned Behavior (Ajzen, 1991) was used to structure the motivational factors with potential of affecting curriculum adoption. The theory postulates that behavioral intentions are best predicted by attitudes, subjective norms, and control beliefs (self-efficacy; Bandura, 1986). Specification of these belief-structures were derived from empirical research on curriculum innovations and teachers' planning behavior and thoughts.

Although some attributes may be inherently linked to a particular innovation, teachers' response will largely depend on how these attributes match their preexisting social and psychological dispositions (cf. Zaltman \& Duncan, 1977; Rogers, 1983; Fullan, 1991 ${ }^{2}$ ). Dołle \& Ponder (197778) addressed this contingency by what is called the "practicality ethic" of teachers. Three criteria appear to constitute this ethic: instrumentality, congruence, and costs. An innovation will be perceived as instrumental when it provides clear procedural referents (how-to specifications). Congruence refers to its compatibility with the prevailing classroom conditions in terms of student reactions (interest, learning) and teachers preferred mode of relating to students. Costs refer to financial and personal costs (time, ease), relative to potential return (e.g. recognition, student enthusiasm).

When elaborating on the issue of congruence, teachers' educational orientations are often contrasted by two ideological inuages: teacher- versus student-centeredness (Rich, 1990). Victor (1976: Victor \& Otis, 1980) associated teacher-centeredness with dogmatism, emphasis on subject matter, and teacher-student social distance. Student-centered teachers appear to take more responsibility for students' performance (Brophy \& Rohrkemper, 1982; Ames, 1983). LevensonGingiss and Hamilton $\left(1989^{3}\right)$ found that high-responsibility teachers were more willing to continue providing a sex education course. Teachers' intentions also appeared to be positively associated with a permissive sexual morality. It is also suggested that teacher attributions for the causes of student performance will direct their decision making about goals, learning activities and classroom management strategies (cf. Brophy \& Rohrkemper, 1981; Weiner, 1985; Clark \& Peterson, 1986).

According to Bandura (1986), behavioral change is not only directed by outcome beliefs, but also by self-efficacy. Teachers' self-efficacy have shown to be positively related to student achievement (Gibson \& Dembo, 1984; Ashton \& Webb, 1986; Midgley et al, 1989; Rosenholz, 1989), and teachers' acceptance of curriculum innovations (Guskey, 1988; Stein \& Wang, 1988; Smylie, 1988).

Important social referents (e.g. colleagues, students, parents) can also provide standards for innovation adoption (cf. Smylie, 1988; Crandall, 1989; Fullan, 1991²). Besides schools' formal policy, frequency of collegial interaction about instruction and participative decision making may contribute to the clarity of change, and reinforce teachers' adoption (Huberman \& Miles, 1984; Smylie, 1988; Rosenholtz, 1989). In case these favorable climate conditions are absent, perceived 


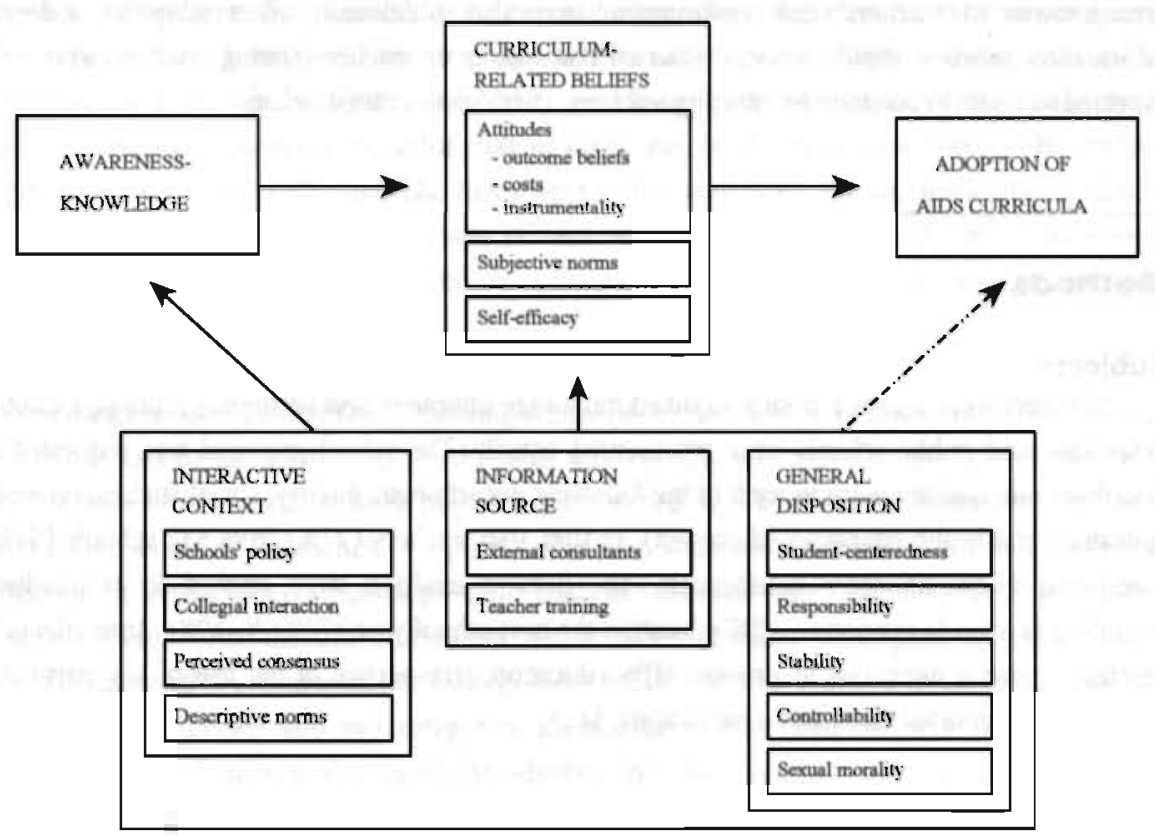

Figure 4.1. Model for explaining teacbers' adoption of exemplary AIDS education curricular materials.

colleague behavior may operate as a descriptive norm for teacher decision making instead (cf. Grube et al., 1986).

These variables were applied to Ajzen's model (1991), either by integrating them into the endogenous constructs, or by adding them as background factors (Figure 4.1$)^{2}$. Regarding curriculum-related attitudes, beliefs about the feasibility and importance of the formulated learning outcomes (outcome beliefs) and financial costs incurred to purchase the curricula, were discerned from instrumentality. Instrumentality refers to whether the curriculum meets teacher's primary planning concems, including time/ease of pre-active planning, clarity of procedural referents, and anticipated student reactions to the proposed activities (interest, enthusiasm). Although the Theory of Planned Behavior suggests that intentions are directly related to attitudinal, normative and control beliefs, more generic dispositions, like feelings of moral obligation and sense of responsibility, might improve the model's prediction (cf. Ajzen, 1991). According to educational research, section of Chapter 1 . 
arrangements in teachers' task environment may also additionally affect adoption. Relevant information sources outside schools, external consultants or teacher training courses, were only expected to relate to adoption by affecting teachers' curriculum-related beliefs.

\section{Methods}

\section{Subjects}

Teachers were selected from a stratified multistage sample of 988 secondary schools; Catholic, Protestant, and public schools were represented equally. The school principal was requested to distribute one questionnaire in each of the following departments: biology, social studies, religious education, and health education (if present). In sum, 956 teachers (27\%) from 532 schools (54\%) completed a questionnaire satisfactorily. The present analyses were applied to respondents intending to provide classroom AIDS education the next school year ( $73 \% ; \mathrm{N}=698)$. Antecedents to teachers' general intentions to provide AIDS education, irrespective of the use of any particular program, are reported elsewhere (see Chapter 3).

\section{The questionnaire}

The teacher questionnaire was based on the reviewed literature, as well as preliminary interviews with 21 secondary teachers and the designers of the four AIDS curricula. Awareness, adoption, and curriculum-related beliefs were assessed for each curriculum separately. Cronbach's $\alpha$ was used to test internal-consistency of the scaled variables.

Awareness-knowledge and adoption. Awareness-knowledge was treated in a binary fashion: unawareness (or only capable of naming program's tite), versus awareness (varying from superficial to profound knowledge). Teachers' adoption was assessed by a 4-point scaled item: "Do you think you will use Curriculum .. when providing AIDS education the next school year?". Teachers also named the curriculum they had already implemented.

Curriculum-related beliefs. Outcome beliefs were indexed as a weighted result of perceived feasibility and importance of the learning outcomes as proposed by the curricula, using 5-point scaled items. Internal-consistency values varied from $\alpha=.77$ (Curriculum A) to $\alpha=.82$ (Curriculum C). Perceived financial costs were assessed by a 5 -point scaled item. Instrumentality was assessed by thirteen 5-point-scaled items, such as: "The materials do provide clearly structured procedural information about content, objectives and activities" (procedural content), "The time necessary for preparing classroom instruction is acceptable" (personal investment), "Students will be motivated to participate in the proposed learning activities" (students' enthusiasm). Internal consistency values varied from $\alpha=.78$ (A) to $\alpha=.86$ (D). Teachers responded to the normative beliefs of students, the 
principal, school board, colleagues in their own and other subject departments, external consultants and parents. These beliefs were weighted by teachers' motivation to comply to these referents; $\alpha$ values varied from $\alpha=.70$ (C) to $\alpha=.83$ (D). Self-efficacy was assessed by 5 -point scaled items, each referring to a particular behavior, role or classroom condition as prescribed by the teaching guide appended to the ADS curricula. Items were included such as: "Do you think you are able to guide a role-play in which students take certain positions toward sexuality?" or "... to prevent torment of students who express minority opinions about sexuality?" The $\alpha$-values varied from $\alpha=.81$ (C) to $\alpha=.86(\mathrm{~A})$.

Exogenous model varlables. Regarding school policy, teachers were asked whether the outline of content and organization of AIDS education was formally prescribed by the school work plan and/or their own curriculum work plan. A 6-point scaled item assessed the frequency of collegial interaction about HIV instruction. A 5-point scaled item assessed the degree to which teachers had achieved consensus with colleagues about the goals and necessary requirements for HIV instruction. Teachers also reported the AIDS curriculum used by their colleagues (descriptive norms).

The alternative communication sources from which teachers received information about the curricula were divided into two categories afterwards: written communication versus personal communication. Teachers also indicated whether they had attended to in-service training on AIDS/sex education.

Student-centeredness was indexed on ten 5-point scaled items (cf. Den Hertog, 1990; $\alpha=80$ ). Fourteen 5-point scaled items assessed teachers' sexual morality (cf. Iuijkx et al., 1987; $\alpha=.87$ ). Two dimensions of teachers' attributional style were measured. Three 4-point scaled items assessed teachers' perceived stability and controllability of factors they assumed to cause students' lack of knowledge, negative attitudes and lack of social skill toward AIDS preventive behaviors ( $\alpha=.68$ and $\alpha=.71$, respectively). Teachers' sense of responsibility toward HIV instruction was assessed by seven 5-point scaled items $(\alpha=.71)$.

Finally, teachers reported their age, religious affiliation, gender, years of teaching experience, subject area, school's denomination (Catholic, Protestant and Public), and educational level. Educational level was classified into junior level (junior vocational and junior general secondary education), and senior level (senior general and pre-university education).

\section{Data analysis}

Awareness-knowledge was modeled by stepwise logistic regression, by only considering exogenous model variables. Adoption of single curricula and teachers' choice intentions were modeled by stepwise multiple regression. Only variables that according to their univariate odds-ratio or Pearson's $\mathbf{r}$ appeared to be related to the criterion $(p<.05)$ were entered in the multivariate analyses. Regression analyses on adoption were restricted to teachers indicating familiarity with the curriculum of interest. Regarding teachers' pairwise choice intentions, only teachers were considered who indicated to be familiar with both alternative curricula. Predictors were entered 
according their theoretically expected order: curriculum-related beliefs were entered in the first step, exogenous model variables in the second step.

Choice intentions were assessed by subtracting teachers' intentions toward using Curriculum B from Curriculum A, C from A and C from B. Similar computations were performed to corresponding curriculum-related beliefs (cf. Sperber et al., 1980). Because the numbers of teachers with combined knowledge about Curriculum D and one of the other curricula were rather small (47 to 53), differential intentions with Curriculum $\mathrm{D}$ were ignored.

\section{Results}

\section{Sample description}

About $62 \%$ of the 698 respondents taught in junior education, and 38\% in senior secondary education. Thirty-three percent was teaching in Public schools, 34\% in Catholic schools, and $33 \%$ in Protestant schools. Respondents were divided into four subject areas: biology (44\%), social studies $(29 \%)$, religious education $(9 \%)$, and a category 'he/counselors' (18\%; consisting of health educators and student counselors). Males comprised $69 \%$ of the subjects and females $31 \%$. Mean age was 42 years ( $s d=7.20$; range $=24 / 63)$. Teaching experience varied from 1 to 40 years $(\bar{x}=17$, $s d=7.62$ ). Personal religious affiliation was divided into: Catholic (32\%), Protestant (29\%), 'others' (7\%), and 'no affiliation' (32\%).

\section{Awareness-knowledge about AIDS curricula}

About $67 \%$ of the respondents indicated they were aware of the AIDS curricula; $34 \%$ knew about one, $19 \%$ two, $7 \%$ three, and $6 \%$ knew about all four curricula. Sixty percent of these informed teachers initially received information about the curricula by written communication (publishers' overviews, direct mail), and $16 \%$ by personal communication with external consultants. A considerable proportion of these knowledgeable teachers named colleagues as an information source; they deliberately had discussed the materials with them $(34 \%)$, and/or knew about colleagues using at least one of these curricula $(63 \%)$. Table 4.2 presents univariate and multivariate odds-ratios of demographic and exogenous model variables that appeared to be related to awareness-knowledge about the AIDS curricula. Religious affiliation, gender, age, experience, perceived consensus, and perceived stability are not presented since they were unrelated to these knowledge indices.

Most teachers were aware of Curriculum A (49\%); followed by B (34\%), C (28\%), and D $(10 \%)$. When adjusting for other variables, awareness-knowledge appeared to be most strongly related to descriptive norms and frequency of collegial interaction. Although the impact of personal dispositions was restricted by adjusting for these contextual factors, the U-ORs of sexual morality, responsibility and student-centeredness suggest that these ideological orientations may also have 
Table 4.2. Univariate- (U-OR) and multivariate odds ratios (M-OR) of variables associated with awareness-knowledge about each AIDS curriculum $\left.(\mathrm{N}=698)^{\prime}\right)^{\prime}$

\begin{tabular}{|c|c|c|c|c|c|c|c|c|}
\hline & \multicolumn{2}{|c|}{ Curriculum A } & \multicolumn{2}{|c|}{ Curriculum B } & \multicolumn{2}{|c|}{ Curriculum C } & \multicolumn{2}{|c|}{ Curriculum D } \\
\hline & U-OR & M-OR & U-OR & M-OR & U-OR & M-OR & U-OR & M-OR \\
\hline \multicolumn{9}{|l|}{ Interactive Context } \\
\hline Schools' policy ${ }^{2}$ & 1.51 & ns & ns & $\ldots$ & 1.89 & ns & ns & - \\
\hline Descriptive norms ${ }^{2}$ & 15.80 & 14.44 & 15.75 & 14.29 & 24.27 & 21.62 & 127.90 & 137.26 \\
\hline Collegial interaction & 1.46 & 1.20 & 1.31 & 1.21 & 1.47 & 1.25 & 1.35 & $\mathrm{~ns}$ \\
\hline \multicolumn{9}{|l|}{ General disposition } \\
\hline Sexual morality & 1.51 & ns & .72 & ns & 1.37 & ns & ns & - \\
\hline Responsibility & 1.50 & ns & ns & - & 2.09 & 1.78 & ns & - \\
\hline Student-centeredness & ns & - & 1.72 & ns & $\mathrm{ns}$ & - & 1.83 & ns \\
\hline Controllability & ns & - & ns & - & 1.65 & $\mathrm{~ns}$ & $\mathrm{~ns}$ & - \\
\hline \multicolumn{9}{|l|}{ Demographics } \\
\hline Educational level ${ }^{2}$ & 1.38 & ns & ns & - & 1.65 & ns & ns & - \\
\hline \multicolumn{9}{|l|}{ Schools' denomination ${ }^{2}$} \\
\hline Public & ns & -- & .52 & .65 & ns & - & ns & - \\
\hline Catholic & ns & - & ns & ns & ns & - & ns & - \\
\hline Protestant & ns & - & 2.11 & 1.82 & ns & - & ns & - \\
\hline \multicolumn{9}{|l|}{ Teaching subject ${ }^{2}$} \\
\hline biology & ns & - & .52 & .52 & ns & - & ns & - \\
\hline social studies & ns & $\cdots$ & ns & ns & ns & - & ns & - \\
\hline religious education & ns & -- & 2.35 & 1.98 & as & - & ns & - \\
\hline he/counselor & $\mathrm{ns}$ & - & ns & $\mathrm{ns}$ & ns & - & ns & - \\
\hline $\begin{array}{l}\text { Multivariate } \\
\text { model Chi-Square }\end{array}$ & \multicolumn{2}{|c|}{$\begin{array}{c}x^{2}(2)=214.36 \\
p<.001\end{array}$} & \multicolumn{2}{|c|}{$\begin{array}{c}\chi^{2}(7)=215.79 \\
\mathrm{p}<.001\end{array}$} & \multicolumn{2}{|c|}{$\begin{array}{c}\chi^{2}(3)=179.70 \\
p<.001\end{array}$} & \multicolumn{2}{|c|}{$\begin{array}{c}\chi^{2}(1)=93.32 \\
p<.001\end{array}$} \\
\hline
\end{tabular}

'Printed ORs are significant at $p<05 ;{ }^{4}$ Coded as deviation contrasts.

directed teachers' information-seeking behavior. For example, sexual morality was positively associated with awareness of Curriculum $A$ and $C$, and negatively with the curriculun developed for Protestant schools (B). Moreover, significantly more teachers in Protestant schools indicated familiarity with Curriculum B than teachers in Public schools. Knowledge about B was also more prevalent among teachers in religious education than teachers in biology. Educational level hardly differentiated the knowledge prevalence, although Curriculum C and D were specifically developed for senior- and junior secondary levels, respectively.

\section{Adoption of AIDS curricula}

About $52 \%$ of the respondents had initially implemented one of the AIDS curricula; $16 \%$ in combination with another curriculum. When asked about the curriculum that provided them the 
most important directive for their instructional planning, 29\% named Curriculum A, 13\% B, 8\% C, and $2 \%$ Curriculum D. Most teachers indicated positive intentions to use Curricula A (38\%), followed by B (23\%), C (20\%), and D (5\%). Table 4.3 provides an overview of factors that were significantly related to teachers' adoption decision. Sense of responsibility, collegial interaction, perceived consensus, and personal contact with external consultants are not presented since they not significantly correlated with the adoption indices.

Subjective norms and instrumentality accounted for most variability in teachers adoption of the AIDS curricula. These two endogenous factors accounted for $27 \%$ of variance in adoption of Curriculum A, in case of B for $42 \%$, in case of C for $31 \%$, and in case of Curriculum D for $46 \%$. Although outcome beliefs and financial costs also significantly correlated with separate adoption indices, these factors failed to enter nearly every regression equation. Self-efficacy showed to be of little help in 'explaining' teachers' adoption of these AIDS curricula. Moreover, only adoption of Curriculum B appeared not to be hindered by feelings of moral obligation. Except for teachers' adoption of Curriculum D, descriptive norms (perceived colleague behavior) additionally entered the regression on all other adoption estimates.

\section{Teachers' choice intentions}

Table 4.4 shows the results of the regression analyses on teachers' preferences toward using Curriculum A or B, A or C, and B or C. A zero score on differential scales expresses an equal predisposition toward the compared curricula; e.g. a positive score on choice intention A-B expresses a preference for using Curriculum $A$, and a negative score a preference for using $B$. The asterisks assigned to the differential scale-means indicate that the mean significantly departs from zero. Frequency of collegial interaction, student-centeredness, responsibility, controllability, stability, and attendance to in-service training were not significantly correlated with any choice intention.

Many teachers familiar with the compared alternatives did not express a preference for using either one of them: $47 \%$ were still undecided when comparing A and B, $53 \%$ had no preference for $A$ or $C$, and $45 \%$ were undecided about using $B$ or $C$. Only when comparing $B$ and $C$, teachers did significantly prefer Curriculum $B$ instead of $C(\bar{x}=.29, p<.05)$.

When comparing Curriculum $B$ with $A$ and $C$ (column one and three), both choice intentions significantly correlated with all differential perceptions, except with differential self-efficacy. Both choice intentions also related to teachers' sexual morality, indicating that adoption of Curriculum B was the one least constrained by feelings of moral obligation. When adjusting for other factors, choice intention A-B was best predicted by (1) differential instrumentality, (2) differential subjective norms, (3) differential costs, (4) differential descriptive norms, and (5) sexual morality; accounting for $49 \%$ of variability in the criterion. Costs, descriptive norms, and sexual morality favored adoption of Curriculum A, while subjective norms and instrumentality favored adoption of B. Teachers' intentions toward using $B$ rather than $C$ was best predicted by (1) differential instrumentality, (2) differential costs, and (3) sexual morality; accounting for $46 \%$ of variability in the criterion. These 
Table 4.3. Results of regression analyses on teachers' adoption of separate AIDS curricula: mean ( $(\ddot{x})$, zero-order correlations (r), and $\beta$-weights.

\begin{tabular}{|c|c|c|c|c|c|c|c|c|c|c|c|c|}
\hline \multirow{2}{*}{ 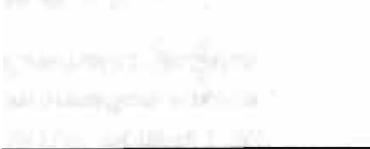 } & \multicolumn{3}{|c|}{$\begin{array}{c}\text { Curriculum A } \\
(n=341)\end{array}$} & \multicolumn{3}{|c|}{$\begin{array}{c}\text { Curriculum B } \\
(n=234)\end{array}$} & \multicolumn{3}{|c|}{$\begin{array}{c}\text { Curriculum } C \\
(n=193)\end{array}$} & \multicolumn{3}{|c|}{$\begin{array}{c}\text { Curriculum D } \\
(n=72)\end{array}$} \\
\hline & $\overline{\mathbf{x}}$ & $\underline{r}$ & $\beta$ & $\overline{\mathbf{x}}$ & $\underline{\mathbf{r}}$ & $\beta$ & $\tilde{\mathbf{x}}$ & $\underline{r}$ & $\beta$ & $\overline{\mathbf{x}}$ & $\underline{r}$ & $\beta$ \\
\hline Intentions (1/4) & 3.14 & -- & -- & 2.91 & - & -- & 2.95 & - & -- & 2.49 & - & - \\
\hline \multicolumn{13}{|l|}{ Curriculum-related beliefs } \\
\hline Outcome beliefs $(1 / 25)$ & 14.18 & $.2 I^{* * *}$ & n.s. & 12.55 & $.13^{*}$ & n.s. & 14.60 & $.12^{*}$ & n.s. & 15.02 & $.33^{* * * *}$ & n.s. \\
\hline Costs $(-2 / 2)$ & .94 & $.19^{* * * *}$ & $.12^{* *}$ & .62 & $.13^{*}$ & n.s. & .82 & $.20^{* * *}$ & n.s. & .46 & $.20^{*}$ & n.s. \\
\hline Instrumentality $(-2 / 2)$ & .54 & $.41^{* * * *}$ & $.21^{* * *}$ & .60 & $.60^{* * *}$ & $.35^{* * *}$ & .58 & $.48^{* * *}$ & $.21^{* * * *}$ & .42 & $.64^{* * *}$ & $.48^{* * *}$ \\
\hline Subjective norms $(-8 / 8)$ & 1.20 & $.46 * * *$ & $.25^{* * * *}$ & 1.63 & $.55^{* * *}$ & $.25^{* * *}$ & 1.15 & $.50^{* * *}$ & $.27^{* * *}$ & .86 & $.64^{* * *}$ & $.23^{*}$ \\
\hline Self-efficacy $(-2 / 2)$ & .44 & $.18^{* * * *}$ & n.s. & .61 & n.s. & -- & .51 & $.18^{* *}$ & n.s. & .59 & n.s. & - \\
\hline \multicolumn{13}{|l|}{ Interactive Context } \\
\hline Schools' policy' & -- & $.12^{* *}$ & n.s. & -. & $.13^{*}$ & n.s. & -- & n.s. & - & - & $.21^{*}$ & n.s. \\
\hline Descriptive norms' & -- & $.37^{* * *}$ & $.24 * * *$ & -. & $.43^{* * * *}$ & $.24^{* * * *}$ & - & $.35^{* * *}$ & $20 * * * *$ & -. & $.46^{* * * * *}$ & n.s. \\
\hline \multicolumn{13}{|l|}{ General disposition } \\
\hline Sexual morality $(-2 / 2)$ & .66 & $.27^{* * *}$ & $.18^{* * *}$ & .50 & n.s. & - & .67 & $.35^{* * * *}$ & $.24^{* * *}$ & .50 & $.33^{* * * *}$ & $.19^{*}$ \\
\hline Student-centeredness $(-2 / 2)$ & 1.03 & n.s. & - & 1.12 & $.18^{* * *}$ & n.s. & 1.07 & n.s. & - & 1.16 & n.s. & -- \\
\hline Controllability $(1 / 4)$ & 2.73 & n.s. & - & 2.75 & n.s. & -- & 2.79 & $.18^{* *}$ & n.s. & 2.78 & $.27 * *$ & n.s. \\
\hline Stability $(1 / 4)$ & 2.71 & $.09^{*}$ & n.s. & 2.73 & n.s. &.. & 2.72 & $.14^{*}$ & n.s. & 2.71 & n.s. & -- \\
\hline \multicolumn{13}{|l|}{ Information source } \\
\hline Teacher training' & -- & n.s. & - & - & n.s. & - & -- & $.14^{*}$ & n.s. & $\cdots$ & $.24^{*}$ & n.s. \\
\hline Multiple R & & $\mathrm{R}=.60$ & & & $\mathrm{R}=.68$ & & & $\mathrm{R}=.62$ & & & $\mathrm{R}=.70$ & \\
\hline
\end{tabular}

$-p<05 ; \cdots p<01 ; \cdots p<.001 ;{ }^{\prime}$ Coded as detiation contrasts. 


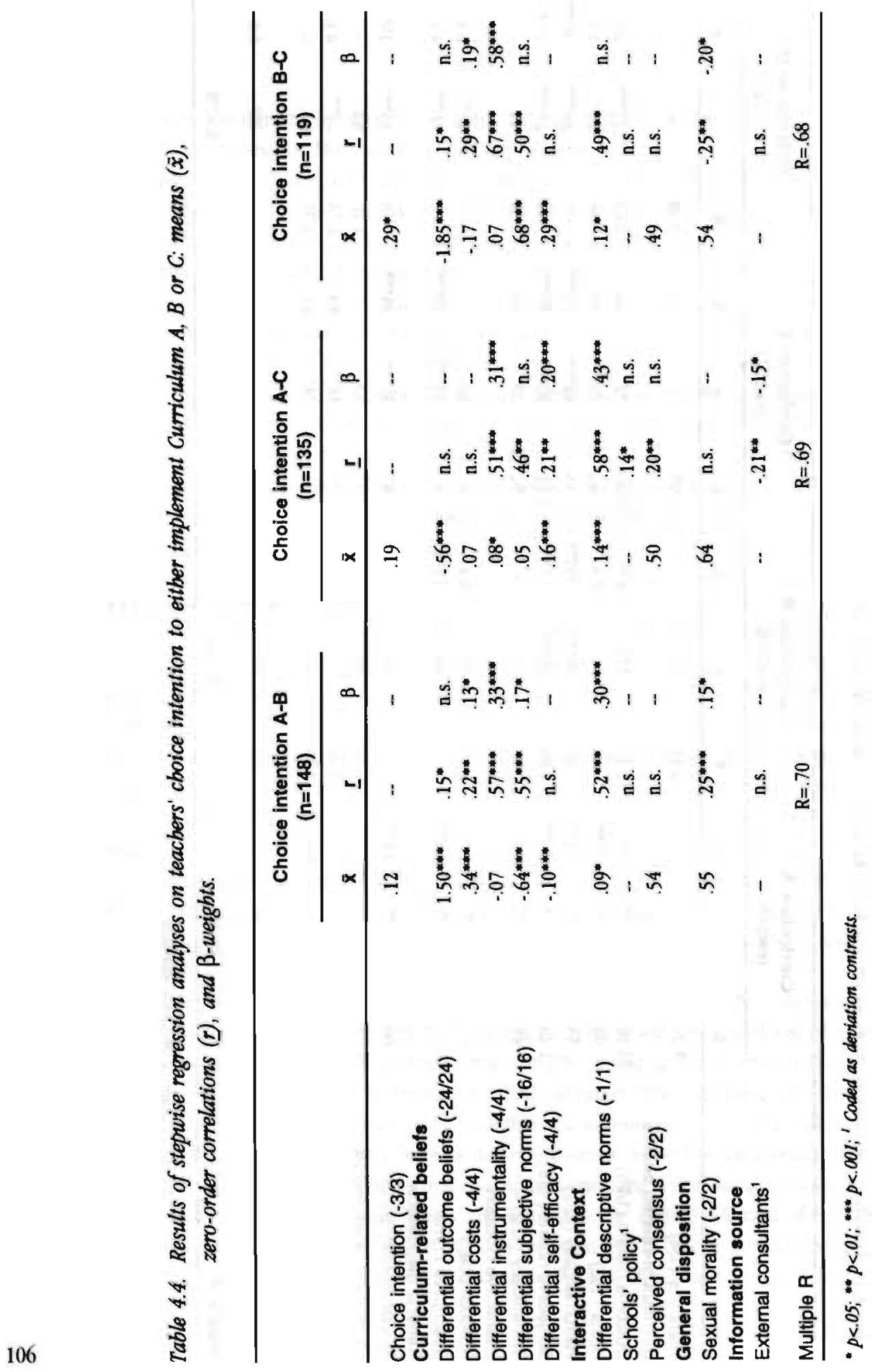




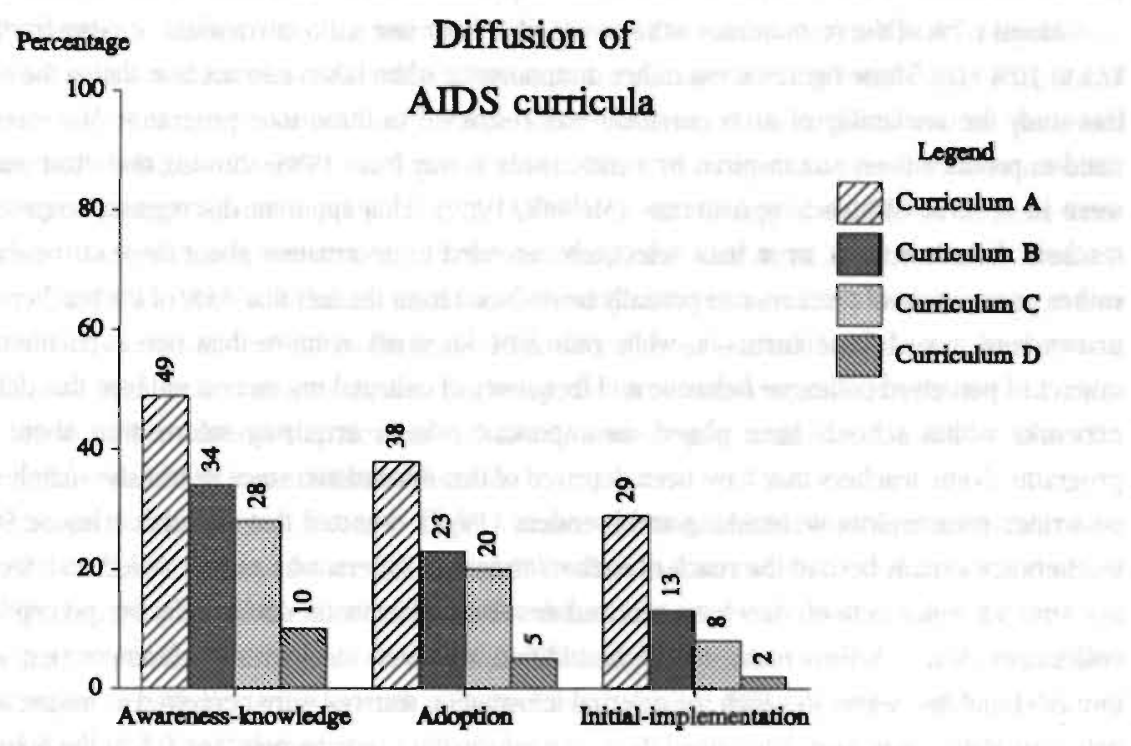

Figure 4.2. Diffision of exemplary AIDS curricula among Dutcb secondary school teachers intending to provide classroom AIDS education ( $N=698$, equals $100 \%$ ).

actors tended to favor adoption of Curriculum

B. Differential costs and sexual morality were not associated with choice intention A-C. The regression model showed this choice intention was best 'explained' by (1) diffierential instrumentality, (2) differential self-efticacy, (3) differential descriptive norms, and (4) contacts with external consultants; accounting for $48 \%$ of variance in the criterion. Except for personal communication with external consultants, all factors favored the acceptance of Curriculum $\mathrm{A}$.

\section{Discussion}

The analyses were applied to Dutch secondary teachers intending to provide classroom AIDS education. The Theory of Planned Behavior (Ajzen, 1991) showed to be a useful reference for conceptualizing the first two stages of the innovation-decision process leading from teachers' awareness-knowledge to adoption of four nationally disseminated AIDS curricula. Figure 4.2 
provides an overview of the percentages of teachers that indicated awareness-knowledge about, positive intentions to use (adoption), and initial-implementation of each of these AIDS curricula.

About $67 \%$ of the respondents were aware of at least one AIDS curriculum; varying from $49 \%$ (A) to $10 \%$ (D). These figures seem rather disappointing when taken into account that at the time of this study the availability of AIDS curricula was restricted to these four programs. Moreover, the need to produce them was inspired by a nationwide survey from 1988, showing that most teachers were in need of HIV teaching materials (Mellink, 1989). This apparent discrepancy suggests that teachers did not actively, or at least selectively, attended to information about these curricula. The rather passive role of teachers can partially be deduced from the fact that $33 \%$ of the teachers were unaware of any of these curricula, while only $34 \%$ knew about more than one curriculum. The impact of perceived colleague behavior and frequency of collegial interaction indicate that diffusion networks within schools have played an important role in acquiring information about these programs. Some teachers may have been deprived of that information since its transfer mainly relied on written communication. Stokking and Leenders (1992) reported that in Dutch schools, 50\% of teachers are usually beyond the reach of such information. Others, who merely relied on intermediary sources within school, may have received distorted information due to selective perception by colleagues (Marsh \& Huberman, 1984). In addition, teachers' ideological preferences (e.g. sexual morality) and the degree to which the external information sources were perceived as having similar beliefs or status, may have determined their own information seeking behavior (cf. Kolbe \& Iverson, 1981, Basch, 1984).

Innovation-decision making have shown to be more than just an act of information seeking and receiving; the information will also be processed, leading to more specific action-related beliefs. When comparing the determinants of curriculum adoption to the antecedents of teachers' general intentions to provide AIDS education, some parallels and differences can be noticed (see Chapter 3). In summary, adoption of AMS education was largely accounted for by perceived subjective norms, self-efficacy, sense of responsibility, sexual morality, school's formal policy, and frequency of collegial interaction. Subjective norms and sexual morality also affected adoption of specific ADS curricula. As far as student-centeredness, stability, controllability, or perceived consensus were associated with adoption of AIIS education or of the exemplary curricula, their impact appeared to be mediated by more specific adoption-related beliefs. The same accounts for most demographics: teachers' gender, age, religious affiliation, teaching experience, teaching subject, educational level, and school's denomination.

As with teachers' intention to provide AIDS education, adoption of specific curricula was not affected by learning outcome beliefs. These findings appear to be congruent with research on teachers' planning behavior demonstrating the primacy of procedural content and anticipated student involvement, rather than learning objectives (cf. Clark \& Peterson, 1986; Porter \& Brophy, 1988; Borko et al., 1990). It stresses the delicacy of the prevailing means-end models in curriculum development and teacher training, usually prescribing a four-step planning sequence: specifying 
objectives, choosing and sequencing learning activities, and selecting evaluation procedures (Borko et al., 1990).

In contrast to teachers' general intentions to provide AIDS education, self-efficacy, responsibility, school policy, and frequency of collegial interaction accounted for little variability in adoption of the AIDS curricula. New determinants came into prominence: descriptive norms, perceived instrumentality, and to a lesser extent financial costs. Subjective norms and perceived instrumentality were most strongly related to adoption of the AIIS curricula. Close examination of the scale-items confirmed the findings in research on teacher planning, and their need for practicality (Doyle \& Ponder, 1977-78). Normative beliefs about students and colleagues in one's own department best differentiated curriculum adoption. Perceived instrumentality was constituted by anticipated student reactions to and perceived procedural clarity of the proposed curriculum activities. In three instances, descriptive norms (Curriculum A, B and C) and sexual morality (A, C, and D) additionally accounted for variability in curriculum adoption.

Although financial costs became slightly more decisive, teachers' choice intentions were generally based on the same factors: instrumentality, subjective norms, descriptive norms and sexual morality. Only adoption of the curriculum for Protestant schools (B) did not appear to be hindered by restrictive moral orientations toward sexuality. Although external information sources had little or no impact on single curriculum adoption, personal contact with external consultants favored adoption of Curriculum $\mathrm{C}$ instead of $\mathrm{A}$.

Methods and the research framework deserve some final remarks. The sample consisted of Dutch secondary teachers in four subject areas intending to provide AIDS education ( $\mathrm{N}=698$ ), and were selected from a larger sample $(\mathrm{N}=956$; see Chapter 3$)$. Generalization of the results beyond these teacher groups needs to be tempered. Non-response in the larger sample was independent of school's denomination, educational level, subject department, and initial implementation of the AIDS curricula. Variance in teachers' curriculum adoption accounted for by the research model was restricted by high correlations among predictors. Although our primary interest was not to test the model's validity, some inter-correlation might be indicative for more complex structures. For example, the common variance between subjective norms and instrumentality suggests that social referents may also provide standards for teachers judgement about the applicability of a curriculum. Furthermore, adoption of these curricula does not necessarily predict accurate implementation, while conclusions about the antecedents are still tentative since they are based on crosssectional data. Future longitudinal or intervention studies are needed to validate the ordering of predictors, and clarification of which variables best facilitate the transition to the stage of implementation. 


\section{Implications}

Some reservations have to be made about diffusing the AIDS curricula because none of them has been evaluated on the student level. This is of specific concern since teachers are invited to invest in modifications of their classroom practices, while lacking enough procedural clarity and a grounded perspective for affecting students' behaviors. In these situations teachers may end up with scepticism and distrust about the innovation and its advocates, not because they think AIDS education is undesirable as a goal, but because the implementation process turned out to be frustrating (Fullan, 1991*).

On the condition that the materials have the potential of guiding teachers through adoption and implementation of effective HIV instruction, enhancing awareness-knowledge about the curricula would be the first and most cost-effective step to take. Not only because awareness is generally low, but also because, when informed, many teachers had decided to use a curriculum. The reach of written communication should be enhanced by addressing information personally, or at least to teachers' subject department (Stokking \& Leenders, 1992).

Perceived normative and practical constraints for adoption can be anticipated by integrating video-based modeling into mass media promotion activities (cf. Bandura, 1986; Parcel et al., $1989^{\mathrm{b}}$ ). Teachers' beliefs may become more congruent with the curricula by observing role model(s) demonstrating short term benefits, effective use, and positive student outcomes. Short term benefits can be made salient by demonstrating students' success in discussing sexuality, and their enjoyment or active involvement in the proposed activities. Anticipated practicality will be enhanced by demonstrating requisite teacher skills for talking about sexuality, as well as for applying student-centered- and management strategies that influence students' attitudinal and skillrelated outcomes.

When redesigning the curricula, learning objectives should not only be matched with sound learning theory, but also with a 'practice-based' frame of reference providing procedural clarity about subsequent courses of action for teacher planning (Van den Akker, 1988; Fullan, 1991²). Before large-scale diffusion, critical barriers for adoption can be detected by linking curriculum designers to representatives of the user system (cf. Orlandi et al, 1990). Together with carefully applied pre-testing procedures, this linking approach will provide leads for passing teachers' 'practicality ethic' or for segmentation according to their differential ideological concerns, during the stage of curriculum development. Overt involvement of the practice-based community may also induce positive norm setting. After all this approach appeared to have yielded its profits with the development of Curriculum B. Before its release, significantly less Protestant schools provided AIDS education than Catholic or Public schools (Mellink, 1989). Three years later, at the time of the present survey, these differences seem to be no longer prevalent (see Chapter 3).

When also anticipating actual implementation, we better not only think about curriculum development and mass media diffusion. Direct personal assistance prior and during implementation 
appears to be imperative for maximum success; especially in case important social referents within teachers' environment provide standards for adoption that might be counter-productive (Crandall, 1989; Fullan, 1991"; Cousins \& Leithwood, 1993). However, it appeared that most respondents intending to provide AIDS education still not had personal contact with external consultants (local health/sex educators). And when they had, or attended to locally provided workshops, it hardly improved teachers' awareness or adoption of available curricula. It confirms that not the availability of these facilitating conditions per se, but the quality with which they are provided is most critical to teachers' innovation-decision making. The mere provision of information, one-shot workshops, or occasional visits by external consultants, have frequently shown to fall short in meeting the affective, cognitive, and skill-related needs of teachers involved in the process of curriculum innovation (Crandall, 1984; Fullan, 1991'). According to Crandall's review of the literature, additional followup assistance by linking agents will be necessary, and should combine: (1) good solid training, demonstration (direct modeling), and ongoing coaching, (2) promotion of cooperation and collegiality through user networks, and (3) communication of a realistic time frame along with expectations that it will be used to identify and solve problems that may arise during implementation. 


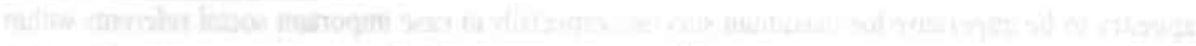

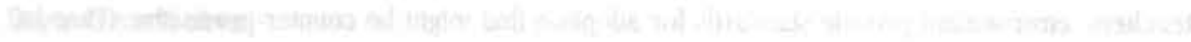

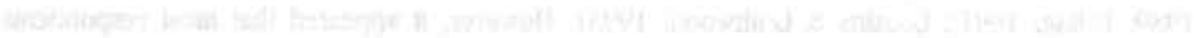

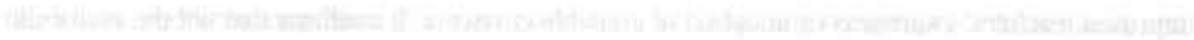

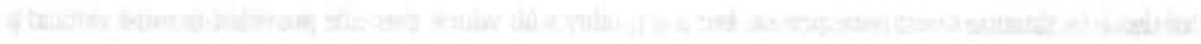

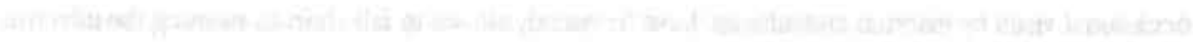

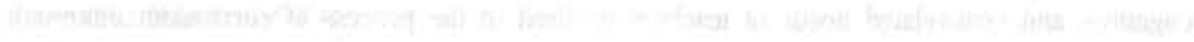
Whith:

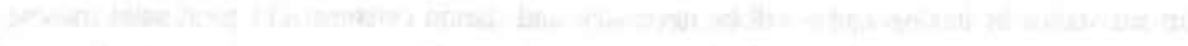

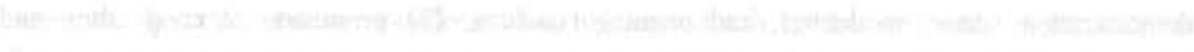

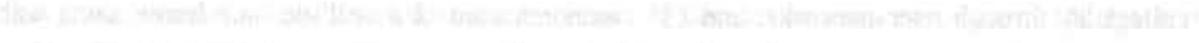

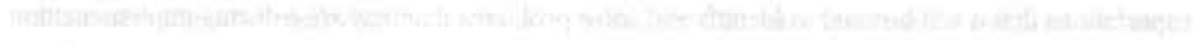


Chapter 5

\section{Implementation of AIDS curricula by Dutch secondary school teachers}

Submitted for publication as: Paulussen, Th.G. F., Kok, GJ. E Schaalma, H.P. Implementation of AJDS curricula by Dutch secondary school teachers. 


\section{Abstract}

This study reports on the antecedents to implementation of three nationally disseminated AlDS curricula by Dutch secondary scbool teachers $(N=388)$. Extent and levels of use of these exemplary materials appeared to be most strongly related to specific curriculum-related beliefs: perceived instrumentality, personal benefits, self-efficacy and subjective norms. It is concluded that the implementation process of HIV instruction should be facilitated by (1) exemplary materials that are both theoretically and practically valid, (2) close collaboration between curriculum designers, linking agents, and teachers, (3) focused mass media promotion, and (4) access to in-person assistance.

\section{Introduction}

Recommendations for classroom AIDS education improvement usually tend to emphasize the efficacy of instruction: AIIS curricula should be based on empirically validated determinants of adolescents' risk behavior and sound learning theory (Kirby, 1992; Schaalma et al., 1993). As yet, these suggestions appear to underestimate the rather critical linkage between development, diffusion, and implementation. The impact of efficacious curricula will be limited if they are not properly disseminated and fail to take into account the social and psychological predispositions of teachers who are expected to use them (Crandall, 1989; Fullan, 1991³ Cousins \& Leithwood, 1993). This paper focuses on the antecedents to teachers' implementation of three AIDS curricula disseminated among secondary schools in the Netherlands since 1989 (Table 5.1). Two years after their initial release, data were gathered in more or less naturalistic teaching settings: apart from written mass media promotion, no systematic diffusion strategies were applied.

The AIDS curricula were not targeted at specific teaching subjects. Development of Curriculum B resulted from Protestant schools' opposition toward Curriculum A. According to their representatives, Curriculum A too narrowly focused on AIDS and condom use. Therefore, Curriculum B places HIV prevention in a broader context of norms and values constituting intimate relationships; AIDS/STDs receives only minor attention. Curriculum $\mathrm{C}$ was designed for higher educational levels, and is not accompanied by a dramatized video. 
Table 5.1. Characteristics of four nationally disseminated AIDS education curricula.

\begin{tabular}{|c|c|c|c|}
\hline & Curriculum A & Curriculum B & Curriculum C \\
\hline Products & $\begin{array}{l}\text { - student magazine } \\
\text { - teacher manual } \\
\text { - video }\end{array}$ & $\begin{array}{l}\text { - student magazine } \\
\text { - teacher manual } \\
\text { - video }\end{array}$ & $\begin{array}{l}\text { - student magavine } \\
\text { - teacher manual } \\
\text { (no video) }\end{array}$ \\
\hline Target group & all secondary schools & $\begin{array}{l}\text { all Protestant } \\
\text { secondary schools }\end{array}$ & $\begin{array}{l}\text { senior general and } \\
\text { pre-university schools }\end{array}$ \\
\hline \# lessons & 4 lessons & 6 lessons & $\begin{array}{l}8 \text { lessons ( } 4 \text { basic and } 4 \text { opt- } \\
\text { onal) }\end{array}$ \\
\hline Content & $\begin{array}{l}\text { AIDS: testing, safe sex, } \\
\text { purchase/use condoms, } \\
\text { anti-discrimination }\end{array}$ & $\begin{array}{l}\text { intimate relationships: } \\
\text { attractiveness, love, sexuality }\end{array}$ & $\begin{array}{l}\text { STD/AIDS: response to STD- } \\
\text { infection, purchase/use con- } \\
\text { doms, anti-discrimination }\end{array}$ \\
\hline $\begin{array}{l}\text { Learning } \\
\text { objectives }\end{array}$ & $\begin{array}{l}\text { knowledge, values, } \\
\text { communication skills }\end{array}$ & norrns and values & $\begin{array}{l}\text { knowledge, values, } \\
\text { communication skills }\end{array}$ \\
\hline $\begin{array}{l}\text { Learning } \\
\text { activities }\end{array}$ & $\begin{array}{l}\text { group discussions, role- } \\
\text { play, questionnaire, demon- } \\
\text { stration, buying condoms }\end{array}$ & $\begin{array}{l}\text { group discussions, reading } \\
\text { articles, optional creative as- } \\
\text { signments }\end{array}$ & $\begin{array}{l}\text { group discussions, role-play, } \\
\text { demonstration, buying con- } \\
\text { doms, writing assignments }\end{array}$ \\
\hline
\end{tabular}

\section{Theoretical framework}

The research framework (see Figure 5.1) $)^{2}$ was developed upon the prenise that teachers' construction of meaning of a curriculum innovation is decisive for its accep-tance (cf. Doyle \& Ponder, 1977-78; Fullan, 1991 ${ }^{2}$; Cousins \& leithwood, 1993). All the more so because AIDS/sex education in Dutch secondary schools are not mandated by any external authority.

The Theory of Planned Behavior (Ajzen, 1991) provided the basis for structuring the research framework. According to the model presented in Figure 5.1, teachers' processing of information about the AIDS curricula will induce specific action-related attitudinal, normative, and control beliefs (self-efficacy; Bandura, 1986). These belief structures will directly affect utilization and mediate the impact of other factors. Research on curriculum innovations, teacher planning and knowledge utilization was reviewed to further specify the model's constructs.

The rational for ignoring other factors in the overall framework is described in the introduction to the results section of Chapter 1 . 


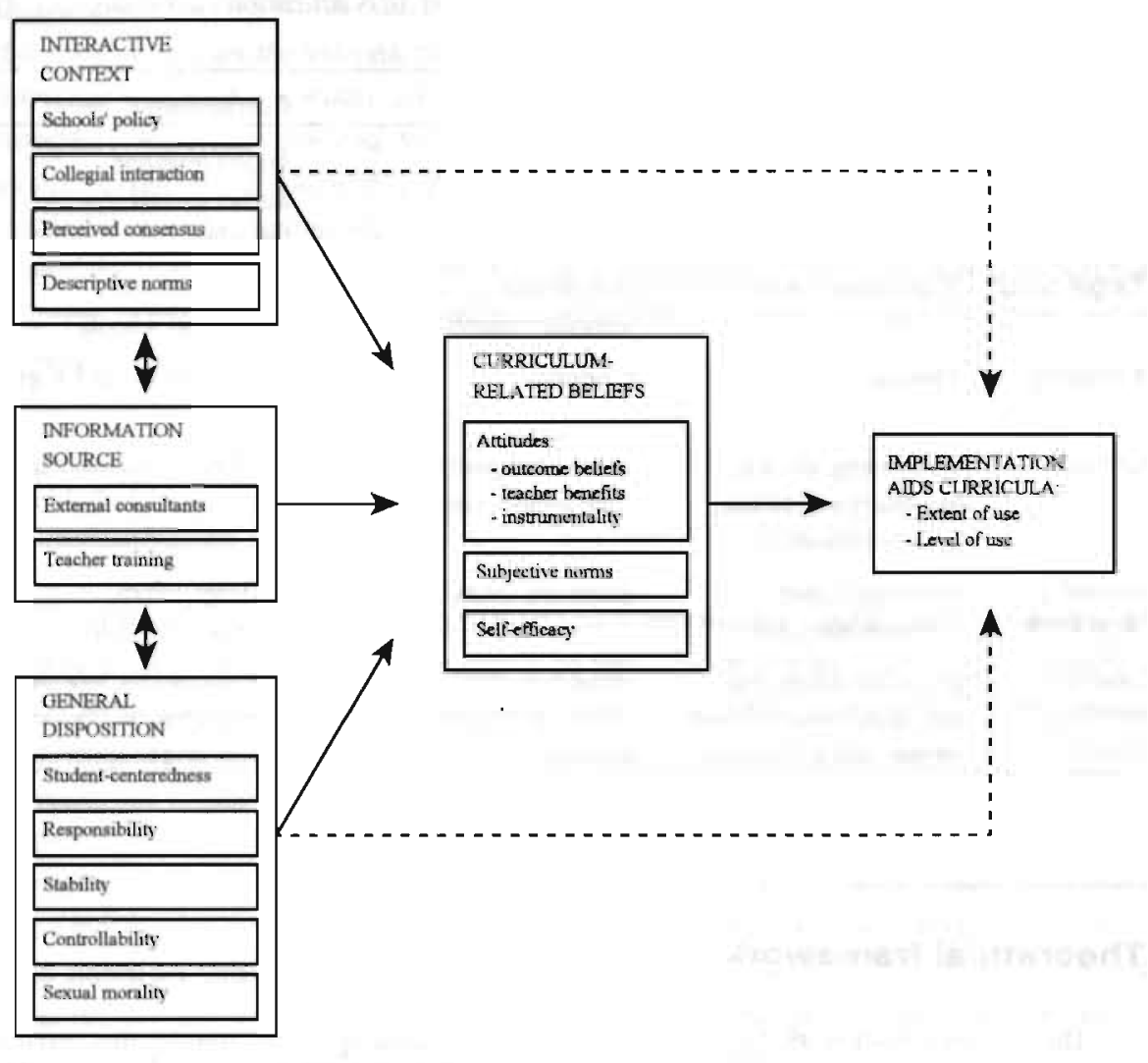

Figure 5.1. Model for explaining teachers' implementation of exemplany AIDS curricula.

\section{Dependent variables}

Implementation is generally conceived of as a multidimensional and multilevel concept (Hall \& Loucks, 1978; Leithwood, 1981). It may not only vary by extent, but also by frequency, intensity, or duration (Tillema et al., 1989 $9^{\mathrm{b}}$ ). Hall and Loucks (1978) distinguished seven levels of use ranging from nonuse, via mechanical use to renewal. These and other attempts to refine levels of use still did not arrive at acceptable measurement procedures (Larsen, 1981; Rich, 1991). Moreover, validation studies only seem to confirm: (1) nonuse, (2) partial use, users select portions which are appropriate, (3) full use, exactly in the form as presented to the users, and (4) adaptive use, users adapt the information to fit their own needs (cf. Tillema et al., 1989 ${ }^{b}$ ). Utilization researchers have discerned these 'instrumental' (observable) aspects of use from 'conceptual use' since new information may also have a diffused impact on users thinking about the subject (Larsen, 1981; Rich, 1991). The dependent variables used in this study are restricted to extent of use and level of 
use. Conceptual use was ignored since it can as well be conceived of as an independent variable, and would, for example, largely overlap the teacher benefits construct.

\section{Curriculum-related beliefs}

Doyle \& Ponder (1977-78) posited that teachers' judgements about classroom innovations are essentially based on perceived instrumentality, congruence, and costs. The curriculum-related attitudinal constructs for this study incorporate these criteria. Outcome beliefs represent teachers' perceived feasibility and importance of student learning outcomes as proposed by the curriculum (congruence). Instrumentality refers to whether the curriculum meets teacher's primary planning concerns: clarity of procedural referents, time/ease of pre-active planning (investment), and student reactions to the curriculum activities (interest, enthusiasm; Doyle \& Ponder, 1977-78; Clark \& Peterson, 1986). Teacher benefits account for perceived outcomes favoring the teacher (e.g. recognition by students, insight in ways to improve own education efforts).

Behavioral change may not only be directed by valued outcomes, but also by self-efficacy (Bandura, 1986). Teachers' self-efficacy appears to be positively related to student achievement (Ashton \& Webb, 1986; Midgley et al., 1989), and application of innovations (Stein \& Wang, 1988; Smylie, 1988).

Perceived subjective norms accounts for the impact of social referents in teachers' task environment providing normative standards for their instructional planning (Smylie, 1988; Crandall, 1989; Fullan, 19913).

\section{Exogenous model variables}

Ajzen (1991) recently discussed that more generic dispositions, like feelings of moral obligation and responsibility to perform, may additionally contribute to the model's prediction. Levenson-Gingiss and Hamilton (1989) found that teachers' willingness to continue providing a sex education course was positively related to perceived responsibility and a permissive sexual morality. Teachers' attributions for the causes of student performance are also assumed to influence their decisions about goals, activities and classroom management strategies (cf. Weiner, 1985; Clark \& Peterson, 1986). The same accounts for teachers' long-term goal-orientations: as opposed to teacher-centeredness, student-centered teachers tend to be more open to new ideas, express more. responsibility for student learning, and reduce teacher-student social distance (Victor \& Otis, 1980; Ames, 1983).

Frequency of collegial interaction and participative decision making have been shown to facilitate innovation implementation (Huberman \& Miles, 198fi; Crandall, 1989). Shared visionbuilding may contribute to clarity about related practices and incorporation into the school's formal policy (Smylie, 1988). Perceived colleague behavior may additionally operate as a descriptive norm (Grube et al., 1986), especially when these favorable climate conditions are absent.

Face-10-face contacts with extemal consultants are generally assumed to exceed over the impact of mass media diffusion of innovations (Rogers, 1983; Crandall, 1989; Fullan, 1991²). In- 
service training, if properly designed, may additionally improve classroom implementation (Joyce \& Showers, 1988).

\section{Methods}

\section{Subjects}

Teachers were selected from a sample of 988 secondary schools. The school principal was contacted to distribute one questionnaire in each of the following departments: biology, social studies, religious education, and health education (if present). In sum, 956 teachers (27\%) from 532 schools (54\%) completed the questionnaire satisfactorily (see Chapter 3 ). About $68 \%$ reported providing classroom ADS education. The present analyses were applied to those respondents (60\%) who had used any of the three nationally disseminated AIDS curricula $(N=388)$.

\section{The questionnaire}

Teachers' responded to the implementation indices and curriculum-related beliefs for each curriculum separately. Outcome beliefs and self-efficacy statements were validated by the curriculum designers. Cronbach's $\alpha$ was used to test the reliability of scaled variables.

Currtculum implementation. Extent of use was measured as the applied proportion of all learning, activities proposed by the curriculum. The level of use index was adapted from Tillema et al. $\left(1989^{\mathrm{b}}\right)$, consisting of five hierarchically ordered descripiors representing: (1) partial use, like: "I am using some of the ideas provided by the curriculum, but others are disregarded," (2) full use, like: "I am making full use of the curriculum, mostly in a form as prescribed," and (3) adaptive use: "I am making full use of the curriculum, and, because of my increased mastery, 1 am able to modify it in a form to better fit my and my pupils' needs." Respondents selected the option that best corresponded to their level of use.

Curriculum-related beliefs. Outcome beliefs were measured as a weighted result of perceived feasibility and importance of the learning outcomes proposed by the curriculum, using seven to nine 5-point scaled items. Internal-consistency values varied from $\alpha=.80$ (Curriculum $B$ ) to $\alpha=.85$ (Curriculum $\mathrm{C}$ ). Instrumentality was assessed by thirteen 5 -point-scaled items, such as: "The materials do provide clearly structured procedural information about content, objectives and activities," "The time necessary for preparing classroom instruction is acceptable," or "Students will be motivated to participate in the proposed learning activities." The $\alpha$-values varied from $\alpha=.74$ (B) to $\alpha=.79$ (A). Teacher benefits were indexed by nine 5-point-scaled items, such as: "Utility of this curriculum increased my insight in improving school-based AIDS education," or "... in ways to 
improve my interactive teaching skills with assistance from external health educators." The $\boldsymbol{\alpha}$-values varied from $\alpha=82$ (B) to $\alpha=.90$ (A).

Regarding subjective norms, teachers responded to the normative beliefs of students, the principal, school board, colleagues in their own and other subject departments, external consultants, and parents. Normative beliefs were weighted by teachers' motivation to comply to these referents; $\alpha$-values varied from $\alpha=.69$ (C) to $\alpha=.77$ (B).

Self-efficacy was assessed by fourteen to seventeen 5-point scaled items, covering four skillrelated domains: (a) application of interactive teaching strategies, (b) talking frankly about sexuality, (c) adaptation of AIDS content to own educational context, and (d) application of management strategies for creating a minimal level of classroom orderliness and safety. The $\alpha$ values varied from $\alpha=.74$ (C) to $\alpha=.85$ (A).

Exogenous model vartables. Student-centeredness was indexed on ten 5-point scaled items adapted from Den Hertog $(1990 ; \alpha=80)$. Teachers' sexual morality was indexed on fourteen 5point scaled items adapted from Luijkx et al. (1987; $\alpha=.86$ ). Two dimensions of teachers' attributional style were measured. Three 4-point scaled items assessed teachers' perceived stability and controllability of factors they assumed to cause students' lack of knowledge, negative attitudes and lack of social skill toward AIDS preventive behaviors ( $\alpha=69$ and $\alpha=.70$, respectively). Sense of responsibility toward providing AIDS education was assessed by seven 5-point scaled items $(\alpha=.71)$.

Regarding school policy, teachers indicated whether the outline of content and orga-nization of ADS education was formally prescribed by the school work plan. A 6-point scaled item assessed the frequency of collegial interaction about HIV instruction. A 5-point scaled item assessed their perceived consensus with colleagues about goals and requirements for AIDS education. Regarding descriptive norms, teachers reported the AIDS curriculum used by their colleagues.

Teachers named the sources from which they received information about the curricula, and were divided into two categories afterwards: written communication (e.g. publishers' overviews, direct mail), versus personal communication (e.g. with local health educators). Teachers also reported whether they had attended to in-service training on AIDS/sex education.

Finally, respondents reported their age, religious affiliation, gender, years of teaching experience, subject area, school's denomination, and educational level. Educational levels were classified into junior level (junior vocational and junior general secondary education), and senior level (senior general and pre-university education). 


\section{Results}

\section{Sample description}

About $60 \%$ of the respondents taught in junior, and $40 \%$ in senior secondary levels. Thirty-two percent taught in Public, 36\% in Catholic, and 32\% in Protestant schools. Teachers of four subject areas were represented: biology $(38 \%)$, social studies $(35 \%)$, religious education $(9 \%)$, and a category 'he/counselors' (19\%, consisting of health educators and student counselors). Males comprised $69 \%$ of the sample and females $31 \%$. Mean age was 42 years ( $s d=7.09$ ). Years of teaching experience varied from 1 to 38 years $(\bar{x}=17 ; s d=7.44)$. Religious affiliation was divided into: Roman Catholic (30\%), Protestant (29\%), 'others' (7\%), and 'no affiliation' $(33 \%)$. Sixty-two percent never participated in in-service training on AIDS/sex education.

\section{Implementation}

Most teachers initially implemented Curriculum A ( $58 \%, n=224)$, followed by Curriculum B (26\%, $n=101)$, and Curriculum C $(16 \%, n=63)$. Relatively more teachers from Protestant schools $\left(48 \%, \chi^{2}(4)=41.48, p<.001\right.$ ), and those who were personally convicted to Protestantism ( $45 \%$, $\left.\chi^{2}(4)=28.13, p<.001\right)$, had used Curriculum $B$. The same accounts for teachers in religious education $(51 \%$ ), while Curriculum A was relatively more prevalent among teachers in biology and social sciences ( $66 \%$ and $61 \%$, respectively) and Curriculum $C$ among teachers in the category 'he/counselors' $\left(32 \%, \chi^{2}(6)=30.28, p<.001\right)$. Past implementation was unrelated to teachers' age, teaching experience, and educational level.

Extent and levels of use were rather moderate. Teachers had used an average of $44 \%$ ( $\mathrm{sd}=19.30$ ) of all learning activities proposed by Curriculum A. Mean extent of use of Curriculum B was $47 \%$ ( $\mathrm{sd}=17.40)$, and $42 \%$ in case of Curriculum $\mathrm{C}(\mathrm{sd}=14.60)$. Most teachers had applied the rather passive forms of leaming. For example, the percentage of teachers who implemented the video-based activities in Curriculum A and B varied from $75 \%$ to $85 \%$. They, however, tended to disregard skill-oriented activities (e.g. role-play), small group discussions, (condom) demonstration, extra-classroom activities (e.g. purchase of condoms); percentages varied from $8 \%$ to $24 \%$. As with extent of use, levels of use of Curriculum B were slightly higher. Mean level of use of Curriculum $B$ approximated full use $(\bar{x}=2.78, s d=1.33)$, whereas levels of use of $A(\bar{x}=2.32, s d=1.21)$ and $C(\bar{x}=2.33(s d=1.24)$ were closer to the level of partial use.

\section{Antecedents to implementation}

Antecedents to extent and level of use were analyzed by stepwise multiple regression. Only factors that significantly correlated with the criterion (Pearson's [ , p<.05) were considered for entrance (Table 5.2). Predictors were entered according their theoretically expected order: curriculum-related beliefs first, followed by exogenous model variables and demographics, respectively. Descriptive norms, in-service training, perceived stability, educational level, age, 
gender, religious affiliation, and teaching experience are absent in Table 5.2 because they not significantly correlated with the implementation indices.

Extent of use. Curriculum-related beliefs appeared to be most strongly associated with extent of use. Perceived instrumentality significantly correlated with all these indices, varying from $r=.39$ (A) to $\underline{r}=.43(\mathrm{C})$. Teachers using Curriculum B seemed more satisfied with its instrumental content $(\overline{\mathrm{x}}=.87)$, than those using $\mathrm{A}(\overline{\mathrm{x}}=.62)$ or $\mathrm{C}(\overline{\mathrm{x}}=.73)$. This also accounts for teacher benefits: teachers using B generally expected more favorable personal outcomes $(\bar{x}=12)$, than teachers using $A$ $(\overline{\mathrm{x}}=-.06)$ or $\mathrm{C}(\overline{\mathrm{x}}=-.01)$. Outcome beliefs and perceived subjective norms were only related to extent of use of Curriculum A and B. Self-efficacy corresponded to extent of use of Curriculum A and C.

Instrumentality entered all, and outcome beliefs entered none of the regressions on extent of use. Self-efficacy accounted for a significant proportion of unique variance in extent of use of Curriculum $A$ and $C$. Perceived subjective norms and teacher benefits entered the regression on extent of use of Curriculum B and $C$, respectively. The proportion of variance in extent of use accounted for by the curriculum-related beliefs appeared to be $30 \%$ (A), 22\% (B), and $27 \%$ (C).

Schools' formal policy and frequency of collegial interaction additionally entered the regression on extent of use of Curriculum $C$ and $A$, respectively. Sexual morality accounted for a significant proportion of unique variance in extent of use of Curriculum A. A multivariate impact of personal contacts with external consultants was only found among teachers using Curriculum B. Teachers in Catholic schools using B and C tended to apply a broader range of activities than teachers in Protestant schools. The final regression models accounted for $35 \%$ of variance in extent of use of A, $36 \%$ in case of $B$, and $42 \%$ in case of $C$.

Level of use. Levels of use were also best 'explained' by curriculum-related beliefs: $20 \%$ (Curriculum A), 20\% (B), and 17\% (C). Perceived instrumentality appeared to be a major determinant of level of use of Curriculum B and C. In contrast to extent of use, teacher benefits entered the regression on level of use of $B$, while a multivariate impact of subjective norms was no longer prevalent. Teacher benefits also accounted for variability in level of use of $A$, whereas the entrance of instrumentality seemed to be suppressed by its common variance with perceived subjective norms.

Perceived controllability and schools' policy additionally accounted for differential levels of use of Curriculum A. Again, teachers in Protestant schools reported lower, and teachers in Catholic schools significantly higher levels of use of Curriculum B. Although teachers in biology also reported a relatively lower extent and level of use of $A$, they only improved the regression on level of use of $C$ $(\beta=-27)$. The final models accounted for $26 \%$ of variability in level of use of $A, 25 \%$ in case of $B$, and $25 \%$ in case of $\mathrm{C}$. 
Table 5.2. Stepwise regression analyses on teachers' extent and level of use of separate AlDS curricula: mean ( $\vec{x}$ ), zero-order correlations ( $\boldsymbol{V}$ ), and $\beta$ weights

\begin{tabular}{|c|c|c|c|c|c|c|c|c|c|c|c|c|c|c|c|}
\hline & \multicolumn{5}{|c|}{ Curriculum A $(n=224)$} & \multicolumn{5}{|c|}{ Curriculum B (n=101) } & \multicolumn{5}{|c|}{ Curriculum $C(n=63)$} \\
\hline & \multirow[b]{2}{*}{$\bar{x}$} & \multicolumn{2}{|c|}{ Extent of use } & \multicolumn{2}{|c|}{ Level of use } & \multirow[b]{2}{*}{$\bar{x}$} & \multicolumn{2}{|c|}{ Extent of use } & \multicolumn{2}{|c|}{ Level of use } & \multirow[b]{2}{*}{$\overline{\mathbf{x}}$} & \multicolumn{2}{|c|}{ Extent of use } & \multicolumn{2}{|c|}{ Level of use } \\
\hline & & $\underline{\mathbf{r}}$ & $\beta$ & $\underline{\mathbf{r}}$ & $\beta$ & & $\underline{r}$ & $\beta$ & $\underline{\mathbf{r}}$ & $\beta$ & & $\underline{\mathbf{r}}$ & $\beta$ & $\underline{\mathbf{r}}$ & $\beta$ \\
\hline \multicolumn{16}{|l|}{ Curriculum-related beliefs } \\
\hline Outcome beliefs $(1 / 25)$ & 14.24 & $.31^{* * * *}$ & n.s. & $.24^{* * * *}$ & n.s. & 12.66 & $.18^{*}$ & n.s. & $.28^{* * * *}$ & n.s. & 14.34 & n.s. & - & n.s. & -- \\
\hline Teacher benefits $(-2 / 2)$ & -.06 & $.34^{* * *}$ & $.24^{* * * *}$ & $.36 * *$ & $.24^{* * * *}$ & .12 & $.21^{*}$ & n.s. & $.32 * * *$ & $.20^{*}$ & -.01 & $.24^{*}$ & n.s. & $.32 * *$ & n.s. \\
\hline Instrumentality $(-2 / 2)$ & .62 & $39^{* * *}$ & $.21 *$ & $32^{* * *}$ & n.s. & .87 & $.42^{* * *}$ & $.28^{* *}$ & $.41^{* * * * *}$ & $.33^{* * *}$ & .73 & $.43^{* * * *}$ & $.31 * *$ & $.41^{* * *}$ & $.40^{* * *}$ \\
\hline Subjective norms $(-8 / 8)$ & 1.55 & $34^{* * * *}$ & n.s. & $.35^{* * *}$ & $.25^{* * * *}$ & 2.26 & $.40^{* * * *}$ & $.21^{*}$ & $.33^{* * * *}$ & n.s. & 1.55 & n.s. & - & $.22^{*}$ & n.s. \\
\hline Self-efficacy $(-2 / 2)$ & .44 & $40^{* * * *}$ & $23^{*+* * *}$ & $21^{* * *}$ & n.s. & .61 & n.s. & - & n.s. & - & .47 & $.40^{* * *}$ & $.33^{* *}$ & n.s. & - \\
\hline \multicolumn{16}{|l|}{ Interactive Context } \\
\hline Schools' policy' & -. & n.s. & -- & $.20^{* * *}$ & $.16 * *$ & - & $.29^{* * * *}$ & n.s. & $.21^{*}$ & n.s. & - & $.22 *$ & $.23^{*}$ & n.s. & - \\
\hline Collegial interaction $(0 / 5)$ & 1.60 & $.12^{*}$ & $.12^{*}$ & n.s. & - & 1.54 & n.s. & - & n.s. & -- & 1.73 & $.21^{*}$ & n.s. & n.s. & - \\
\hline Perceived consensus $(-2 / 2)$ & .58 & $.19^{* * * *}$ & n.s. & $.12^{*}$ & n.s. & .47 & n.s. & -- & n.s. & - & .37 & n.s. & - & n.s. & - \\
\hline \multicolumn{16}{|l|}{ General dlsposition } \\
\hline Sexual morality $(-2 / 2)$ & .74 & $.25^{* * *}$ & $.19^{* * * *}$ & n.s. & -- & .37 & $.26^{* *}$ & n.s. & n.s. & -. & .76 & n.s. & -- & n.s. & - \\
\hline Student-centeredness $(-2 / 2)$ & .97 & $.25^{* * *}$ & n.s. & $.21^{* * *}$ & n.s. & 1.14 & n.s. & -- & n.s. & -. & 1.02 & n.s. & - & n.s. & - \\
\hline Controliability (1/4) & 2.72 & $.22^{* * *}$ & n.s. & $.27^{* * * *}$ & $.18^{+\infty}$ & 2.68 & n.s. & - & n.s. & .- & 2.84 & $.28^{\text {now }}$ & n.s. & n.s. & - \\
\hline Responsibility (-2/2) & 1.43 & $.24^{m * *}$ & n.s. & $.24^{* * * *}$ & n.s. & 1.34 & n.s. & -- & n.s. &.- & 1.49 & n.s. & - & n.s. & - \\
\hline \multicolumn{16}{|l|}{ Information source } \\
\hline Extemal consultants' & - & $.18^{* *}$ & n.s. & n.s. & -- & -- & $.27^{* *}$ & $.27^{* *}$ & n.s. & -- & - & n.s. & - & n.s. & - \\
\hline \multicolumn{16}{|l|}{$\begin{array}{l}\text { Demographics } \\
\text { Schools' denomination' }\end{array}$} \\
\hline Public & -. & n.s. & - & n.s. & - & - & n.s. & - & n.s. & -. & - & n.s. & -- & a.s. & - \\
\hline Catholic & - & n.s. & -- & n.s. & -- & -- & $.28^{* * *}$ & $.23^{* * *}$ & $.21^{*}$ & $.23^{* *}$ & -- & $.33^{* * *}$ & $.34 * * *$ & n.s. & - \\
\hline Protestant & - & n.s. & -- & n.s. & - & - & $-.21 * *$ & n.s. & $-.23^{* *}$ & n.s. & - & $-.21^{*}$ & n.s. & n.s. & - \\
\hline \multicolumn{16}{|l|}{ Teaching subject' } \\
\hline Biology & -. & $-.14^{*}$ & n.s. & $-.11^{*}$ & n.s. & - & n.s. & - & n.s. & -- & -- & n.s. & - & $-.28^{* *}$ & $-.27^{*}$ \\
\hline Social studies & -- & $.12^{*}$ & n.s. & n.s. & n.s. & - & n.s. & - & n.s. & -- & - & n.s. & -- & n.s. & - \\
\hline Religious education & -. & n.s. & - & n.s. & -- & -- & n.s. & - & n.s. & -- & -- & n.s. & - & n.s. & - \\
\hline He/counselor & -- & $.13^{*}$ & n.s. & n.s. & - & - & n.s. & - & n.s. & -- & -- & $.24^{*}$ & n.s. & $.30^{* *}$ & n.s. \\
\hline Multiple R & & \multicolumn{2}{|c|}{$\mathrm{R}=.59$} & \multicolumn{2}{|c|}{$\mathrm{R}=.51$} & & \multicolumn{2}{|c|}{$R=.60$} & \multicolumn{2}{|c|}{$\mathrm{R}=.50$} & & \multicolumn{2}{|c|}{$R=.65$} & \multicolumn{2}{|c|}{$\mathrm{R}=.50$} \\
\hline
\end{tabular}

" $p<.05 ; *{ }^{* *} p<.01 ; * \cdots p<.001 ; '$ Dummy variables coded as deviation contrasts. 


\section{Discussion}

The results indicated that curriculum implementation was more attributable to specific actionrelated beliefs than to global personality traits, school- or demographic factors. This was confirmed by additional regression analyses using a free format for entrance. Anticipated instrumentality, personal benefits, self-efficacy and subjective norms appeared to be vital to teachers' processing of innovation information disseminated by these ADS curricula.

Perceived instrumentality was most determinative for curriculum implementation. Close examination of the scale-items showed that most respondents believed the materials to be instrumental for reaching the learning outcomes, and that the curriculum activities were based on sound learning theory. However, the materials appeared to have left teachers with uncertainty about classroom procedures and students' response to the proposed activities (interest, enthusiasm). This confirms the prevailing findings in research on teacher planning indicating the primacy of content and activities, rather than objectives (Clark \& Peterson, 1986; Borko et al., 1990). The limited impact of the outcome belief constructs also suggests that valued objectives will at best partially affect implementation. Implementation seemed to be more directed by short-term rewards (normative or personal) and self-efficacy.

Although, assessments of teacher benefits were generally moderate, high implementation teachers reported more improvement in teacher-student relations and in insight in the essentials of HIV instruction that may also be worthwhile applying to other content areas. It underscores that early rewards and some tangible success are critical incentives for curriculum change (Fullan, $\left.1991^{\prime 2}\right)$.

Non-compliance to (parts of the) curriculum activities may also refer to teachers' need for a shared frame of reference. When facing performance ambiguity, individuals generally tend to gain approval by conformity to majority positions of referents within their task-environment; even objectively erroneous ones (Nemeth \& Staw, 1989). It may explain why students, colleagues, and the principal best constituted teachers' perceived subjective norms. Moreover, in case of uncertainty, individual decision makers tend to mistrust external information sources (Rich, 1991), and may explain why only few respondents contacted extemal consultants, and why this hardly impacted utilization.

Regarding self-efficacy, teachers generally did not anticipate problems with adapting ADS content to student needs or experiences. Implementation seemed to be more constraint by perceived comfort in talking about sexuality with students, applying interactive classroom activities, and controlling disruptive student behaviors.

The present results only apply to Dutch secondary teachers in four subject areas who had used three nationally disseminated ADS curricula. Implementation prevalence may be accurate for these teacher groups since the rather low response to the initial sample (27\%) from which the present subjects were drawn, did not appear to be affected by use/nonuse of the AIDS curricula. Conclusions 
are, however, still rather tentative because they are based on cross-sectional data. Longitudinal data are needed to explore the ordering of variables which are most important for improving implementation. The dependent variable(s) might also be prone to criticism (Rich, 1991). This is best illustrated by Larsen (1981) asserting: "Utili-zation is to a great extent a function of the operational definition used". The results appear to confirm this; both implementation indices were not always related to the same set of variables. Besides, we disregarded other purposes of use which may also have facilitated desirable outcomes. For example, the curricula may have been used to raise the issue, to formulate new policies, to evaluate alternative practices, to mobilize support (Rich, 1991). Future research needs to clarify wether these outcomes can validly be conceptualized as dependent variables.

\section{Implications}

Implications need some qualification because none of the ADS curricula has been systematically evaluated on the student level. Given the practical problems teachers appeared to be facing, while the disseminator of the curricula still can not legitimize teachers' investment in some thorough modifications of their classroom practices, it seems throughout rational that many teachers have only implemented rather superficial changes (Fullan, 1991 ${ }^{3}$ ).

The AIDS curricula may need improvement to better meet teachers' need for practicality. Leads for redesigning the materials can be derived from experimental work in the field of science education. Van den Akker (1988) illustrated that teachers' learning about a curriculum innovation was induced by materials that (1) stimulated teachers to a pre-active 'internal dialogue' about their teaching role (e.g. by asking questions about one's own situation, suggesting trials with unfamiliar elements, structuring expectations about possible student reactions), and that (2) provided clear advice about classroom procedures (e.g. by estimation of time, and by suggestions for grouping, distribution of tasks, or for variations of responses during classroom interaction).

However, since teachers usually do not fully comply to externally developed curriculum guidelines, even where strict adoption is recommended, either exclusively "top-down" or "bottomup" approaches will fail to meet the implementation impediments (Crandall, 1989; McLaughlin, 1990; Cousins \& Leithwood, 1993). By strengthening the linkage between development, diffusion, and utilization, curriculum designers will be better equipped to bridge the gab between knowledge that is theoretically sound and practically valid (Orlandi et al., 1990; Rich, 1991). Carefully applied pre-testing procedures will provide additional input of practitioners' feedback infornation before large-scale dissemination. Perceived normative and practical constraints may further be anticipated by integrating (video-based) 'symbolic modeling' into mass media dissemination of the AIDS curricula (Bandura, 1986; Parcel et al., 1989 ${ }^{\mathrm{b}}$ ). After all, peer-teachers generally appeared to be valued sources of innovation information (Fullan, $1991^{2}$ ). Since outcome beliefs hardly appeared to 
affecl curriculum implementation, limited impact can be expected from a promotion strategy that merely communicates the desirability of achieving specific student learning objectives.

Successful implementation policies not only provide access to validated materials, but also arrange for in-person assistance during later implementation (Crandall, 1989; Mclaughlin, 1990). As indicated by the present results, one-shot workshops or occasional visits will fall short in solving skill-related problems (Joyce \& Showers, 1988; Fullan, 1991 ${ }^{2}$ ). According to Crandall's overview (1989), effective follow-up assistance encompasses: (1) solid training, demonstration (direct modeling), and ongoing coaching, (2) promotion of cooperation and collegiality through user networks, and (3) communication of a realistic time frame, that will be used to identify and solve problems that may arise. 


\section{References}

Ajzen, I. (1987). Attitudes, traits, and actions: dispositional prediction of behavior in personality and social psychology. In: Berkowitz, I. (ed), Advances in experimental social psycbology, vol. 20. New York: Academic Press.

Ajzen,I. (1991). The theory of planned behavior. Organizalional Bebavior and Human Decision Processes, 50, 79-211.

Ajzen, I. \& Fishbein, M. (1980). Understanding attitudes and predicting social bebaviour. Englewood Cliffs: Prentice-Hall.

Akker, J.J. van den $\left(1988^{\circ}\right)$. The teacher as learner in curriculum implementation. Journal of Curriculum Studies, 20, 47-55.

Akker, J.J. van den $\left(1988^{b}\right)$. Ontwerp en implementatie van natuuronderwijs (Design and implementation of science education). Amsterdam/Lisse: Swets \& Zeitlinger.

Ames, R. (1983). Teachers' attributions for their own teaching. In: Levine, J.M. \& Wang, M.C. (eds), Teacher and student perceptions: implications for leaming. Hillsdale, NJ: Lawrence Erlbaum.

Anderson, C.A., Jennings, D. \& Amoult, L.H. (1988). Validity and utility of the attributional style construct at a moderate level specificity. Journal of Personality and Social Psychologg, 55, 979. 990 .

Appelhof, P.N. (1989). Implementatie-strategieën voor bet invoeren van curricula in scbolen (Implementation strategies toward the introduction of curricula in scbools). Onderwijskundig lexicon: (E5020-3-E5020-17).

Ashton, T.A. \& Webb, R.B. (1986). Making a difference: teacbers' sense of efficacy and student achievement. New York/london: Longman.

Bandura, A. (1977). Social learning theory. Englewood Cliffs: Prentice-Hall.

Bandura, A. (1986). Social foundations of thought and action: a social cognitive tbeory. Englewood Cliffs: Prentice-Hall. 
Bandura, A. (1989). Perceived self-efficacy in the exercise of control over AIDS infection. In: Mays, V.M., Albee, G.W. \& Schneider, S.F. (eds), Primary prevention of AIDS. Newbury Park: Sage.

Basch, C.E. (1984). Research on disseminating and implementing health education programs in schools. Journal of School Health, 54, 57-66.

Basch, C.E. (1989). Preventing AIDS through education: concepts, strategies, and research priorities Journal of School Health, 59, 296-300.

Basch, C.E., Sliepcevich, E.M., Gold, R.S., Duncan, D.F. \& Kolbe, L.J. (1985). Avoiding type III errors in health education program evaluation: a case study. Healtb Education Quarterly, 12, 315-331.

Basen-Engquist, K. \& Parcel, G.S. (1992). Attitudes, norms, and self-efficacy: a model of adolescents' HIV-related sexual risk behavior. Health Education Quarterly, 19, 263-277.

Becker, M.H. \& Joseph, J.G (1988). AIDS and behavioral change to reduce risk: a review. American Journal of Public Health, 78, 394-410.

Berman, P., Mclaughlin, M., Bass, G., Pauly, E. \& Zellman, G. (1977). Federal programs supporting educational change. Vol. 7: Factors affecting implementation and continuation. Santa Monica, CA: The Rand Corporation.

Berman, P. \& McLaughlin, M.W. (1978). Federal programs supporting educational change: final report. Santa Monica, CA: The Rand Corporation.

Borko, H., Livingston, C. \& Shavelson R.J. (1990). Teachers' thinking about instruction. Remedial and Special Education, 11, 40-49.

Brophy, J.E. \& Evertson, C.M. (1981). Student cbaracteristics and teaching. White Plains, NY: Longman.

Brophy, J, \& Rohrkemper, M.M. (1981). The influence of problem ownership on teachers' perceptions of and strategies for coping with problem students. Journal of Educational Psychology, 73 , 295-311.

Brophy, J. \& Rohrkemper, M.M. (1982). Motivational factors in teachers' handling of problem students. Paper presented at the anmual meeting of the American Educational Research Association, New York. 
Brown, S. \& McIntyre, D. (1982). Influences upon teachers' attitudes to different types of innovation: a study of Scottish integrated science. Curriculum Inquiry, 12, 35-51.

Brucker, B.W., Martin, J.J. \& Shreeve, W.C. (1989). AIDS in the classroom: a survey of teacher attitudes. Early Child Development and Care, 43, 61-64.

Brucker, B.W. \& Hall, W.H. (1991). ADDS in the classroom: are teacher attitudes changing? Early Cbild Development and Care, 77, 137-147.

Bush, P.J., Zuckerman, A.E., Taggart, V.S., Theiss, P.K., Peleg, E.O. \& Smith, S.A. (1989). Cardiovascular risk factors prevention in black school children: the "Know Your Body" Evaluation Project. Health Education Quarterly, 16, 215-227.

Chief Inspectorate of Public Health (1993). Epidemiologie Nederland (Epidemiology in The Netherlands). AIDS Bestrijding (AIDS Prevention), 14, 14.

Clark, C.M. \& Peterson, P.L. (1986). Teachers' thought processes. In: Wittrock, M.C. (ed), Third bandbook of research on teacbing. New York: Macmillan.

Cohen, J. \& Cohen, P. (1983). Applied multiple regression/correlation analysis for the bebavioral sciences. Hillsdale (NJ): Lawrence Erlbaum.

Connell, D.B., Turner, R.R. \& Mason, E.F. (1985). Summary of findings of the School Health Education Evaluation: health promotion effectiveness, implementation, and costs. Journal of School Health, 55, 316-321.

Conner, R.F. (1981). Measuring evaluation utilization: a critique of different techniques. In: Ciarlo, J.A. (ed), Utilization evaluation, concepts and measurements tecbniques. Beverly Hills: Sage.

Cousins, J.B. \& Leithwood, K.A. (1986). Current empirical research on evaluation utilization. Review of Educational Research, 56, 331-363.

Cousins, J.B. \& Leithwood, K.A. (1993). Enhancing knowledge utilization as a strategy for school improvement. Knowledge: Creation, Diffusion, Utilization, 14, 305-333.

Crandall, D.P. (1989). Implementation Aspects of Dissemination. Knouledge: Creation, Diffusion, Utilization, 11, 79-106.

Creemers, B.P.M. (1991). Effectiene instructie (Effective instruction). Den Haag: SVO. 
Damanpour, F. (1988). Innovation type, radicalness, and the adoption process. Communication Research, 15, 545-567.

DiClemente, R.J. (1989). Prevention of human immunodeficiency virus infection among adolescents: the interplay of health education and public policy in the development and implementation of school-based ADS education programs. AIDS Education and Prevention, 1, 70-78.

Doyle, W. (1986). Classroom organization and management. In: Wittrock, M.C. (ed), Third bandbook of research on teaching. New York: Macmillan.

Doyle, W. \& Ponder, G.A. (1977-78). The practicality ethic in teacher decision making. Intercbang$e, 8,1-12$.

Ellis, N.T. \& Torabi, M.R. (1992). HIV/AIDS education in Indiana public schools: grades 7-12. Journal of School Health, 62, 93-96.

Errecart, M.T., Walberg, H.J., Ross, J.G., Gold, R.S., Fiedler, J.L. \& Kolbe, L.J. (1991). Effectiveness of Teenage Health Teaching Modules. Joumal of School Healtb, 61, 26-30.

Eveland, J.D. (1987). Diffusion, technology transfer, and implementation. Knowledge: Creation, Diffusion, Utilization, 8, 303-322.

Feller, I. (1981). Three coigns on diffusion research. In: Rich, R.F. (ed), The knouledge cycle. Beverly Hills: Sage.

Fishbein, M. \& Ajzen, I. (1975). Belief, attitude, intention and behavior: an introduction to theory and research. Reading, Mass: Addison Wesley.

Flay, B.R. (1985). Psychosocial approaches to smoking prevention: a review of findings. Health Psychology, 4, 449-488.

Fullan, M.G. $\left(1991^{2}\right)$. The new meaming of educational change. New York: Teachers College Press.

Fullan, M. $\left(1991^{b}\right)$. Curriculum implementation. In: Lewy, A. (ed), The international encyclopedia of curriculum. New York: Macmillan.

Fullan, M. \& Pomfret, A. (1977). Research on curriculum and instruction implementation. Review of Educational Research, 47, 335-397 
Fuller, B., Wood, K., Rapoport, T. \& Dornbusch, S.M. (1982). The organizational context of individual efficacy. Review of Educational Research, 52, 7-30.

Gibson, S. \& Dembo, M.H. (1984). Teacher efficacy: a construct validation. Journal of Educational Psychology, 76, 569-582.

Gilchrist, L.D. \& Schinke, S.P. (1983). Coping with contraceptive and behavioral methods with adolescents. Cognitive Therapy and Research, 7, 379-388.

Glathorn, A.A. (1987). Curriculum renewal. Alexandria, VA: ASCD.

Gold, R.S. \& Kelly, M.A. (1991). Cultural sensitivity in AIDS education: a misunderstood concept. Evaluation and Program Planning, 14, 221-231.

Goodlad, J.I., Klein, M.F. \& Tye, K.A. (1979). The domains of curriculum and their study. In: Goodlad, J.I. et al. (eds), Curriculum inquiry: the study of curriculum practice. New York: McGraw Hill.

Green, L.W. \& Kreuter, M.W. (1991). Health promotion planning: an educational and environmental approach. Mountain View: Mayfield Publishing Company.

Grube, J.W., Morgan, M. \& McGree, S.T. (1986). Attitudes and normative beliefs as predictors of smoking intentions and behavior: a test of three models. British Journal of Social Psycbology, 25, $81-93$.

Guskey, T.R. (1988). Teacher efficacy, self-concept, and attitudes toward the implementation of instructional innovation. Teacbing \& Teacher Education, 1, 63-69.

Hall, G.E. \& Hord, S.M. (1987). Change in schook: facilitating the process. Albany: State University of New York Press.

Hall, G.E. \& Loucks, S.F. (1978). Levels of use of the innovation: a framework for analyzing innovation adoption. Educational Review, 26, 48-56.

Hammonds, M.M. \& Schulz, J.B. (1984). Sexuality education instructional techniques, teacher usage and student preference. Joumal of School Health, 54, 235-238.

Hansen, W.B. (1992). School-based substance abuse prevention: a review of the state of the art in curriculum, 1980-1990. Health Education Research, 7, 403-430. 
Havelock, R.G. (1969). Planning for innovation tbrough dissemination and utilization of knouledge. Ann Arbor: University of Michigan.

Hertog, P.C. den (1990). Persoonlijkbeidskenmerken en causale attributies (Personality traits and causal attributions). Amsterdam: Thesis.

Ilerz, E.J.. Reis, J.S. \& Barbera-Stein, L. (1986). Family life education for young teens: an assessment of three interventions. Health Education Quarterly, 13, 201-221.

Huberman, M. (1983). Recipes for busy kitchens. Knowledge: Creation, Diffusion, Utili-zation, 4 , 478-510.

Huberman, M. \& Miles, M. (1984). Innovation up close. New York: Plenum.

Joyce, B. \& Showers, B. (1988). Student achievement through staff development. New York: Longman.

Kerr, D.L., Allensworth, D.D. \& (aayle, J.A. (1989). The ASHA national HIV education needs assessment of health and education professionals. Journal of School Health. 59, 301-307.

Kirby, D. (1992). School-based programs to reduce sexual risk-taking behaviors. Joumal of School Healtb, 62, 280-287.

Kolbe, L.J. \& Iverson, D.C. (1981). Implementing comprehensive health education: educational innovations and social change. Health Education Quarterly, 8, 57-80.

Lagerweij, N.A.J. (1987). Theorie van onderwijsvernieuwing (Theory of educational innovations). In: Kemenade, J.A. van, Lagerweij, N.A.J., Leune, J.M.G. \& Ritzen, J.M.M. (eds), Onderwijs in ontwikkeling (Developments in Education). Groningen: Wolters-Noordhoff.

Larsen, J.K. (1981). Knowledge utilization: current issues. In: Rich, R.F. (ed), The knowledge cycle. Beverly Hills: Sage.

Leithwood, K.A. (1981). The dimensions of curriculum innovation. Journal of Curriculum Studies, 13, 25-36.

Leithwood, K.A. (1991). Curriculum diffusion. In: Lewy, A. (ed), The international encyclopedia of curriculum. New York: Macmillan. 
Leithwood, K.A. \& Montgomery, D.J. (1980). Evaluation program implementation. Evaluation Review, 4, 193-214.

Leonard-Barton, D. (1988). Implementation characteristics of organizational innovations: limits and opportunities for management strategies. Communication Researcb, 15, 603-631.

Levenson-Gingiss, P. \& Hamilton, R. (1989'). Determinants of teachers' plans to continue teaching a sexuality education course. Family $\&$ Community Health, 12, 40-53.

Levenson-Gingiss, P. \& Hamilton, R. $\left(1989^{\circ}\right)$. Evaluation of training effects on teacher attitudes and concerns prior to implementing a human sexuality education program. Journal of School Health, 59, $156-160$.

Levenson-Gingiss, P. (1992). Enhancing program implementation and maintenance through a multiphase approach to peer-based staff development. Journal of Scbool Health, 62, 161-166.

Levine, D.U. \& Lezotte, L.W. (1990). Usually effective schools: a review and analysis of research and practice. Madison: National Center for Effective Schools Research and Development.

locke, E.A. \& Latham, G.P. (1991). A theory of goal setting and task performance. Englewood Cliffs: Prentice-Hall.

Loucks, S.F. (1991). Curriculum adoption. In: Lewy, A. (ed), The intemational encyclopedia of curriculum. New York: Macmillan.

Louis, K.S. (1992). Comparative perspectives on dissemination and knowledge use policies. Knowledge: Creation, Diffusion, Utilization, 13, 287-304.

Luijkx, J.B., Marsman, G.W. \& Rijt, G.A.J. van der (1987). De seksuele moraal: een interveniërende variable voor voorlichting over geslachtsziekten (Sexual morality: an intervening variable for education on sexual transmitted diseases). Tijdschrift voor Seksuologie (Vournal for Sescology), $11,100-115$.

Marsh, C. \& Huberman, M. (1984). Disseminating curricula: a look from the top down. Journal of Curriculum Studies, 16, 53-66.

McCormick, L.K. (1992). Implementation of bealtb curricula: a study of diffusion and organizational change processes. Chapel Hill: University of North Carolina. 
McGuire, W.J. (1974). Communication-persuasion models for drug education. In: Goodstadt, M. (ed), Researcb on methods and programs of drug education. Toronto: Addiction Research Foundation of Ontario.

McGuire, W.J. (1985). Attitudes and attitude change. In: Lindzey, G. \& Aronson, E. (eds), The handbook of social psycbology' (vol. 2). New York: Random House.

McLaughlin, M.W. (1990). The Rand Change Agent Study revisited: macro perspective and micro realities. Educational Researcher, 19, 11-16.

Mellink, E.C. (1989). Seksuele vorming en Aidswoorlichting: een inventariserend onderzoek naar de stand van zaken met betrekking tot seksuele vorming en Aidsvoorlichting in bet voortgezet ondenvijs (Sex education and ADS education in secondary schools: a stute of affairs). Ansterdam: SCO.

Memon, A. (1990). Young people's knowledge, beliefs and attitudes about HIV/AIDS: a review of research. Health Education Research, 5, 295-298.

Midylev, C.M., Feldlaufer, H. \& Eccles, J.S. (1989). Change in teacher efficacy and student self- and task-related beliefs in mathematics during the transition to junior high school. Journal of Educational Psycbology, 81, 247-258.

Miles, M.B. \& Louis, K.S. (1987). Research on institutionalization: a reflective review. In: Miles, M.B., Ekholm, M. \& Vandenberghe, R. (eds), Lasting scbool improvement: exploring the process of institutionalization. Amersfoort: Acco.

Mullan, P.D., Green, L.W. \& Persinger, G. (1985). Clinical trials of patient education for chronic conditions: a comparative meta-analysis of intervention types. Preventive Medicine, 14. 753-781.

Nemeth, C.J. \& Staw, B.M. (1989). The tradeoffs of social control and innovation in groups and organizations. In: Berkowitz, L. (ed), Advances in experimental social psycbology, vol. 22. New York: Academic Press.

Orlandi, M.A., Landers, C., Weston. R. \& Haley. N. (1990). Diffusion of health promotion innovations. In: Glanz, K, Lewis, F.M. \& Rimer, F.M. (eds), Health behavior and bealth education: theory, research, and practice. San Francisco: Jossey Bass. 
Parcel, G.S., Simons-Morton, B., O'Hara, N.M., Baranowski, T. \& Wilson, B. $\left(1989^{\mathrm{a}}\right)$. School promotion of healthful diet and physical activity, impact on learning outcomes and self-reported behavior. Health Education Quarterly, 16, 181-199.

Parcel, G.S., Taylor, W.C., Brink, S.G., Gottlieb, N., Engquist, K, O'Hara, N.M. \& Eriksen, M.P. $\left(1989^{b}\right)$. Translating theory into practice: Intervention strategies for the diffusion of a health promotion innovation. Family \& Community Health, 12, 1-13.

Parcel, G.S., Perry, C.I. \& Taylor, W.C. (1990). Beyond demonstration: diffusion of health promotion innovations. In: Bracht, N. (ed), Health promotion at the community level. Newbury Park: Sage.

Parcel, G.S., Ross, J.G., Lavin, A.T., Portnoy, B., Nelson, G.D. \& Winters, F. (1991). Enhancing implementation of Teenage Health Teaching Modules. Journal of School Health, 61, 35-38.

Pelgrum, W.J. (1989). Educational assessment, monitoring, evaluation and the curriculum. De Lier: Academisch Boeken Centrum.

Pentz, M.A., Trebow, E.A., Hansen, W.B., MacKinnon, D.P., Dwyer, J.H., Anderson-Johnson, C., Flay, B.R., Daniels, S. \& Cormack, C. (1990). Effects of program implementation on adolescent drug use behavior. Evaluation Review, 14, 264-289.

Perry, C.L., Murray, D.M. \& Griffin, G. (1990). Evaluating the statewide dissemination of smoking prevention curricula: factors in teacher compliance. Journal of School Health, 60, 501-504.

Porter, A.C. \& Brophy, J. (1988). Synthesis of research on good teaching: insights from the work of the institute for research on teaching. Educational Leadership, 45, 74-85.

Remafedi, G. (1993). The impact of training on school professionals' knowledge, beliefs, and behaviors regarding HIV/AIDS and adolescent homosexuality. Joumal of School Health, 63, 153157.

Resnicow, K, Cohn, L., Reinhardt, J., Cross, D., Futterman, R., Kirschner, E., Wynder, E.L. \& Allegrante, J.P. (1992). A three-year evaluation of Know Your Body Program in inner-city schoolchildren. Health Education Quarterly, 19, 463-480.

Rich, R.F. (1991). Knowledge creation, diffusion, and utilization. Knowledge: Creation, Diffusion, Utilization, 12, 319-337. 
Rich, X. (1990). Ideological impediments to instructional innovation: the case of cooperative learning. Teaching \& Teacher Education, 6, 81-91.

Richard, R. \& Pligt, J. van der (1991). Factors affecting condom use among adolescents. Joumal of Community \& Applied Social Psycbology, 1, 105-116.

Rogers, E.M. (1983). Diffusion of innovations. New York: The Free Press.

Rogers, E.M. \& Shoemaker, F.F. (1971). Communication of innovations: a cross-cultural approach. New York: The Free Press.

Rosenholz, S. (1989). Teachers' workplace: the social organization of schools. New York: Longman.

Ross. J.G., Luepker, R.V., Nelson, G.D., Saavedra, P. \& Hubbard, B.M. (1991). Teenage Health Teaching Modules: impact of teacher training on implementation and student outcome. Journal of School Health, 61, 31-34.

Ross, M.W. \& Rosser, B.R.S. (1989). Education and AIDS risks: a review. Health Education Research, 4, 273-284.

Schaalma, H.P., Kok, G.J. \& Peters, L. (1993). Determinants of consistent condom use by adolescents: the impact of experience with sexual intercourse. Health Education Research, 8, 255-269.

Schaalma, H.P., Poelman, J., Reinders, J. \& Kok, G.J. (1994). The development of AIDS education for Dutch secondary schools. In: Rutter, D.R. (ed), The social psychology of bealth and safety, European perspectives. Aldershot: Avebury.

Scheerens, J. (1989). Wat maakt scbolen effectief (What does make scbools effective)? The Hague: SVO.

Scheirer, M.A. \& Rezmovic, E.L. (1983). Measuring the degree of program implementation: a methodological review. Evaluation Review, 7, 599-633.

Schinke, S.P., Botvin, G.J. \& Orlandi, M.A. (1991). Substance abuse in children and adolescents. Newbury Park: Sage.

Schultz, J.B. \& Boyd, J.R. (1984), Sexuality attitudes of secondary teachers. Family Relations, 33, 537.541 . 
Schunk, D.H. (1990). Introduction to the special section on motivation and efficacy. Journal of Educational Psychology, 82, 3-6.

Scriven, M. (1991). Beyond formative and summative evaluation. In: McLaughlin, M.W. \& Philips, D.C. (eds), Evaluation and education: at quarter century. Chicago, Ill: The University of Chicago Press.

Shavelson, R.J. \& Stern, P. (1981). Research on teachers' pedagogical thoughts, judgements, decisions, and behavior. Review of Educational Research, 51, 455-498.

Smith, P.B., Flaherty, C., Webb, L.J. \& Mumford, D.M. (1984). The long-term effects of human sexuality training programs for public school teachers. Journal of School Health, 54, 157-159.

Smith, D.W., McCormick, L.K., Steckler, A.B. \& McLeroy, KR. (1993). Teachers' use of health curricula: implementation of Growing Healthy, project Smart, and the Teenage Health Teaching Modules. Journal of School Health, 63, 349-354.

Smylie, M.A. (1988). The enhancement function of staff development: organizational and psychological antecedents to individual teacher change. American Educational Research Joumal, 25, 1-30.

Sperber, B.M., Fishbein, M. \& Ajzen, I. (1980). Predicting and understanding women's occupational orientations: factors underlying choice intentions. In: Ajzen, I. \& Fishbein, M. (eds), Understanding attitudes and predicting social behaviour. Englewood Cliffs, Prentice-Hall.

Stein, M.K. \& Wang, M.C. (1988). Teacher development and school improvement: the process of teacher change. Teaching \& Teacher Education, 4, 171-187.

Stokking, K.M. \& Leenders, F.J. (1990). Informatieverspreiding in bet onderwijs: kanalen, knelpunten en rendement (Diffusion of information in education: channels, bottlenecks, and return). Litrecht: ISOR.

Stokking, K.M. \& Leenders, F.J. (1992). Heeft verspreiding van informatie zin? (Does spread of information make sense?). Utrecht: ISOR.

Stone, E.J., Perry, C.L. \& Luepker, R.V. (1989). Synthesis of cardiovascular behavioral research for youth health promotion. Health Education Quarterly, 16, 155-169. 
Tillema, H.H., Batenburg, T.A. van \& Koster, A.J. $\left(1989^{2}\right)$. Het meten van gebruik (Measuring utilization). In: Vandenberghe, R. \& Vegt, R. van der (eds), Onderwijsvernieuwing (Educational innovation). Amsterdam: Swets \& Zeitlinger.

Tillema, H.H., Koster, A.J. \& Batenburg, T.A. van $\left(1989^{\circ}\right)$. Aanbod en gebriik van onderwijsverzorging (Supply and use of educational support). Groningen: RION.

Tillema, H.H. \& Koster, A.J. (1990). Impact of educational support programs in schools. Knowledge: Creation, Diffusion, Utilization, 12, 43-52.

Tjosvold, D. \& McNeely, L.T. (1988). Innovation through communication in an educational bureaucracy. Communication Research, 15, 568-581.

Tortu, S. \& Botvin, G.J. (1989). School-based smoking prevention: the teacher training process. Preventive Medicine, 18, 280-289.

Victor, J.B. (1976). Relation between teacher belief and teacher personality in four samples of teacher trainetes. Joumal of Experimental Education, 45, 4-9.

Victor, J.B. \& Otis, J.P. (1980). Teacher strength and sensitivity behavior: attitude personality correlates. Journal of Experimental Education, 49, 9-15.

Vogels, T. \& Vliet, R. van der (1990). Jeugd en seks (Youth and sex). The Hague: SDU.

Vries, H. de (1989). Smoking prevention in Dutch adolescents. Maastricht: University of Limburg.

Wang, M.C., Haertel, G.D. \& Walberg, H.J. (1990). What influences leaming?: a content analysis of review literature. Joumal of Educational Research, 84, 30-43.

Weerden, JJJ. van (1990). De eindevaluatie van het curriculum voor gezondheidseducatie (The evaluation of a health education curriculum). Tijdschrift Gezondbeidsbevordering, 11, 5-13.

Weiner, B. (1985). An attributional theory of achievement motivation and emotion. Psycbological Review, 92, 548-573.

Westerman, D.A. (1992). Expert and novice teacher decision making. Journal of Teacher Education, 42, 292-305. 
Wijnsma, P. (1989). AIDS en bet voortgezet onderwijs (AIDS and secondary education). Leiden: Zom.

Woolfolk, A.E. \& Hoy, W.K. (1990). Prospective teachers' sense of efficacy and beliefs about control. Journal of Educational Psychology, 82, 81-91.

Zaltman, G. \& Duncan, R. (1977). Strategies for planned cbange. New York: Wiley. 


\section{Summary}

Since in the early eighties the first cases of ADS were diagnosed in the Netherlands, many efforts have been devoted to prevention of the spread of the perpetrator of the disease, the human immune deficiency virus (HIV). Prevention, and in particular health education, is the only policy instrument that can effectively be applied for that purpose so far. From the beginning, AIDS education in the Netherlands focused not only on high-risk groups, like homosexual men and intravenous drug users, but also on the general population, including young people. As far as youth is concerned, high priority was given to the introduction of AIDS education in secondary schools since these schools reach nearly all teenagers. In 1988, a project was installed at the Dutch Centre for Health Promotion and Health Education (DCH) in order to coordinate and initiate activities facilitating the innovation process in secondary schools. The support activities initiated by the DCH's AIDS project mainly focused on mass media promotion, networking, teacher training, development of exemplary AIDS curricula, and research.

This thesis describes the results of an investigation, conducted in 1991, into the state of affairs in Dutch secondary schools concerning classroom-based ADS education in general, and in particular teachers' utilization of four nationally disseminated AIDS curricula. 'The study among 956 teachers from 532 schools strongly focused on exploring factors that had impeded or facilitated the introduction of classroom AIDS education in secondary schools. Systematically gathered insights into these antecedents are indispensable for optimizing external support for schools and teachers involved in this process of curriculum innovation.

Chapter 1 provides a general overview of the dissertation. It briefly describes why an adequate implementation of school-based AIDS education is essential for the success of any national AIDS prevention policy, and the kind of school support that has been developed in the Netherlands since 1988. Also the four nationally disseminated AIDS curricula are briefly described, as well as the conceptual framework used for investigating adoption and implementation of these curricular materials. After that, the main research findings are summarized. Some methodological aspects of the research are also discussed. Subsequenty, conclusions of the research findings are formulated and discussed in relation to their implication for school support practices. The results confirm that one needs to make a clear distinction between dissemination, adoption, and actual implementation of the AIDS curricula when evaluating the present support policy. Transfer to these subsequent stages in the innowation process has not appeared obvious since they are partially affected by different factors which cannot always be effectively dealt with during the stage of curriculum development. Therefore, recommendations are formulated not only for adjusting the present school support policy, which is characteristically focused on (shor-term) dissemination and adoption of curricular materials, but also for developing a new policy focused on actual implementation of highquality programs. 
Cbapter 2 provides the theoretical and empirical basis for the development of the conceptual framework that was used for the research described in this thesis. First, the concepts of curriculum and curriculum evaluation are specified. After a brief description of the classical diffusion of innovation theory and related assumptions and limitations, the concept of "curriculum innovation" is further outlined. It is asserted that the process of curriculum innovation, like AIDS education, is usually affected not only by (a) characteristics of the innovation itself, but also by (b) characteristics of the sociopolitical context, (c) characteristics of the adopting unit (schools/teachers), and (d) characteristics of the innovation strategy. These characteristics are not entirely controllable on the part of the external advocate of a given curriculum innovation. These four distinguishable categories comprise a variety of specific determinants of more or less successful curriculum innovations. An overview of determinants is provided within each category by, among other things, referring to theory and empirical research on curriculum innovation, and teachers' planning behavior and related thoughts. It is concluded that curriculum innovation is more than just the development and dissemination of new information or products. Above all, the outcomes will be dominated by the processing of newly acquired information and the construction of meaning about that information by all actors involved; external change agents, teachers, as well as students. Subsequently, the chapter provides a review of empirical research on effectiveness and determinants of implementation of school-based health education, sex education, and AIDS education. In general, it appears that the learning objectives of school health education programs can be reached if they are strongly theoryand research-based, and if they are adequately implemented. There is, however, little research available addressing the determinants of particular school health education programs, and it is even completely absent in the area of school-based AIDS education. And when this kind of research is carried out, mainly in the U.S., the analyses are often restricted to a limited number of determinants, like a bivariate estimate of teachers' training status, or the analyses lack an adequate theoretical basis. The chapter finally describes in what way the results of the review of the literature were applied to the central concepts in Ajzen's Theory of Planned Behavior. This theory was used as a leading principle for developing the conceptual framework for the research on teachers' adoption and implementation of AIDS education (curricula).

Chapter 3 describes the results of the investigation among 956 Dutch secondary teachers concerning the determinants of adoption on classroom-based AIDS education, irrespective of their utilization of any particular curricular material. About $68 \%$ of the respondents already provided classroom AIDS education, while $73 \%$ intended to do so during the next school year. Teachers' intentions to provide AIDS education appeared to be positively related to (a) perceived subjective norms (notably students, colleagues in own department, and the school principal), (b) teachers' self-efficacy (comfort in talking frankly about sexuality with students, adaptation to students' entry behavior, and application of requisite classroom management strategies). (c) permissiveness of teachers' sexual morality, (d) sense of responsibility, (e) frequency of collegial interaction about HIV instruction, and (f) the presence of a formal school policy concerning AIDS education. Perceptions of importance or feasibility of prespecified student learning outcomes scarcely 
appeared to affect teachers' adoption of AIDS education. Moreover, teachers' sense of responsibility seem to be constituted by a highly personal decision making process which not appear to be affected by their teaching subject.

Chapter 4 reports the results of the investigation among 698 teachers concerning their awareness-knowledge about the four nationally disseminated AIDS curricula, their intention to use them (adoption), and their preference for adopting one curriculum rather than another (choice intentions). All teachers were intending to provide classroom ADS education. About $67 \%$ of them did know about at least one of these four AIDS curricula, while half of these teachers reported being aware of only one curriculum. Awareness-knowledge appeared to be strongly determined by diffusion of information within schools (by collegial consultation or perceived colleague behavior). Besides, teachers from Protestant schools were most knowledgable about Curriculum B, the curriculum that was specifically developed for Protestant education. Curriculum adoption was, above all, related to perceived instrumentality, mainly referring to teachers' need for clearly defined procedural referents and to their concerns about students' reactions to the proposed practices. Also descriptive norms (perceived colleague behavior) appeared to be strongly related to teachers' adoption of the AIDS curricula. As with adoption of AIDS education in general, adoption of these exemplary curricular materials was also affected by subjective norms and teachers' sexual morality. Financial costs hardly appeared to relate to adoption of single AIDS curricula. However, financial costs seem to become slightly more important when teachers need to choose between alternative curricula. Apart from that, teachers' choice intentions appeared to be related to nearly the same factors as were related to their adoption of single AIDS curricula.

Chapter 5 describes the results of the study among 388 teachers concerning the degree of implementation of the AIDS curriculum used by them. In general, implementation (extent and level of use) appeared to be most strongly associated with specific curriculum-related beliefs: (a) perceived instrumentality, (b) subjective norms, (c) teacher benefits (perceived outcomes favoring the teacher), and (d) teachers' self-efficacy. Implementation of two AIDS curricula was also positively affected by the presence of a formal school policy on AIDS education. Although relatively more teachers in biology generally tended to engage in classroom AIDS education, their degree of curriculum implementation appeared to be lower when compared to teachers in other subject areas. Moreover, teachers from Catholic schools generally implemented two of the exemplary curricula to a significantly higher degree than their counterparts in Protestant or public schools.

The main conclusion of this thesis is that the Theory of Planned Behavior provides a useful frame of reference for conducting empirical research on teachers' adoption and implementation of curriculum innovations. Moreover, the research findings confirm that the present approach to curriculum development and diffusion needs to be adjusted in order to facilitate actual classroom implementation too. This new school support policy should combine at least the following features: (a) development of both theoretically and practically validated exemplary curricular materials (development), (b) a focused promotion of available curricular programs, both by mass media and face-to-face communication (adoption), (c) in-person assistance of teachers during classroom 
implementation (implementation), (d) development of collegiality and school level support (continuation), and (e) empowerment of the support capacity at the local level. 


\section{Samenvatting}

Vanaf begin jaren tachtig, toen in Nederiand de eerste mensen met AIDS werden gediagnostiseerd, zijn aanzienlijke inspanningen verricht om te voorkomen dat de veroorzaker van deze ziekte, het human immune deficiency virus (HIV), zich verder zou verspreiden. Vooralsnog is primaire preventie, en dan met name voorlichting over de risico's van besmetting met het HIV, het enige beleidsinstrument dat voor dit doel adequaat kan worden aangewend. Aidsvoorlichting in Nederland heeft zich van het begin niet alleen gericht op groepen met een verhoogd risico, zoals homoseksuele mannen of intraveneuze druggebruikers, maar ook op het algemene publiek, waaronder jongeren. Wat de doelgroep jongeren betreft is hoge prioriteit gegeven aan de invoering van Aidsvoorlichting in het voortgezet onderwijs, temeer omdat via het onderwijs nagenoeg alle jongeren bereikt kunnen worden. In 1988 werd bij het Landelijk Centrum GVO (LCG) een project geformeerd met de opdracht het coördineren en initiëren van activiteiten ter ondersteuning van dit invoeringsproces in het voortgezet onderwijs. De activiteiten van dit project richtten zich vooral op massamediale promotie, netwerkontwikkeling, training van docenten, ontwikkeling van voorbeeldlesmaterialen en onderzoek.

Dit proefschrift beschrijft de resultaten van een onderzoek uit 1991 naar de stand van zaken op scholen voor voortgezet onderwijs wat de invoering van klassikale Aidsvoorlichting in het algemeen betreft, en het gebruik van vier speciaal daarvoor landelijk verspreide lespakketten Aidsvoorlichting. In dit onderzoek, waaraan 956 docenten van 532 scholen deelnamen, is veel nadruk gelegd op het verkennen van factoren die de invoering van Aidsvoorlichting in het voortgezet onderwijs belemmeren dan wel bevorderen. Systematisch verkregen inzicht in deze factoren is onontbeerlijk voor een optimaal ontwerp van de externe ondersteuning en begeleiding van scholen/docenten bij de invoering van deze curriculum-vernieuwing.

Hoofdstuk 1 biedt een overzicht van het hele proefschrift. Er wordt kort aangegeven waarom een adequate invoering van Aidsvoorlichting in het onderwijs essentieel is voor het welslagen van een nationaal Aidspreventiebeleid, en wat sinds 1988 op dit gebied aan onderwijsondersteuning in Nederland is gerealiseerd. Hierna volgt een korte typering van vier landelijk verspreide Aidscurricula, en van de conceptuele onderbouwing van het onderzoek naar adoptie en implementatie van deze lesmaterialen. Daarna worden de belangrijkste onderzoeksresultaten samengevat. Tevens wordt ingegaan op de methodologische beperkingen van het onderzoek. Vervolgens worden de conclusies uit het onderzoek geformuleerd en bediscussieerd in relatie tot aanbevelingen voor de praktijk van de onderwijsondersteuning. De resultaten bevestigen dat voor een adequate beoordeling van het gevoerde onderwijsondersteuningsbeleid een duidelijk onderscheid gemaakt moet worden tussen de verspreiding, adoptie en de daadwerkelijk implementatie van lesmaterialen Aidsvoorlichting. Deze opeenvolgende fasen in het invoeringsproces bleken niet als vanzelfsprekend in elkaar over te gaan omdat ze deels worden bepaald door verschillende factoren, waarop bovendien niet in alle gevallen afdoende geanticipeerd kan worden tijdens de ontwikkeling van 
lesmaterialen. Er worden dan ook niet alleen aanbevelingen geformuleerd voor verbetering van de bestaande praktijk van de onderwijsondersteuning op dit gebied, die zich vooral laat kenmerken door haar gerichtheid op (korte termijn) verspreiding en adoptie van lesmaterialen, maar ook voor het ontwikkelen van een nieuw beleid gericht op de daadwerkelijke implementatie van kwalitatief hoogwaardige programma's.

Hoofdstuk 2 beschrijt de theoretische en empirische basis voor de ontwikkeling van een conceptueel raamwerk voor het onderzoek dat in deze dissertatie centraal staat. Allereerst worden de begrippen curriculum en curriculum-evaluatie nader gedefinieerd. Na een korte typering van de klassieke diffusie-theorie en de daarmee verbonden assumpties en beperkingen, wordt het begrip "curriculum-innovatie" nader afgebakend. Gesteld wordt dat het proces van curriculum-innovatie, zoals Aidswoorlichting, in het algemeen niet alleen wordt bepaald door (a) kenmerken van de vernieuwing zelf, maar ook door (b) kenmerken van de social politieke context, (c) kenmerken van de adopterende eenheid (in dit geval scholen/docenten), en (d) kenmerken van de invoeringsstrategie. Deze kenmerken worden doorgaans niet volledig gecontroleerd door degenen die het initiatief nemen tot de invoering van een curriculurn-vernieuwing. Deze vier categorieën omvatten een veelheid aan nader omschreven determinanten van meer of minder succesvol gebleken curriculum-vervieuwingen. Binnen elke categorie wordt daarvan een overzicht gegeven, waarbij onder andere wordt verwezen naar theorieën over en empirisch onderzoek naar curriculuminnovaties en het planningsgedrag van docenten en daarmee verbonden cognities. Geconcludeerd wordt dat curriculum-innovatie meer is dan alleen het ontwikkelen en verspreiden van nieuwe informatie of produkten. De uitkomst ervan wordt bovenal gedomineerd door een proces van informatieverwerking en betekenisgeving door al diegenen die daarbij betrokken zijn; zowel externe ondersteuners, docenten, als leerlingen. Vervolgens biedt dit hoofdstuk een overzicht van resultaten van binnen- en buitenlands onderzoek naar de effecten en determinanten van invoering van gezondheidseducatie in het onderwijs, waaronder seksuele vorming en Aidsvoorlichting. Uit dit overzicht blijkt dat de beoogde leerdoelen van gezondheidseducatie in het onderwijs in het algemeen bereikt kunnen worden mits de programma's een sterke theoretische en empirische basis hebben en adequat worden geimplementeerd. Er is echter maar weinig onderzoek verricht naar de determinanten van invoering van gezondheidseducatie op scholen; en ontbreekt zelfs op het gebied van Aidswoorlichting. Daar waar dergelijk onderzoek wel is uitgevoerd, doorgaans in de U.S, wordt in de analyses veelal gecontroleerd voor een beperkt aantal factoren, zoals al dan niet deelname aan een docententraining, of missen de analyses een adequate theoretische onderbouwing. Ten slotte wordt toegelicht op welke wijze de resultaten van de literatuurstudie zijn verwerkt in de centrale concepten van Ajzen's Theory of Planned Behavior. Deze theorie vormde de leidraad voor de ontwikkeling van het conceptueel raamwerk dat is gebruikt voor het in deze dissertatie beschreven onderzoek.

Hoofdstuk 3 beschrift de resultaten van het onderzoek onder 956 docenten in het Nederlandse voortgezet onderwijs naar de determinanten van hun intentie tot het geven van klassikale Aidswoorlichting (adoptie); ongeacht het gebruik van een specifiek lesprogramma. De resultaten 
laten zien dat $68 \%$ van de respondenten in hun lessen reeds aandacht besteedde aan Aidsvoorlichting, en dat $73 \%$ voomemens was om dit ook in het daaropvolgende schooljaar te doen. De bereidheid tot het geven van Aidsvoorlichting bleek vooral positief te zijn gerelateerd aan (a) ervaren sociale invloed (m.n. van leerlingen, directe collega's en de schoolleiding), (b) vertrouwen in eigen vaardigheden (m.n. praten over seksualiteit, aansluiten bij ervaringen van leerlingen en klassemanagement), (c) een permissieve seksuele moraal, (d) de eigen taakopvatting (verantwoordelijkheid), (e) frequentie van overleg met collega's over Aidsvoorlichting, en (f) de aanwezigheid van een formeel schoolbeleid op dit gebied. Opvattingen over het belang en de realiseerbaarheid van specifieke leerdoelen bleken van ondergeschikt belang te zijn voor de bereidheid van docenten tot het geven van Aidswoorlichting. Aan de taakopvatting van docenten, de verantwoordelijkheid die men voelt voor het geven van Aidswoorlichting, lijkt een hoogst persoonlijk afwegingsproces ten grondslag te liggen, dat niet wordt bepaald door de aard van het vak dat men doceert.

Hoofdstuk 4 bespreekt de resultaten van het onderzoek onder 698 docenten naar hun bekendheid met de vier landelijk verspreide lespakketten Aidsvoorlichting, hun bereidheid tot gebruik ervan (adoptie) en hun relatieve voorkeur voor een bepaald pakket ten opzichte van de andere pakketten (keuze-intentie). Het betrof hier een groep docenten die allen voornemens waren om Aidsvoorlichting te geven. Ongeveer $67 \%$ van de docenten kende tenminste één van de vier lespakketten, de helft van hen kende slechts één pakket. Kennis van de betreffende lespakketten bleek vooral te worden bepaald door de informatieverspreiding in scholen (via intercollegiaal overleg en/of een collega die het pakket gebruikt). Daarnaast waren docenten van scholen voor protestant onderwijs het meest bekend met "Een wereld van verschil", het pakket dat speciaal voor deze scholen is ontwikkeld. Adoptie van de lespakketten bleek eerst en vooral te zijn gerelateerd aan de verwachte instrumentaliteit ervan (bruikbaarheid); met name wat verwachte reacties van leerlingen betreft op de voorgestelde leeractiviteiten en de mate waarin het pakket voorziet in duidelijk omschreven handelingsvoorschriften voor de docent. Ook het gebruik wan een lespakket door een collega op school bepaalde mede de beslissing om het pakket ook zelf te gaan gebruiken (descriptieve norm). Evenals bij adoptie van Aidsvoorlichting in het algemeen, was adoptie van deze specifieke voorbeeldlesmaterialen gerelateerd aan de ervaren sociale omgevingsinviloed (subjectieve norm) en de eigen seksuele moraal. Aanschafkosten bleken slechts in geringe mate samen te hangen met adoptie van afzonderlijke pakketten. Deze factor lijkt belangrijker te worden bij een keuze tussen alternatieve lespakketten. Verder bleek de keuze-intentie van docenten gerelateerd te zijn aan nagenoeg dezelfde factoren als die werden gevonden bij adoptie van afzonderlijke lespakketten.

In Hoofdstuk 5 worden de resultaten gepresenteerd van het onderzoek onder 388 docenten naar de implementatie van de door hen gebruikte lespakketten. Implementatie (volledigheid en niveau van gebruik) bleek in het algemeen vorral samen te hangen met curriculum-specifieke opvattingen: (a) verwachte instrumentaliteit van het pakket, (b) subjectieve norm, (c) secundaire effecten (verwachte voordelen voor de docent zelf), en (d) vertrouwen in eigen vaardigheden. In het geval van "Aids, het komt je niet aanwaaien" en "Ziek van de liefde" bleek implementatie tevens te 
worden bevorderd indien de school reeds een formeel beleid voerde op het gebied van Aidsvoorlichting. Hoewel relatief meer docenten biologie betrokken zijn bij het geven van Aidsvoorlichting op school, bleken zij de Aidscurricula in het algemeen minder verregaand te implementeren dan docenten uit andere vaksecties. Daarnaast bleken docenten van katholieke scholen "Een wereld van Verschil" en "Ziek van de Liefde" in het algemeen verdergaand te implementeren dan docenten van scholen voor protestant of openbaar onderwijs.

De hoofdconclusie van dit proefschrift is dat de Theory of Planned Behavior een bruikbaar referentiekader biedt voor het ontwikkelen empirisch onderzoek naar de adoptie en implementatie van curriculum-vernieuwingen. Daarnaast bevestigt het onderzoek dat het vigerende beleid ten aanzien van de ontwikkeling en verspreiding van lesmaterialen Aidswoorlichting aanpassing verdient om ook daadwerkelijke implementatie ervan in de klas mogelijk te maken. Een dergelijk aangepast beleid zou tenminste de volgende elementen moeten bevatten: (1) ontwikkeling van zowel theoretisch als praktisch gevalideerde voorbeeldlesmaterialen (ontwikkeling), (2) een gerichte promotie van beschikbare programma's, zowel massamediaal als via interpersoonlijke netwerken (adoptie), (3) persoonlijke begeleiding van docenten bij daadwerkelijke gebruik in de klas (implementatie), (4) bevordering van samenwerkingsrelaties tussen betrokken docenten en beleidsmatige verankering op schoolniveau (continuering), en (5) versterking van de onderwijsbegeleidingscapaciteit op regionaal niveau. 


\section{Curriculum Vitae}

Theo G.W. Paulussen werd op 29 oktober 1956 geboren te Alphen en Riel. In 1974 behaalde hij het HAVO diploma aan het Cobbenhagencollege in Tilburg. Een jaar later startte hij met de Hogere Beroepsopleiding Verpleegkundigen (H.B.O.-V.) aan de Katholieke Hogere School voor Verpleegkundigen in Nijmegen. In 1979 behaalde hij het diploma van deze opleiding. Na een jaar als groepsleider verbonden te zijn geweest aan het Observatie- en Behandelingshuis Huize St. Joseph te Rijsbergen, was hij tussen 1981 en 1984 werkzaam als wijkverpleegkundige bij de Kruisvereniging Breda. In 1984 begon hij zijn studie Gezondheidswetenschappen aan de Rijksuniversiteit Limburg. In 1988 werd deze studie afgerond met als specialisatie Gezondheidsvoorlichting en -opvoeding (GVO). Direct aansluitend begon hij zijn loopbaan als onderzoeker bij de Sectie Onderwijs van het Landelijk Centrum GVO (LCG), bij welke instelling hij tot op heden werkzaam is. Het onderzoek dat in dit proefschrift wordt beschreven heeft hij geïnitieerd en uitgevoerd in het kader van zijn betrokkenheid bij het LCG-project "Introductie Aidsvoorlichting in het voortgezet onderwijs". Daarnaast heeft hij gepubliceerd over onderzoek naar de aan HIV gerelateerde risicogedragingen van intraveneuze druggebruikers en over verschillende onderwerpen die in algemene zin gerelateerd zijn aan de invoering van gezondheidsbevordering in het onderwijs. 

This book addresses the process of AIDS curriculum implementation in Dutch secondary schools. It describes the results of empirical research among 956 teachers working within a naturalistic school setting. They were questioned about a variety of factors facilitating and impeding their utilization of four nationally disseminated ADS curricula. Besides, the review of the literature enables the reader to become familiar with contemporary theory and research on curriculum innovation, teachers' planning behavior, and school health education innovation, including sex and AIDS education.

The research findings indicated that the success of a curriculum innovation like AIDS education, largely depends on teachers' social construction of meaning about the proposed classroom practices. Their innovation decision making showed to be more than just an act of information seeking and receiving; this information will also be processed leading to highly specific action-related beliefs. Since the outcomes of this decision making process can only partly be anticipated during the stage of curriculum development, it is concluded that the exclusive use of either 'lop-down' or 'bottom-up' strategies are unlikely to produce any real change in practice.

This book is highly recommended for researchers and practitioners interested or involved in curriculum innovation in general, and health curriculum innovation in particular. It illustrates how behavioral theory and educational theory can effectively be combined for generating detailed empirical data for the purpose of management of a specific curriculum innovation. Additionally, it provides an overview of the antecedents of teachers' adoption and implementation of classroom AIDS education, as well as of related strategies that are recommended for improvement purposes. 